$$
\begin{gathered}
\text { UC-80 } \\
\text { TID-4500 (22nd ed.) }
\end{gathered}
$$

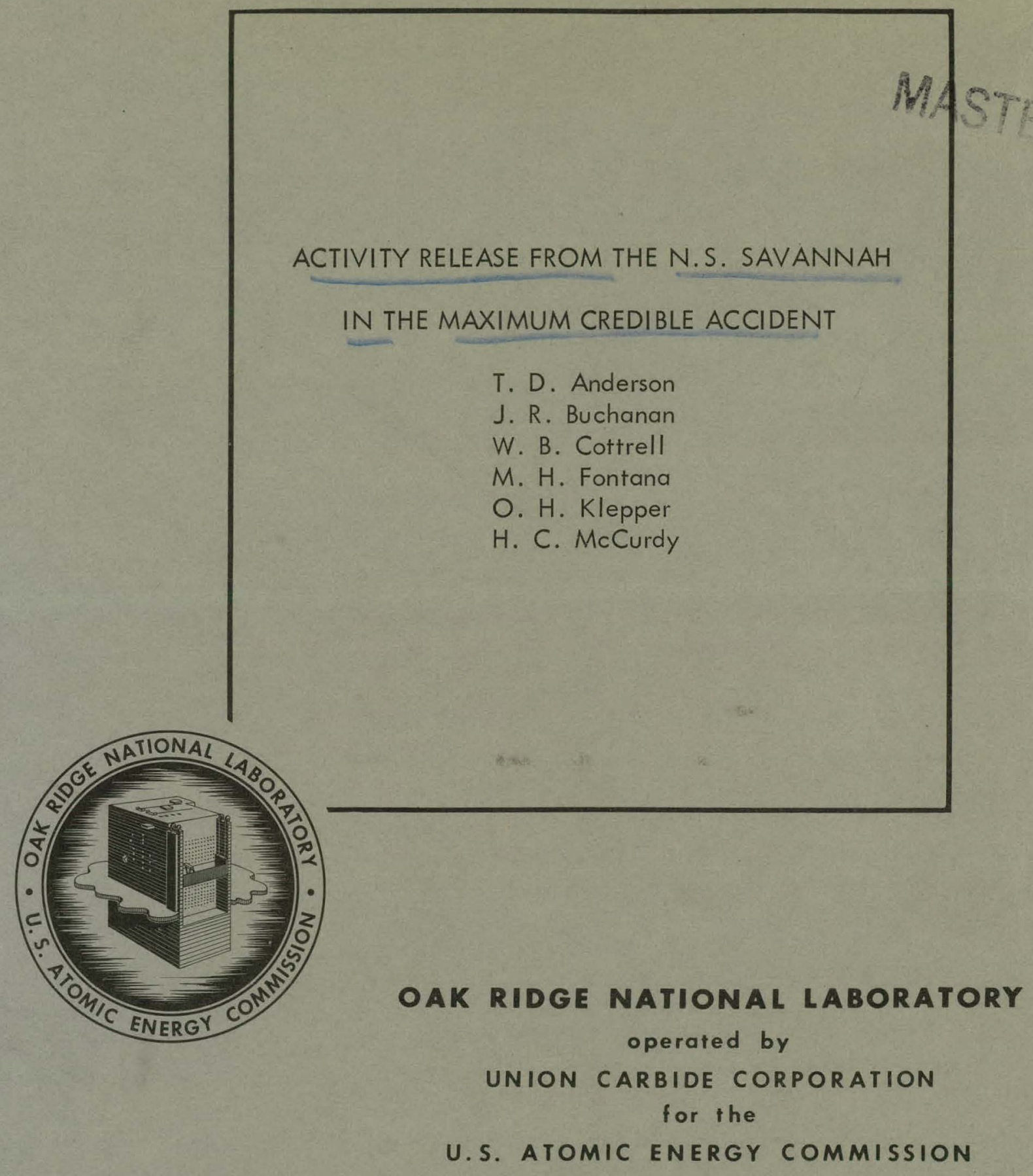




\section{DISCLAIMER}

This report was prepared as an account of work sponsored by an agency of the United States Government. Neither the United States Government nor any agency Thereof, nor any of their employees, makes any warranty, express or implied, or assumes any legal liability or responsibility for the accuracy, completeness, or usefulness of any information, apparatus, product, or process disclosed, or represents that its use would not infringe privately owned rights. Reference herein to any specific commercial product, process, or service by trade name, trademark, manufacturer, or otherwise does not necessarily constitute or imply its endorsement, recommendation, or favoring by the United States Government or any agency thereof. The views and opinions of authors expressed herein do not necessarily state or reflect those of the United States Government or any agency thereof. 


\section{DISCLAIMER}

Portions of this document may be illegible in electronic image products. Images are produced from the best available original document. 


\section{Printed in USA. Price: $\$ 2.50$ Available from the}

Office of Technical Services

U. S. Department of Commerce

Washington 25, D. C.

\section{LEGAL NOTICE}

This report was prepared as an account of Government sponsored work. Neither the United States, nor the Commission, nor any person acting on behalf of the Commission:

A. Makes any warranty or representation, expressed or implied, with respect to the accuracy, completeness, or usefulness of the information contained in this report, or that the use of any information, apparatus, method, or process disclosed in this report may not infringe privately owned rights; or

B. Assumes any liabilities with respect to the use of, or for damages resulting from the use of any information, apparatus, method, or process disclosed in this report.

As used in the above, "person acting on behalf of the Commission" includes any employee or contractor of the Commission, or employee of such contractor, to the extent that such employee or contractor of the Commission, or employee of such contractor prepares, disseminates, or provides access to, any information pursuant to his employment or contract with the Commission, or his employment with such contractor. 
Contract No. W-7405-eng-26

Reactor Division

ACTIVITY RELEASE FROM THE N.S. SAVANNAH IN THE MAXIMUM CREDIBLE ACCIDENT

T. D. Anderson

M. H. Fontana

J. R. Buchanan

O. H. Klepper

W. B. Cottrell

H. C. McCurdy

Date Issued

\section{OCT 161963}

OAK RIDGE NATIONAL LABORATORY

Oak Ridge, Tennessee operated by

UNION CARBIDE CORPORATION

for the

U.S. ATOMTC FINFRTY COMMTSSTON 
THIS PAGE

\section{WAS INTENTIONALLY \\ LEFT BLANK}


CONTENTS

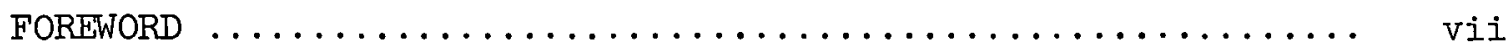

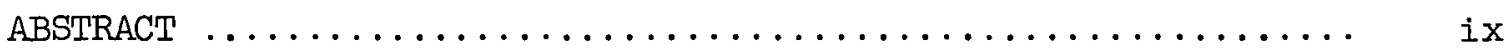

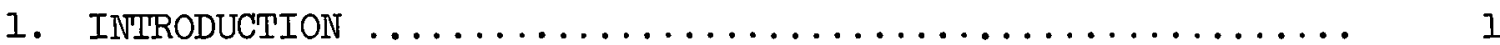

2. POWER REQUIREMEITIS IN HARBOR AREAS $\ldots \ldots \ldots \ldots \ldots \ldots \ldots \ldots \ldots$

Power Requirements in New York and Seattle ............ 5

Power Requirementa for Generalized Cases .............. 5

3. ITFTCT OF OPERATING HISTORY ON TIME FOR FUEL-

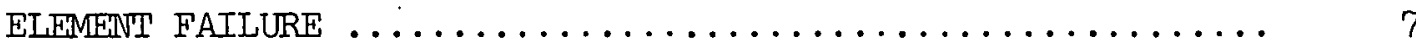

Analytical Method for Estimating Failure Times ........... 7

Relative Failure Times for Various Cases .............. 9

Time Dependence of Failure $\ldots \ldots \ldots \ldots \ldots \ldots \ldots \ldots \ldots \ldots \ldots \ldots$

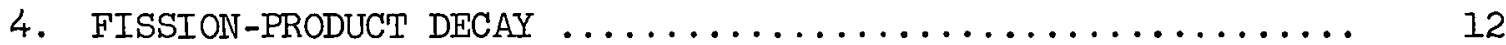

Calculation of Fission-Product Inventory for Various

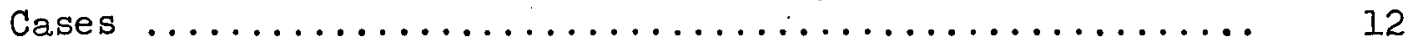

Results of Fission-Product Inventory Calculations ......... 14

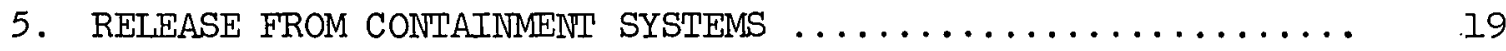

Effects of System Holdup ...................... 20

Combined Effects of Decay and Holdup .............. 26

6. EFFECT OF RELFASE MECHANISMS ON EXPOSURE ............ 26

Assumptions Employed in Exposure Calculations .......... 32

Calculational Modes ....................... 32

Fission-Product Release to Containment System ......... 33

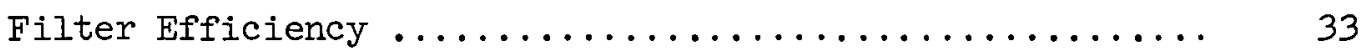

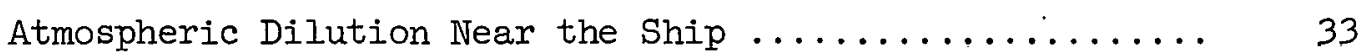

Ventilation System Dilution and Source Elevation ....... 34

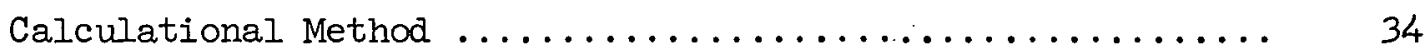

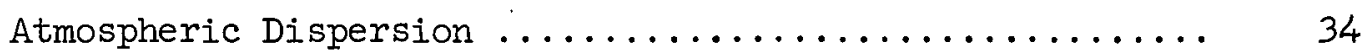

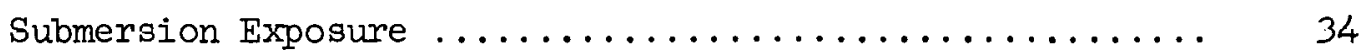

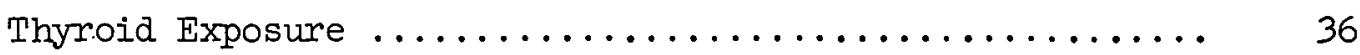

Results of Exposure Calculations ................ 37 


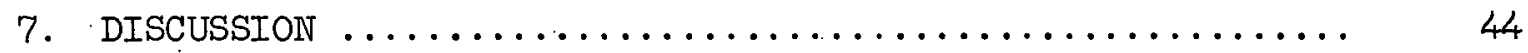

Implications of Exposure Calculations $\ldots \ldots \ldots \ldots \ldots \ldots \ldots .44$

Integrated Submersion Exposure $\ldots \ldots \ldots \ldots \ldots \ldots \ldots \ldots, \quad 47$

Integrated Thyroid Exposure $\ldots \ldots \ldots \ldots \ldots \ldots \ldots \ldots \ldots . .48$

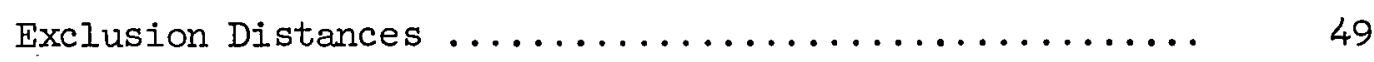

Justification of Mechanisms Evaluated ............... 49

Power History $\ldots \ldots \ldots \ldots \ldots \ldots \ldots \ldots \ldots \ldots \ldots \ldots \ldots, \quad 49$

Core Failure Sequence $\ldots \ldots \ldots \ldots \ldots \ldots \ldots \ldots \ldots \ldots . .6 \ldots$

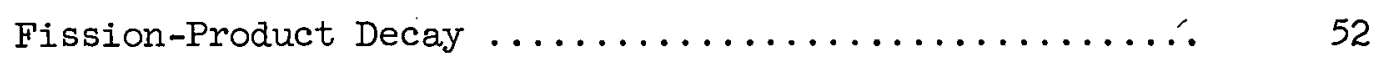

Holdup Effect of Reactor Compartment .............. 53

other Pertinent Factors ......................... 54

Ability to Remove Ship from Dock After Accident

in the Time Required $\ldots \ldots \ldots \ldots \ldots \ldots \ldots \ldots \ldots \ldots . .6 \ldots$

Performance of the Filters and Compartment Ventilation Systems .............................. 55

Implications of Total Population Exposure ............ $\quad 56$

Implications of Limited Time in Port .............. 57

Proximity and Resulting Exposure of Passengers and Visitors Abroad Ship ...................... 57

Effect of Radioactive Cloud Size on Exposure .......... 58

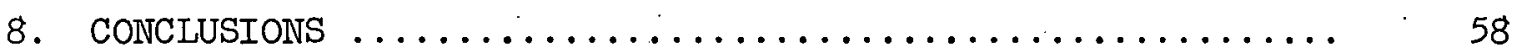

APPENDIX A. DIFFERENCES BEIWEEN N.S. SAVANNAH AND

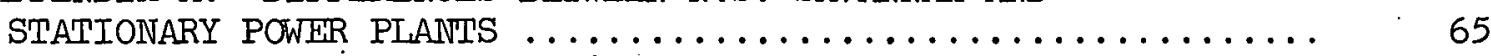

The "Population Center Distance"..................... 65

Characteristics of the Area Surrounding the Ship Berth .... 66

Proximity of Some Members of the Public to the Reactor .... 66

Effect of Operating Power History ................... 67

Removal of Ship to a Remote Anchorage ................ 67

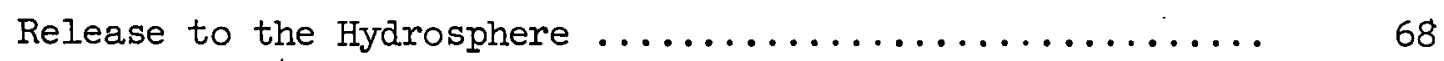

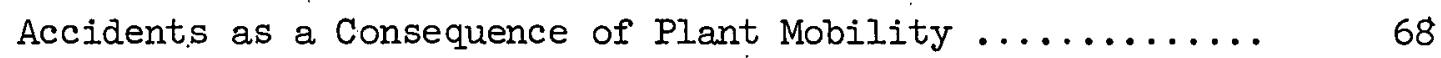

Electrical Power ............................... 69

Evacuation of the Ship at Sea .................... . 69

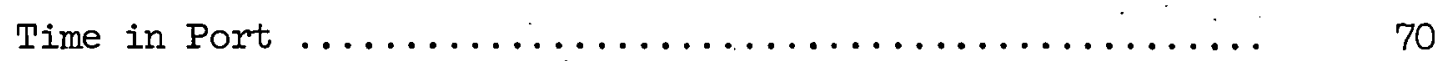

Ship Compartmentalization $\ldots \ldots \ldots \ldots \ldots \ldots \ldots \ldots \ldots \ldots . . . \ldots \ldots$

Collision Protection ........................... . 71 
APPENDIX B. FISSION-GAS RELEASE DURING OPERATION .......... 72

Discussion of the Conductivity Integral ............. 73

Determination of the Pellet Surface Temperature .......... 74

Use of the Conductivity Integral ................. 76

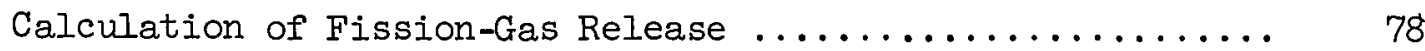

Pressure Buildup and Cladding Stress in Fuel Rod ......... 81

Fuel Element Failure Criterion .................. 87

APPENDIX C. COMPARISON OF ACTUAL AND SYNTHESIZED DECAY

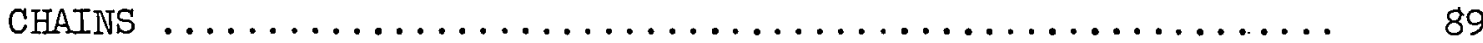

APPENDIX D. BUILDUP OF ACTIVITY IN REACTOR COMPARTMENT ....... 92

APPENDIX E. POPULATION EXPOSURE AROUND NEW YORK HARBOR . ...... 94

APPENDIX F. EFFECT OF CLOUD SIZE ON SUBMERSION EXPOSURE ...... 104

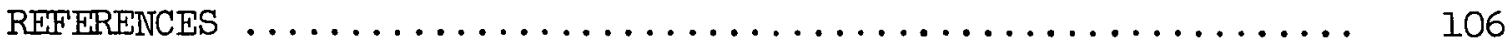


THIS PAGE

WAS INTENTIONALLY

LEFT BLANK 
vii

FOREWORD

During the late spring and summer of 1962 an intensive study was made of the hazards associated with the operation of the N.S. SAVANNAH in harbor areas. Based on the findings of this study by government and contractor personnel, tentative criteria were developed for port operation that received approval of the regulatory authorities for the interim operating period of the N.S. SAVANNAH. The pertinent calculations of the ORNL personnel who participated in the study are presented in this document. 
THIS PAGE

\section{WAS INTENTIONALLY \\ LEFT BLANK}


The release of fission products that would occur following the maximum credible accident aboard the N.S. SAVANNAH has been examined. Four significantly different, but realistic, operating histories were considered. The rate of release of noble gases and of iodine isotopes as a function of time after the accident was determined for each operating history and for both normal and emergency reactor-compartment ventilation systems. The influence of radioactive decay and of the time delay in release and transport of activity through the containment system was investigated. Most of the results are expressed in terms of activity release and resultant individual expusures, although some consideration is given to population exposures and to the interpretation of these results in the light of stationary reactor site criteria. 


\section{ACTIVITY RELEASE FROM THE N.S. SAVANNAH IN THE MAXIMUM CREDIBLE ACCIDENT}

$\begin{array}{ll}\text { T. D. Anderson } & \text { M. H. Fontana } \\ \text { J. R. Buchanan } & \text { O. H. Klepper } \\ \text { W. B. Cottrell } & \text { H. C. McCurdy }\end{array}$

\section{INTRODUCTION}

The activity released in the maximum credible accident of any nuclear installation is the starting point for site evaluation. In the case of stationary power reactors the common siting practices, as they have evolved under the supervision of the Atomic Energy Commission over the last ten years, were recently formalized in a criteria guide, which was issued as part of the Code of Federal Regulations. 1 These regulations specifically excepted nuclear ships. Separate interim criteria ${ }^{2}$ were developed by N.S. SAVANNAH project personnel to provide rational bases for port and berth evaluations during the initial operating period.

Of the many differences between stationary reactors and ship reactors (see Appendix A), the point of greatest concern in port evaluations is the proximity of the large number of people usually found around major port areas. A comparable condition is precluded in the siting of stationary power reactors by the somewhat arbitrary city distance criterion. Although port criteria cannot be identical with stationary reactor site criteria, it is essential that the two provide comparable safeguards for the general public, and it is necessary that the required exclusion areas around ships be compatible with areas available at major port berths. In order to permit the assessment of port site requirements the activity release from the N.S. SAVANNAH in the maximum credible accident has been evaluated in considerable detail.

The N.S. SAVANNAH power plant* is a pressurized-water reactor system designed for a continuous power output of $69 \mathrm{Mw}$ (thermal). The fuel is slightly enriched uranium (approximately $4.4 \% \mathrm{U}^{235}$ ) in the form of sintered uranium dioxide pellets encapsulated in 1/2-in. -OD stainless steel

* See ref. 3 for detailed description of the N.S. SAVANNAH reactor and propulsion systiem. 
tubes with a fueled length of 66 in. The core contains a total of 5248 of these fuel elements in 32 fuel element assemblies, which are arranged in a square array, with the corner assemblies omitted, to form roughly a 5-ft cube. Heat removal from the core is provided by two primary coolant loops having two pumps and one steam generator in each loop. The system normally operates at a pressure of 1750 psia and an average coolant temperature of $508^{\circ} \mathrm{F}$.

The entire primary system is contained in a shielded steel containment vessel that is designed to withstand the pressure and temperature excursion of the maximum credible accident. Piping lines that penetrate the containment vessel are provided with isolation valves which are closed upon an increase in containment pressure. The maximum permissible leakage rate of the containment vessel has been specified as $1.5 \%$ of the contained gases per day, ${ }^{2}$ and periodic leak tests are conducted to assure that the specified leakage rate is not exceeded. The containment vessel is located within a closed compartment of the ship that is designated as the "reactor compartment." This compartment meets normal watertightness requirements of regulatory agencies, but it is not designed to the leakage standards usually associated with containment vessels and is not periodically leak tested. The compartment is maintained at negative pressure, however, by either of two independent ventilation systems, and the exhaust air is passed through high-efficiency particulate matter and iodine removal filters before being released to the environment. Thus, the reactor is provided with two containment systems in series that serve both to delay and to reduce the release of activity following an accident.

The maximum credible accident of the N.S. SAVANNAH reactor has been established ${ }^{3}$ as a large rupture of the primary coolant system. In previous analyses 4,5 of the consequences of this accident, it was assumed that (1) the accident occurred after long-term operation of the reactor at maximum power, (2) all fuel elements would fail at the onset of the accident and all releasable activity would be immediately dispersed throughout the containment vessel, (3) the released activity would leak from the containment vessel at the specified maximum leakage rate and would pass to the environment with no further time delay, and (4) the activities would not be depleted by radioactive decay. Similar assumptions are 
commonly employed in analyses of stationary power plants where a lesser degree of conservatism is either difficult to justify or there is little incentive for doing so.

In the case of the N.S. SAVANNAH, however, there is incentive for a more realistic treatment of release mechanisms, particularly. those which influence the rate of activity release during the period immediately following the accident. The time-dependence of the activity release is an important consideration in assessing the inherent mobility of the ship as a potential means for reducing the consequences of an accident after it occurs.

Other studies ${ }^{2}$ have indicated that with proper planning and preparation, it would be physically feasible to evacuate unnecessary personnel from the ship and to move the ship from a dock position to an isolated anchorage within a period of $24 \mathrm{hr}$ and, probably, within $2 \mathrm{hr}$. The actual feasibility of carrying out such a move would, of course, be dependent on assurance that radiation exposure to tug crews, essential ship personnel, and the general public could be held to acceptable levels. The anchorage to which the stricken vessel would be moved would be determined for each port as a part of the port evaluation studies.

The purpose of the present work is to investigate the effects of power history, time delay in release and transport of activity through the containment system, and radioactive decay of fission products on the rate at which activity would be released from the N.S. SAVANNAH in the maximum credible accident. The rate of release of noble gases and of iodine isotopes as a function of time after the accident were estimated for four cases of power history and for alternate reactor compartment ventilation systems* and compared with a "reference release rate" estimated. by the previous simplified treatment. Also, to illustrate the effect of

\footnotetext{
* Note that the reactor compartment ventilation systems considered in this report are those which existed on the N.S. SAVANNAH during its initial port visits. In early 1963, following an interim period of sea and port operations, the reactor compartment ventilation systems were extensively modified. The modified arrangement is believed to provide increased reliability and simplicity of operation. Particulate and iodine filtration equipment remained unchanged.
} 
the more detailed treatment of factors influencing release, exposures were estimated for several of the cases of interest and compared with exposures for the reference case.

\section{POWER REQUIREMEINTS IN HARBOR AREAS}

The methodology of evaluating hazards arising from nuclear reactor accidents has been developed using stationary power plants as a basis. Stationary water-cooled reactors have almost universally been associated with an accident in which all releasable fission products are released instantaneously to the containment vessel and start leaking at the maximum rate to the atmosphere. The reasons for this treatment of activity release are associated with the type of reactor, mode of operation, and type of accident considered. In this context, the maximum credible accident for stationary, water-cooled, power reactors is usually a lossof-coolant accident preceded by a long history of operation at $100 \%$ power. A short time after the loss of all cooling, a high-power-density reactor core will fail, and most of the releasable fission products will be dispersed throughout the containment system.

Although the N.S. SAVANNAH reactor design is similar to that of some stationary reactors, there are significant differences between ship- and. land-based plants that should be considered in evaluating the consequences of an accident. As pointed out in Appendix A, perhaps the biggest single difference lies in the fact that a ship is inherently mobile, and therefore in the event of an accident the radioactive source could be moved out of a heavily populated area within a few hours. Furthermore, ship operation while in populated port areas is characterized by reduced power. This normal reduction in power is necessary because of the marine traffic, restricted area for maneuvering, and shallow water. A history of reduced power operation has two effects on the release of activity. First, the total amount of the fission products is decreased, and, second, the rate of core failure is slowed because of the decreased decay heat. This decrease and delay in fission-product release allows fuller exploitation of ship mobility to safeguard against the release of dangerous quantities of radioactive material near the populated areas. It is important, 
therefore, to consider in more detail the power requirements of harbor operation.

\section{Power Requirements in New York and Seattle}

Upon approaching a port area the speed and therefore power of oceangoing vessels are reduced, as mentioned above. The operating pattern while in the port area usually precludes sustained output above $50 \%$ of rated power. After docking, the power is further reduced to that required for the hotel load and is maintained at this level for the duration of the period at dockside. In the case of the N.S. SAVANINAH, the hotel load is $15 \%$ of full power.

As examples of in-port operation, the approximate power requirements ${ }^{6}$ for the harbors of New York and Seattle are shown in Figs. 1 and 2. Although each harbor has its own peculiar characteristics, the operating requirements given in Figs. 1 and 2 are probably typical.

\section{Power Requirements for Generalized Cases}

The following cases of operating history are defined for purposes of further evaluation in subsequent sections of this report:

Case 1

Operating sequence prior to maximum credible accident

Situation

100\% power for infinite time

Occurrence of accident preceded by full-power operation for a long time; this is the power history on which previous hazards evaluations were based

Case 2

Operating sequence

100\% power for infinite time; $50 \%$ power for $5 \mathrm{hr}$

Situation

This might represent a typical operating mode for port entry

Case 3

Operating sequence

100\% power for infinite time; zero power for $5 \mathrm{hr}$

Situation

Port entry under other than reactor power 


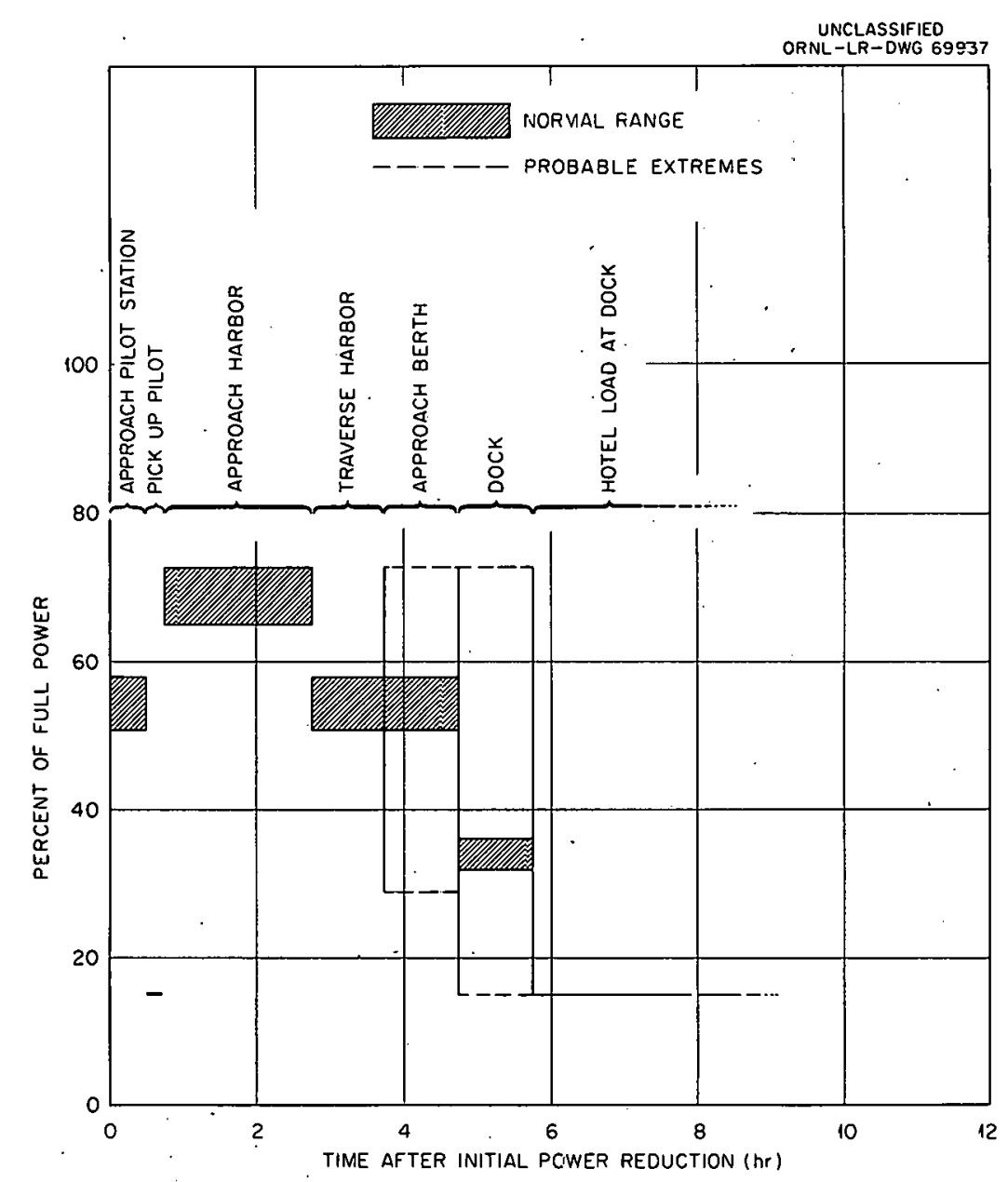

Fig. 1. Reactor Operation While Entering New York.

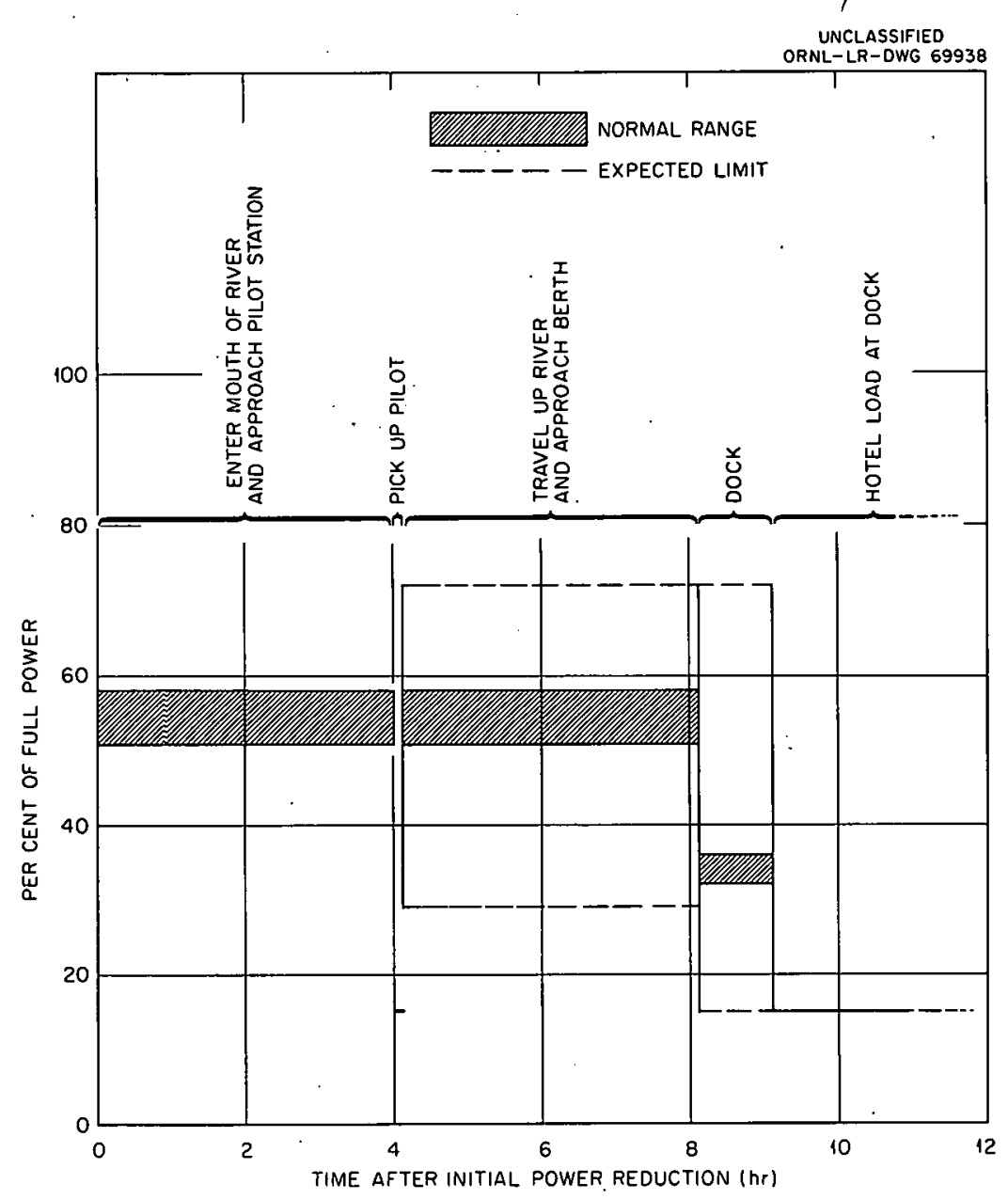

$a$

Fig. 2. Reactor Operation While Entering Seattle. 
Case 4

Operating sequence

Situation

Case 5

Operating sequence

Situation
100\% power for infinite time; $50 \%$ power for $5 \mathrm{hr}$; 15\% power for $12 \mathrm{hr}$

Typical port entry followed by base-load operation for $12 \mathrm{hr}$ at dockside

100\% power for infinite time; $50 \%$ power for $5 \mathrm{hr}$; zero power for $12 \mathrm{hr}$

Typical port entry followed by restricted base-load operation

3. EFFECT OF OPERATING HISTORY ON TIME FOR FUEL-ELEMENT FAILURE

The time available between the occurrence of the maximum credible accident and fuel-element failure depends on the reactor power at the time of the accident and the reactor operating history. Previous failure analyses were made by the Babcock \& Wilcox Company for a number of reactor conditions, 7 but a sequence of reactor operations that might be representative of in-port conditions was not explicitly covered. The case of essentially infinite-time operation at $100 \%$ power preceding the accident was considered for most of the previous hazards studies. As indicated in Section 2, reactor operation while entering and within a port is normally restricted to less than full-power. It was of interest therefore to determine the int'luence of reduced-power operation on the time available between the accident and fuel-element failure.

\section{Analytical Method for Estimating Failure Times}

It must, of course, be recognized that the conditions prior to and after an accident such as the maximum credible accident are not well defined. It is therefore necessary to make a number of assumptions that may have little connection with reality but which, hopefully, will set an upper limit on the consequences of the accident. In order to go beyond this "upper Iimit" analysis and to consider the effects of certain 
detailed changes, as in the present analysis, it is important to realize that the relative results are much more significant than absolute results. With this in mind, the approach taken in this analysis was to estimate the time for cladding failure for a given case in terms of the time for the same failure for a reference case (case 1) and to apply the relative results to the information given previously by Babcock \& Wilcox for case 1 . In this way the time to failure for each case was estimated on a basis consistent with the previous analysis.

First, the cladding temperature, $T_{1}$, for case $I$ was expressed as some function $G_{1}(t)$ of time after the mca:

$$
\mathrm{T}_{1}=\mathrm{G}_{1}(\mathrm{t}) \text {. }
$$

For another case, say case $i$, the cladding temperature is given by

$$
T_{i}=G_{i}(t) \text {. }
$$

If the criterion yfor cladding failure is some predetermined temperature, $\mathrm{T}_{F}$, and the times for cladding failure are designated $t_{1}$ and $t_{i}$ for case $I$ and case $i$, respectively, these failure times can be determined from the equations

$$
G_{1}\left(t_{1}\right)=T_{F}
$$

and

$$
G_{i}\left(t_{i}\right)=T_{F}
$$

The relationship between $t_{1}$ and $t_{i}$ is then given by

$$
G_{1}\left(t_{i}\right)=G_{i}\left(t_{i}\right) \text {. }
$$

In obtaining the G-functions, two major assumptions were made: (1) immediately following the accident the outer surface of the cladding is thermally insulated, and (2) the cladding and $\mathrm{UO}_{2}$ temperatures are the same at all times following the accident.

In view of the desire to maintain consistency with the Babcock \& Wilcox analysis, the first assumption is questionable when it is considered that the Babcock \& Wilcox analysis did not assume an insulated fuel element until $30 \mathrm{sec}$ after the accident. Nevertheless, in their analysis the heat transfer coefficient decreased quite rapidly in the 
first $2 \mathrm{sec}$. Thus, assumption 1 is probably a fair approximation. To . further substantiate the first assumption, the method developed for this analysis was used to predict the time to a given temperature for three cases previously analyzed by Babcock \& Wilcox. The maximum difference in predicted time was less than 15\% for all test cases. The second assumption is of little consequence except for short times, since temperature equilibrium in the insulated element is established in less than 2 min.

\section{Rclativc Failure Times for Various Cases}

Equation 1 was used to determine the time to fuel-element failure for a particular power history in terms of the failure time for case 1 . The results of this analysis are shown in Fig. 3. It should be recalled that the criterion for cladding failure is some predetermined temperature. However, up to this point, it has not been necessary to specify the failure temperature. Thus Fig. 3 is valid for any fuel-element failure that is uniquely determined by temperature.

Time Dependence of Failure

As indicated in Appendix B, it appears that fuel-element-cladding failure will not occur until the cladding temperature is very near the melting point. Once the cladding of a fuel element reaches the melting point, approximately $2 \%$ of the gaseous fission products will be released instantaneously. The other $98 \%$ will be retained in the $\mathrm{UO}_{2}$ fuel bodies. If the $\mathrm{UO}_{2}$ continues to increase in temperature, a sizeable fraction of the volatile fission products retained in the $\mathrm{UO}_{2}$ will be released upon attaining grain-growth temperature $\left(\sim 3200^{\circ} \mathrm{F}\right)$. If the fuel temperature continues to increase, some diffusion of the remaining fission products will occur until, finally, when the $\mathrm{UO}_{2}$ temperature reaches the melting point, almost all the volatile material will have been released from the fuel.

It can be seen from the above discussion that a number of mechanisms are involved in the release of activity from the core, and a proper 

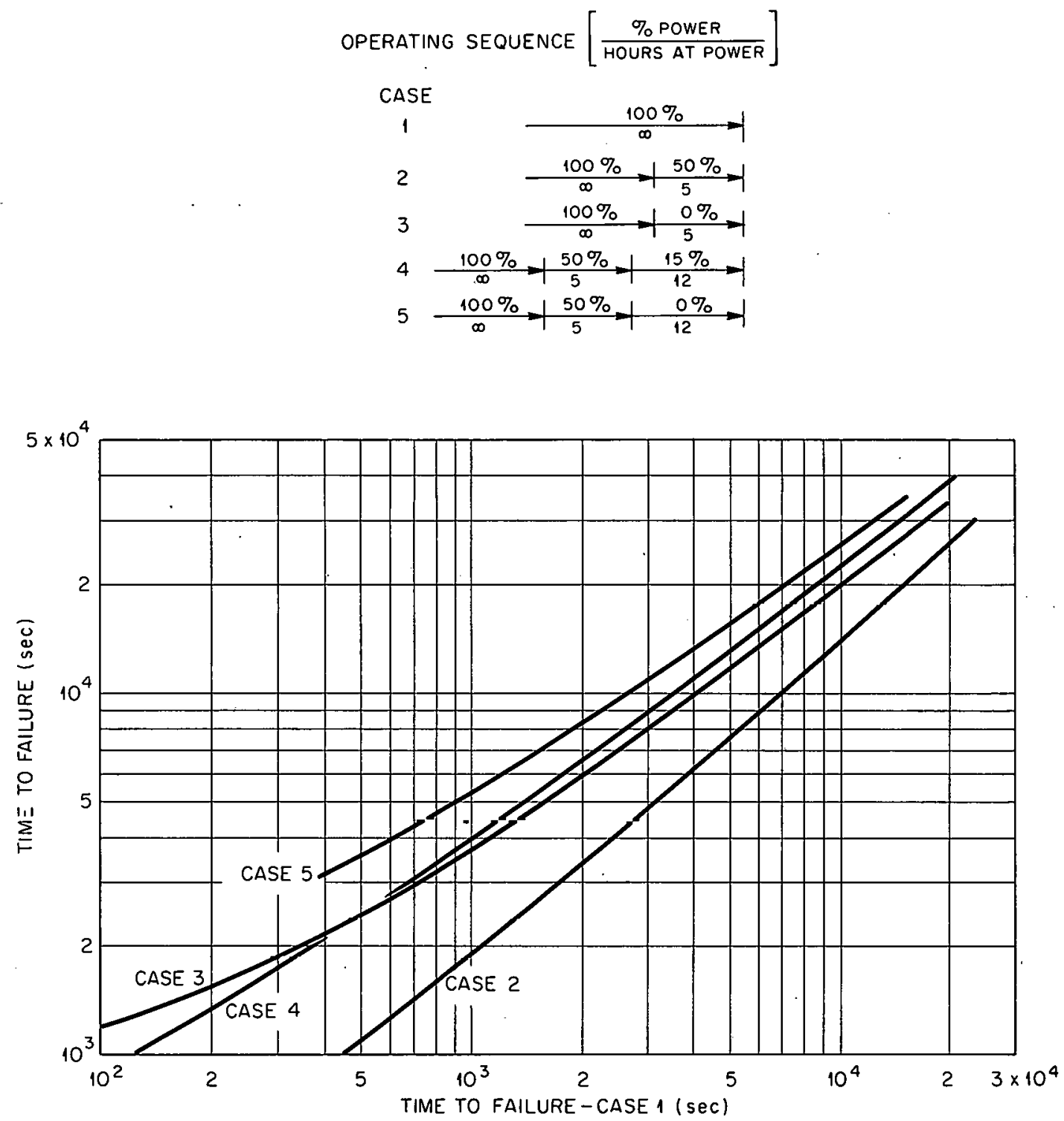

Fig. 3. Effect of Operating History on Time for Fuel-Element Failure After MCA.

analysis of the time dependence of release would take these mechanisms into account. The uncertainties involved in such a detailed analysis are great, however, and therefore for the present work the only mechanism considered was cladding failure by melting. It was assumed that once any part of the cladding of a fuel element reached the melting temperature, all fission products that would ultimately be released were released. 
Although not realistic, this assumed model for fission-product release gives conservative results from the standpoint of the hazards analysis.

According to this model the fraction of a given fission product released after an elapsed time, $t$, following the accident is given by

$$
F(t)=f E(t) \text {, }
$$

where $F(t)$ is the amount of a given fission product released from the core as a gas up to time, $t$, expressed as a fraction of the total quantity of the fission product in existence at $t i m e, t, E(t)$ is the fraction of the fissioned fuel exposed by cladding failure up to time $t$, and $f$ is the fraction of a fission product associated with the exposed fuel that is released as a gas. It should be noted that $F(t)$ may be different for each fission product because $f$ is characteristic of the particular fission product being considered. On the other hand, the quantity $E(t)$ is common to all fission products.

For case 1 , the quantity $\mathrm{E}_{1}(\mathrm{t})$ was calculated by Babcock \& Wilcox. ${ }^{7}$ By using their results for $E_{1}(t)$, the information given in Fig. 3 could be applied to obtain fuel-element failure curves for any of the power history cases considered; this was done, and the results are shown in Fig. 4.

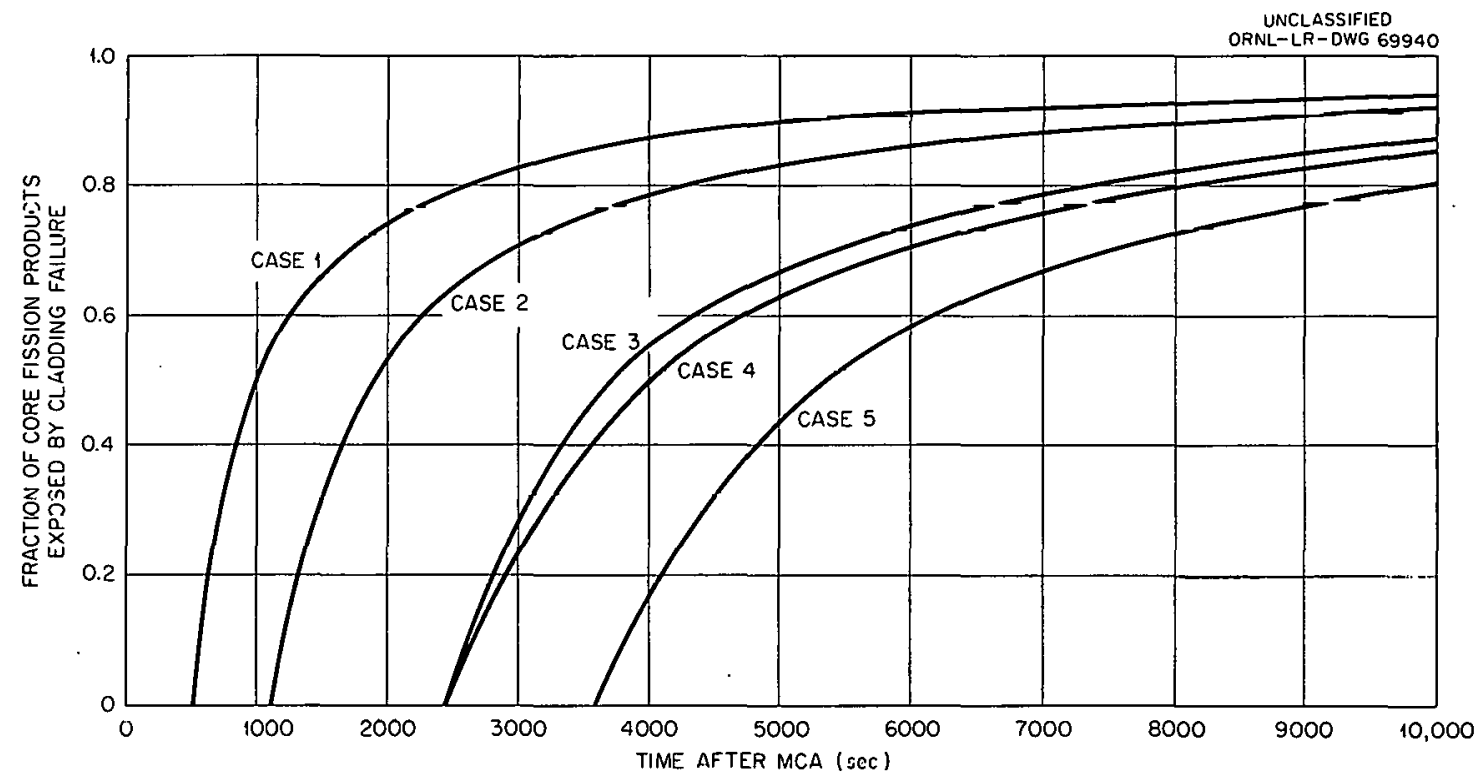

Fig. 4. Fuel Exposed by C1.ariline Me1ting. 


\section{FISSION-PRODUCT DECAY}

The power requirements for the cases of interest (cases 1, 2, 4, and 5 )* were defined in Section 2, and the fuel-element failure times for these cases were evaluated in Section 3. The amounts of noble gas and iodine available during the accident are also of interest because the exposure to one or the other of these fission products would be controlling following the accident. Whether it would be the iodine or the noble gases that would be controlling would depend largely on the iodine removal efficiency of the filter in the compartment ventilation system.

\section{Calculation of Fission-Product Inventory for Various Cases}

The source of fission products as a function of irradiation time, decay time, and neutron flux was calculated by solving the following differential equations:

$$
\frac{d N_{i}}{d t}=\Sigma_{f} \phi Y_{i}^{i n d}+k N_{i-1} \lambda_{i-1}-N_{i} \lambda_{i}-N_{i} \phi_{i} \sigma_{i}
$$

and

$$
\frac{d N_{i-1}}{d t}=\sum_{f} \phi Y_{i-1}^{c u m}-\lambda_{i-1} N_{i-1}-\sigma_{i-1} \phi N_{i-1} \text {. }
$$

When $t=0, N_{i}=N_{i}^{O}$, and $N_{i-1}=N_{i-1}^{O}$, solving for $N_{i}$ yields:

$$
\begin{aligned}
& N_{i}=N_{i}^{o} e^{\lambda_{\text {eff }}^{i} t}+\Sigma_{f} \phi\left(\frac{Y_{i}^{i n d}}{\lambda_{\text {eff }}^{i}}+\frac{k Y_{i-1}^{c u m} \lambda_{i-1}}{\lambda_{\text {eff }}^{i-1} \lambda_{\text {eff }}^{i}}\right)\left(1-e^{-\lambda_{\text {eff }}^{i}}\right)+ \\
& +\frac{\lambda_{i-1}}{\lambda_{e f f}^{i}-\lambda_{e f f}^{i-1}}\left(k N_{i-1}^{o}-\frac{\sum_{f} \phi k Y_{i-1}^{c u m}}{\lambda_{e f f}^{i-1}}\right)\left(e^{-\lambda_{e f f}^{i-1} t}-e^{-\lambda_{e f f}^{i}}\right),
\end{aligned}
$$

* Case 3 was not considered because of the similarity of the core failure curve in that case to that of case 4 and the lack of interest in the operational mode that it implied. 
where

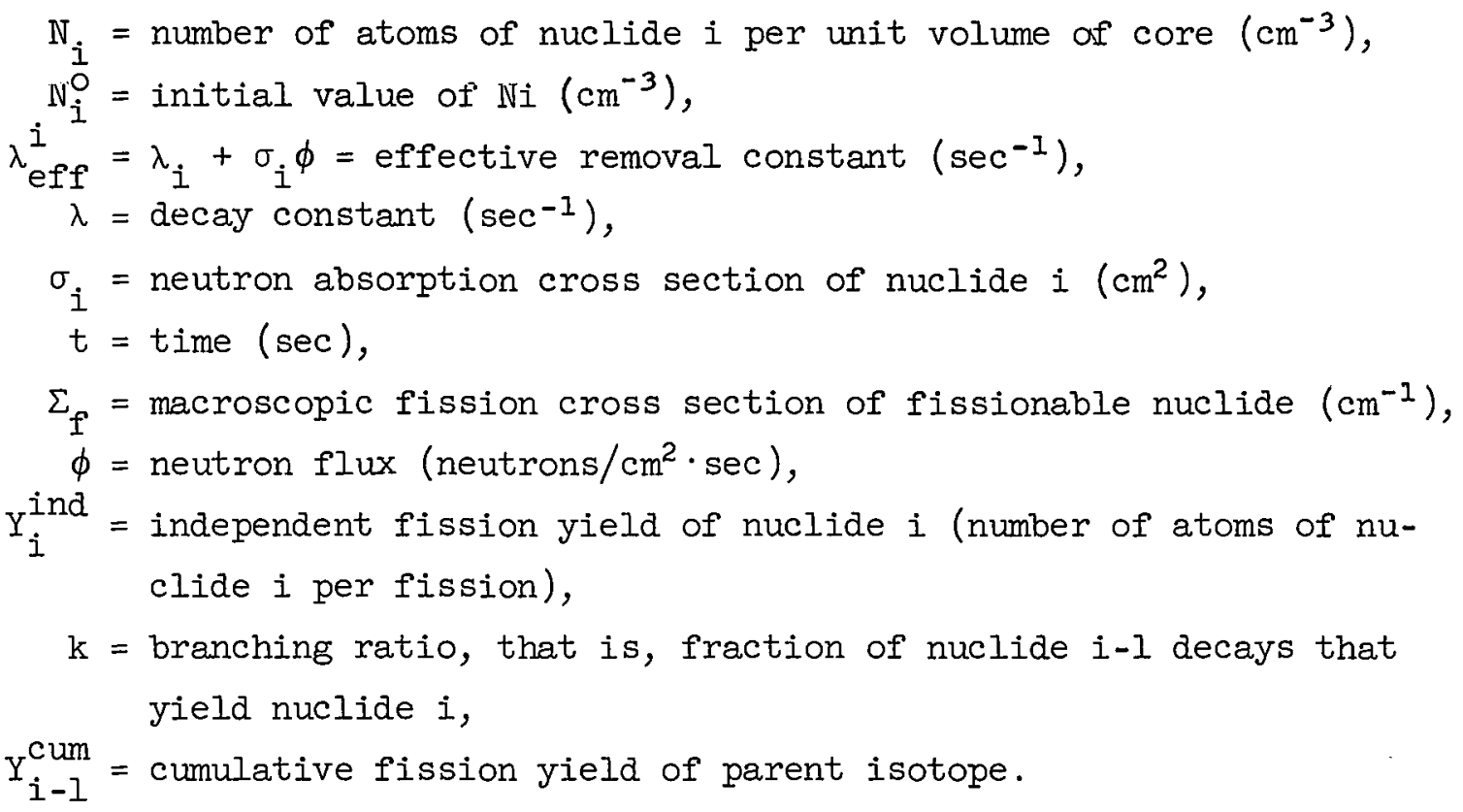

Equation (4) can be used for decay calculations by setting the neutron flux equal to zero. It is to be noted that Eq. (4) is strictly applicable for a nuclide with one precursor and removal by both radioactive decay and neutron capture. No provision was made for buildup of nuclide $\mathbb{N}_{i}$ or $\mathbb{N}_{i-1}$ by neutron capture of the nuclide of the same atomic number in the chain of next lower atomic mass. This latter restriction is not important for the nuclides of interest here. For the time periods considered the restriction of one precursor introduces only a small error, because, in general, the $\mathbb{N}_{i-2}$ nuclides have very short half-lives compared with the half-lives of the nuclides of interest. Therefore the cumulative yield is used for the $\mathrm{N}_{i-1}$ nuclide, assuming that it is instantly generated by fission.

Equation 4 was solved by means of the ORSFT compiler for the IBM7090 computer. The program was written so that after a time period at a given power the calculated values of nuclides $\mathrm{N}_{i}$ and $\mathrm{N}_{i-1}$ were stored so that these values could be used as the initial values, $N_{i}^{0}$ and $N_{i-I}^{O}$, in the following time period of the same case.

The calculated values of $\mathrm{N}_{i}$ and $\mathrm{N}_{i-1}$ for the various time periods were converted to the total core inventory (in curies) by the relation: 


$$
Q_{i}=\frac{\lambda_{i} N_{i}}{3.7 \times 10^{10}} \mathrm{~V}
$$

where $Q_{i}$ is the total core inventory of nuclide $i$ (curies) and $V$ is the core volume $\left(\mathrm{cm}^{3}\right)$. The fission products studied were the important gammaemitting noble gases and the important iodine isotopes. Some approximations were made to fit the decay-chain structure to the requirements of Eq. (4). The true chains and the synthesized decay chains that were used in the calculations are shown in Appendix C.

\section{Results of Fission-Product Inventory Calculations}

The core inventory in curies of the various isotopes at the time of the accident was calculated as indicated. It is shown in Table 1 for cases 1, 2, 4, and 5. The noble gas energy release rates are shown in Fig. 5 for the various cases. In each case; the number of curies of each isotope was multiplied by the average garma energy of that isotope and the resulting energy release rates of the seven rare-gas nuclides were added. This procedure was repeated for various times after shutdown, and

Table 1. Core Krypton, Xenon, and Iodine Inventory At Time of Accident.

\begin{tabular}{|c|c|c|c|c|c|c|}
\hline \multirow{2}{*}{ Nuclide } & \multirow{2}{*}{$\begin{array}{l}\text { Half- } \\
\text { Life }\end{array}$} & \multirow{2}{*}{$\begin{array}{c}\text { Average } \\
\text { Gamma } \\
\text { Energy } \\
\text { (Mev) }\end{array}$} & \multicolumn{4}{|c|}{ Inventory at Time of Accident (curies) } \\
\hline & & & Case 1 & Case 2 & Case 4 & Case 5 \\
\hline$K r^{85 m}$ & $4.36 h$ & 0.181 & $8.67 \times 10^{5}$ & $6.31 \times 10^{5}$ & $2.04 \times 10^{5}$ & $9.30 \times 10^{4}$ \\
\hline $\begin{array}{l}\mathrm{nI} \\
\mathrm{Kr}\end{array}$ & $78 \mathrm{~m}$ & $\begin{array}{l}0.101 \\
0.56\end{array}$ & $1.53 \times 10^{6}$ & $8.19 \times 10^{5}$ & $2.30 \times 10^{5}$ & $1.38 \times 10^{3}$ \\
\hline$K r^{88}$ & $2.77 \mathrm{~h}$ & 2.07 & $2.13 \times 10^{6}$ & $1.38 \times 10^{6}$ & $3.72 \times 10^{5}$ & $6.84 \times 10^{4}$ \\
\hline $\mathrm{Xe}^{133 \mathrm{~m}}$ & $2.3 \mathrm{~d}$ & 0.233 & $9.02 \times 10^{4}$ & $7.00 \times 10^{4}$ & $8.73 \times 10^{4}$ & $8.69 \times 10^{4}$ \\
\hline $\mathrm{Xe}^{133}$ & $5.27 d$ & 0.081 & $3.67 \times 10^{6}$ & $3.66 \times 10^{6}$ & $3.61 \times 10^{6}$ & $3.61 \times 10^{6}$ \\
\hline $\mathrm{Xe}^{135}$ & $15.6 \mathrm{~m}$ & 0.52 & $1.02 \times 10^{6}$ & $8.28 \times 10^{5}$ & $3.51 \times 10^{5}$ & $2.43 \times 10^{5}$ \\
\hline $\mathrm{Xe}^{135}$ & $9.13 \mathrm{~h}$ & 0.268 & $1.75 \times 10^{6}$ & $1.88 \times 10^{6}$ & $1.60 \times 10^{6}$ & $1.60 \times 10^{6}$ \\
\hline$I^{131}$ & $8.05 \mathrm{~d}$ & (a) & $1.67 \times 10^{6}$ & $1.65 \times 10^{6}$ & $1.60 \times 10^{6}$ & $1.58 \times 10^{6}$ \\
\hline$I^{132}$ & $2.4 \mathrm{~d}$ & (a) & $2.54 \times 10^{6}$ & $2.52 \times 10^{6}$ & $2.33 \times 10^{6}$ & $2.30 \times 10^{6}$ \\
\hline$I^{133}$ & $20.8 \mathrm{~h}$ & (a) & $3.98 \times 10^{6}$ & $3.74 \times 10^{6}$ & $2.74 \times 10^{6}$ & $2.56 \times 10^{6}$ \\
\hline$I^{135}$ & $6.68 \mathrm{~h}$ & (a) & $3.41 \times 10^{6}$ & $2.72 \times 10^{6}$ & $1.14 \times 10^{6}$ & $7.80 \times 10^{5}$ \\
\hline
\end{tabular}

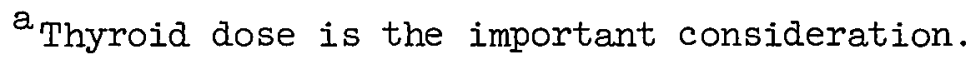




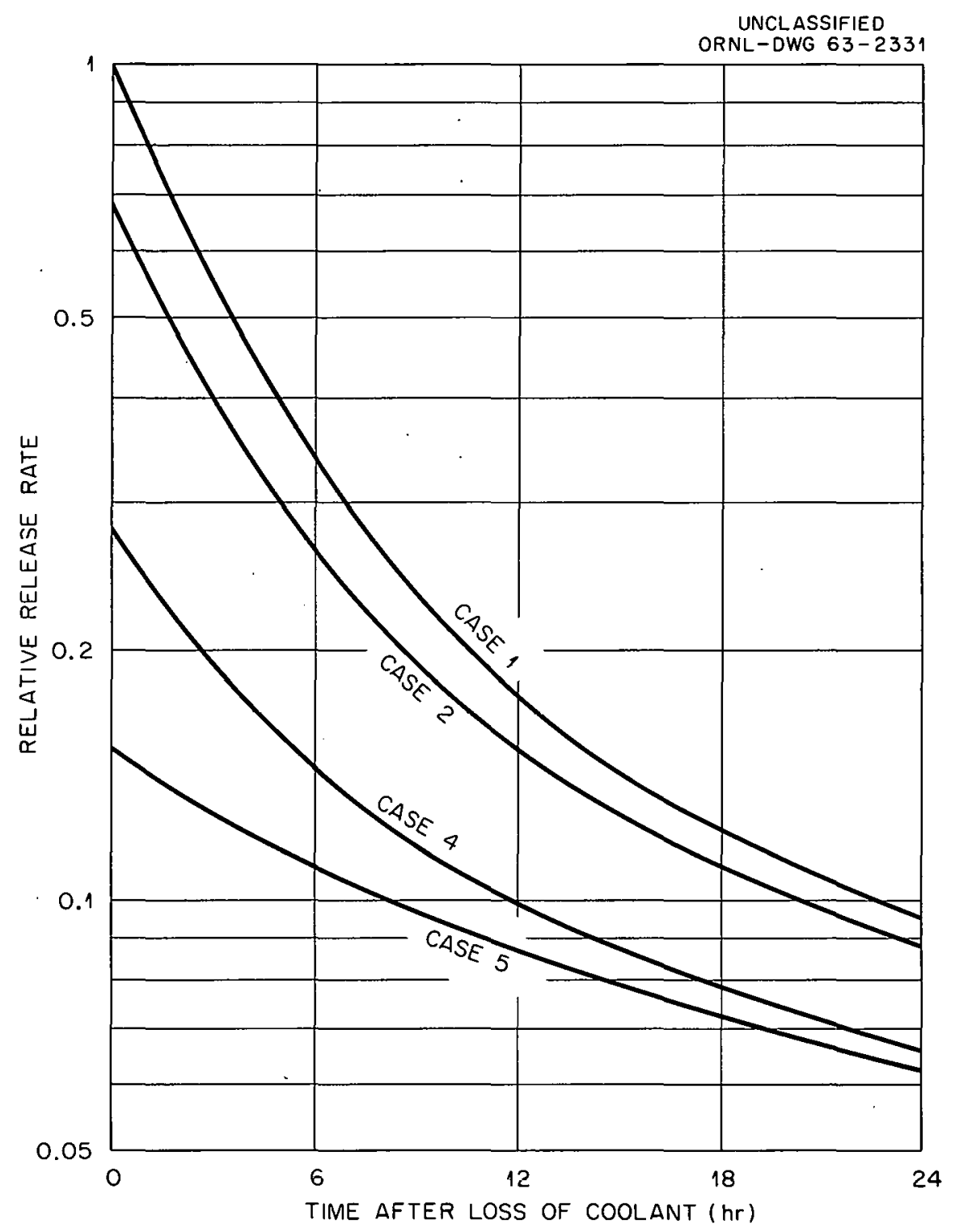

Fig. 5. Noble Gas Gamma Energy Release Rate Relative to Initial Rate for Case 1 .

the results were expressed as fractions of the value obtained for case $\perp$ at the time of the accident. The results were gamma-energy weighted functions that were directly useful in submersion exposure calculations:

$$
\text { Relative release rate }=\frac{\sum_{i=1}^{n} E_{\gamma}^{i} Q_{i}(t)(\text { case } n)}{\sum_{i=1}^{n} E_{\gamma}^{i} Q_{i}(0)(\text { case } 1)} \text {, }
$$


where

$$
\begin{aligned}
E_{\gamma}^{i} & =\text { the average gamma photon energy of nuclide } i \text { (Mev), } \\
n & =\text { number of nuclides, } \\
Q_{i}(t) & =\text { curies of nuclide } i \text { at time } t \text { after the accident, } \\
Q_{i}(0) & =\text { curies of nuclide } i \text { at the time of the accident. }
\end{aligned}
$$

The initial values of the gamma-energy-weighted release rate are given in Table 2 .

Table 2. Initial Noble Gas Energy
Release Rates for the
Various Cases

\begin{tabular}{ccc}
\hline Case & $\begin{array}{c}\text { Initial Energy } \\
\text { Release Rate } \\
\text { (Mev.curies) }\end{array}$ & $\begin{array}{c}\text { Initial Noble } \\
\text { Gas Release } \\
\text { Rate as } \\
\text { Fraction of } \\
\text { Case 1 Rate } \\
\text { [Eq. (6)] }\end{array}$ \\
\hline 1 & $6.74 \times 10^{6}$ & 1.000 \\
2 & $4.68 \times 10^{6}$ & 0.694 \\
4 & $1.059 \times 10^{6}$ & 0.270 \\
5 & $1.026 \times 10^{6}$ & 0.152 \\
\hline
\end{tabular}

The variations of iodine activity as a function of time after the accident are shown in Figs. 6 through 9. Table 3 gives the relative initial inventory of the iodine isotopes for the various cases.

\begin{tabular}{|c|c|c|c|c|}
\hline \multirow{2}{*}{ Nuclide } & \multirow{2}{*}{ Hälf-Life } & \multicolumn{3}{|c|}{$\begin{array}{c}\text { Initial Iodine Release Rate as } \\
\text { Fraction of Case } 1 \text { Rate }\end{array}$} \\
\hline & & Case 2 & Case 4 & Case 5 \\
\hline$I^{131}$ & $8.05 a$ & 0.982 & 0.958 & 0.946 \\
\hline$I^{132}$ & $2.4 \mathrm{~h}$ & 0.992 & 0.917 & 0.906 \\
\hline$I^{133}$ & $20.8 \mathrm{~h}$ & 0.940 & 0.688 & 0.643 \\
\hline$I^{135}$ & $6.68 \mathrm{~h}$ & 0.798 & 0.334 & 0.228 \\
\hline
\end{tabular}

Table 3. Initial Value of Iodine Isotopes for Various Cases as a Function of Initial

Value for Case 1 


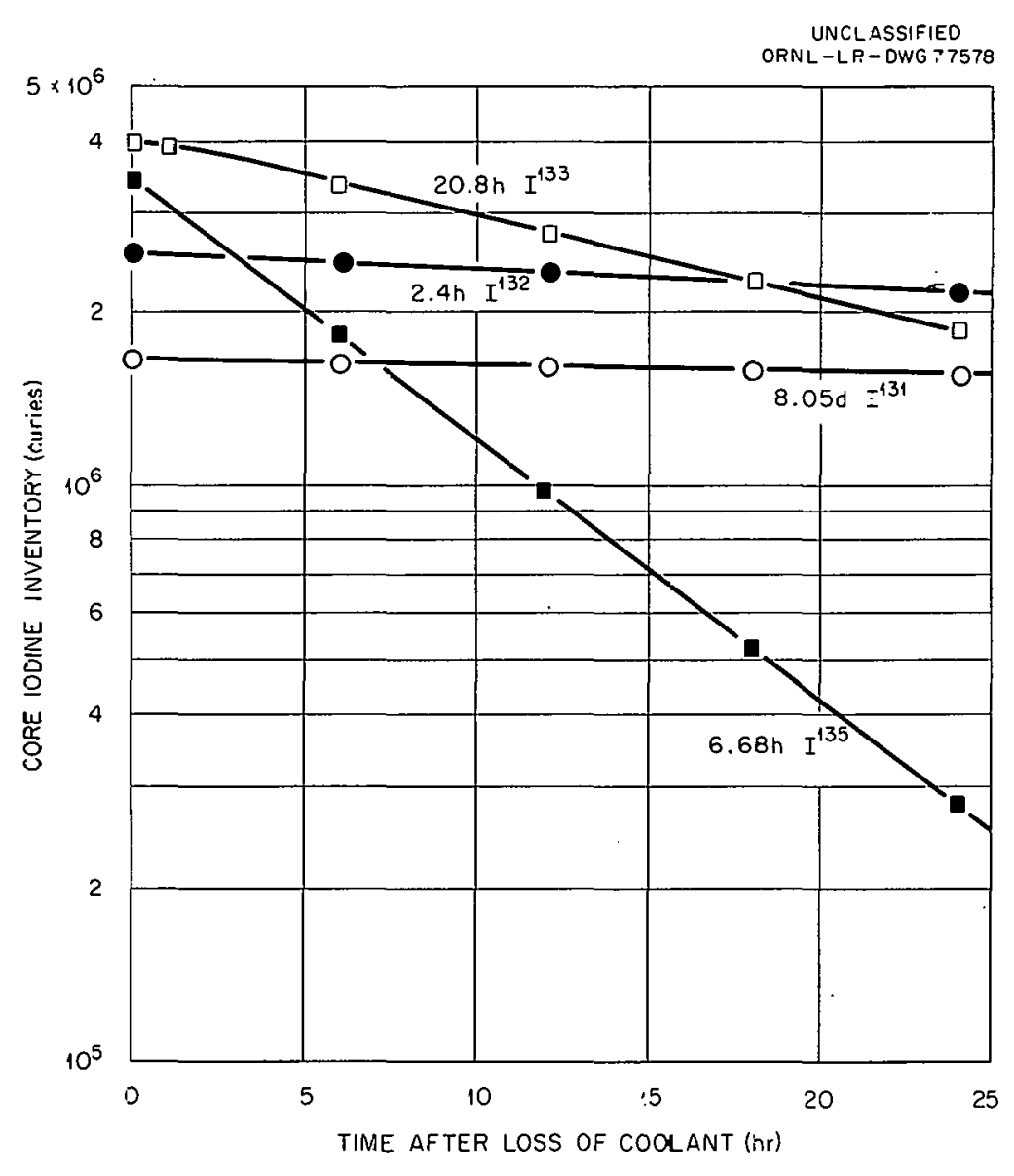

Fig. 6. Radioiodine Inventory in N.S. SAVARNAH Core - Case 1.

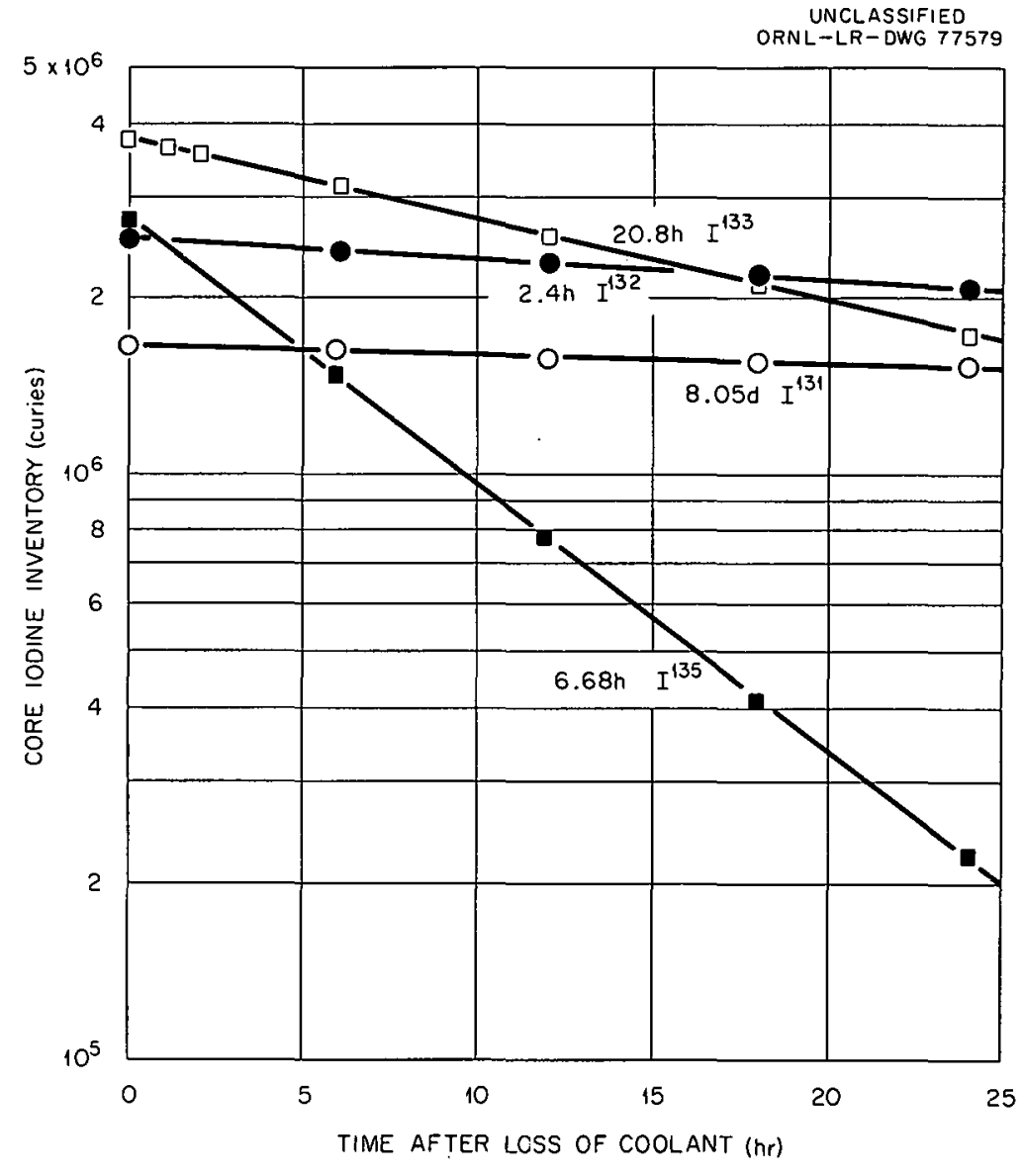

Fig. 7. Radioiodine Inventory in N.S. SAVANNAH Core - Case 2. 


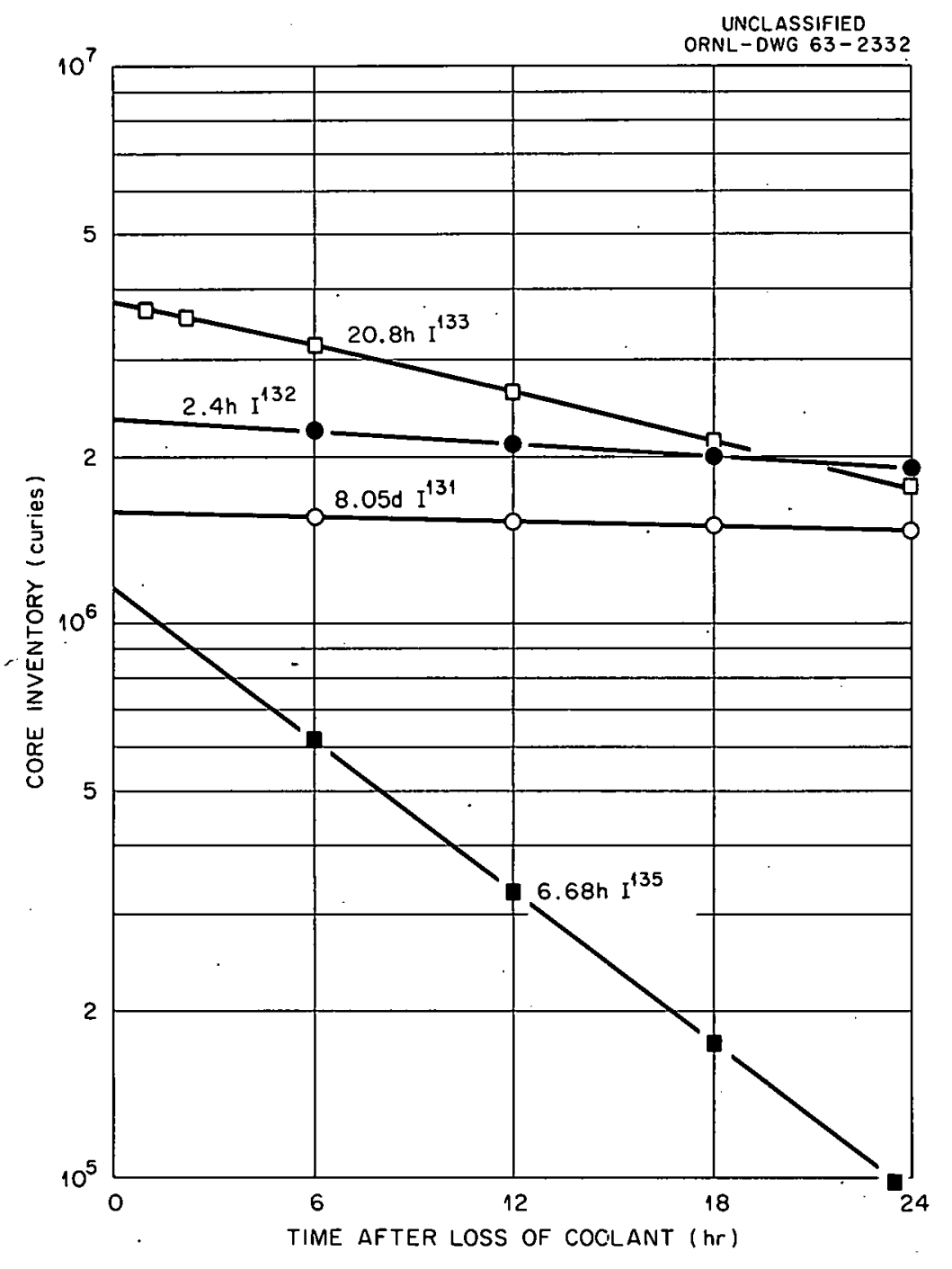

Fig. 8. Radioiodine Inventory in N.S. SAVANNAH Core - Case 4.

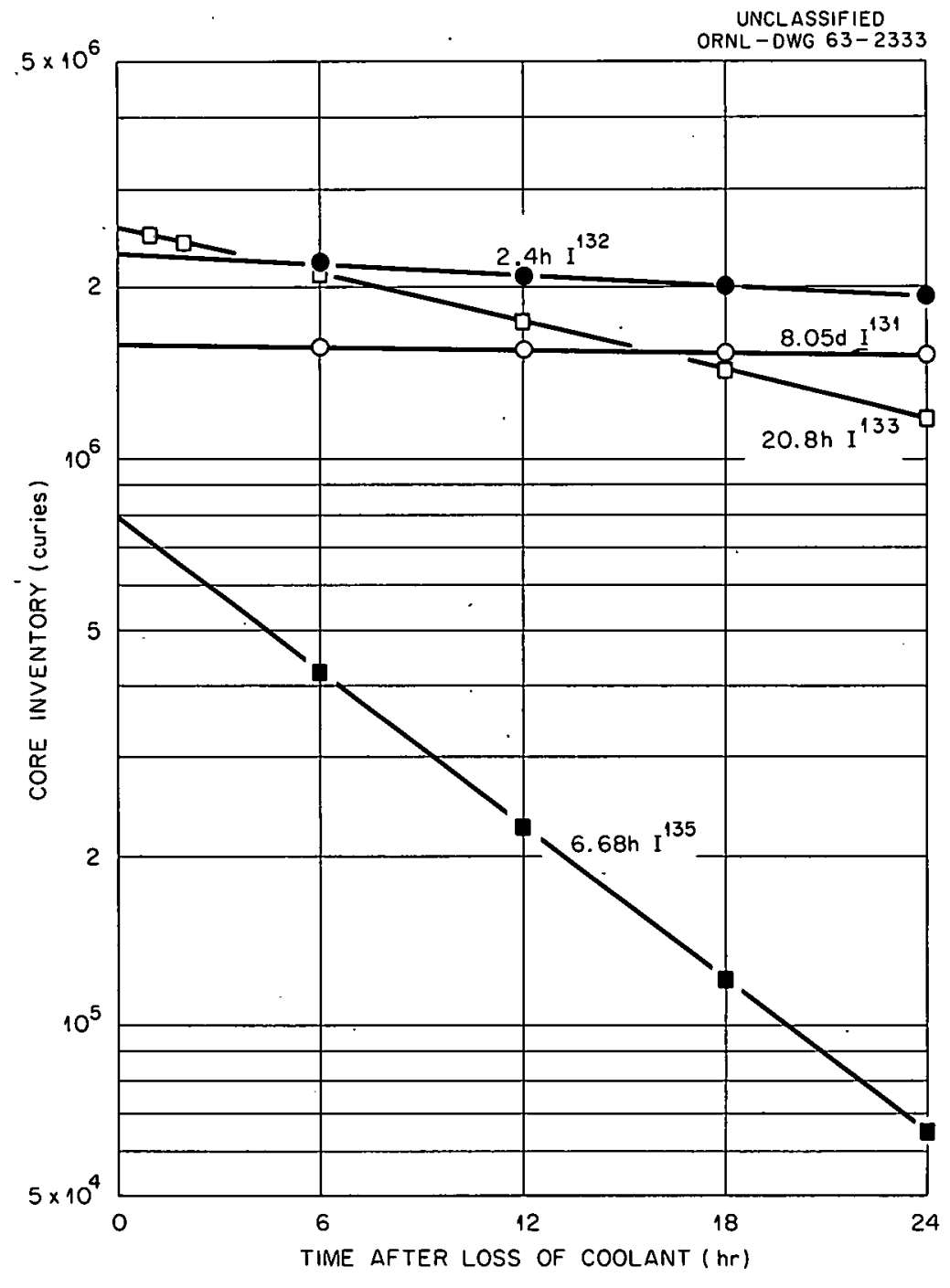

$\stackrel{\leftrightarrow}{\infty}$
Fig. 9. Radioiodine Inventory in N.S. SAVAINAH Core - Case 5. 
The data presented in this analysis provided the "source term" for the activity available in the core. This term was modified by the fuelelement rupture rate, the containment and filter holdup effects, and meteorological dispersion factors to arrive at dose rates external to the ship.

\section{RELFASE FROM CONTAINMEIVT SYSTEMS}

The calculated rate of release of activity from the containment system establishes the exposure potential (which has a direct bearing on the siting requirements) of a nuclear reactor. Previous siting evaluation of the N.S. SAVANNAH made use of many simplified and conservative assumptions concerning the release of fission products to the atmosphere in the event of the maximum credible accident. In view of the fact that application of these greatly simplified assumptions would in some instances indicate exposures that are not compatible with the berthing requirements of a nuclear ship, the present analysis presents a more detailed evaluation of activity release from the N.S. SAVANNAH containment system.

The following conservative assumptions concerning the release of fission products from the reactor system to the atmosphere had previously been employed. ${ }^{4}$

1. The reactor would operate for an essentially infinite time at full power up to the occurrence of the accident (power history case $I$ as הefined in ser. ?).

2. The core would fail immediately following the maximum credible accident and release all volatile fission products to the containment vessel.

3. Immediately following the accident the containment system would start to leak activity to the atmosphere at a rate determined by the tightness of the containment vessel.

4. Depletion of the fission products by decay would not be significant.

The leak rate of fission products to the atmosphere as calculated on the basis of the above assumptions will hereafter be designated as 
the "reference release rate"; it is given by

$$
\text { Reference release rate }=l \mathrm{fN}_{0} \text {, }
$$

where $l$ is the leak-rate constant for the containment vessel (fraction of enclosed material released per unit time), $f$ is the fraction of a given radioactive material that is released to the containment vessel as a gas, and $N_{0}$ is the total quantity of a given fission product in the core after operation at full power for a long time. In contrast to this simplified calculation, the present analysis accounts for holdup effects provided by the core and reactor compartment, decay of the fission products, and actual cases of power history, as presented in Section 2.

\section{Effects of System Holdup}

A schematic diagram of the three-barrier containment model is shown in Fig. 10. As may be seen, an isotope may enter an enclosure by leakage from a preceding enclosure and by decay of a precursor isotope. An isotope may leave an enclosure by leakage and may decay to a daughter isotope. The rate processes involved in the analysis are illustrated in Fig. 11. The symbols used in Fig. 11 are:

$$
\begin{aligned}
R(t)= & \text { rate of escape of given isotope from reactor core, } \\
F(t)= & \text { fraction of total quantity of isotope that has escaped from } \\
& \text { the core, } \\
\mathrm{Q}(\mathrm{t})= & \text { quantity of isotope held up in first containment barrier, } \\
\mathrm{U}(\mathrm{t})= & \text { quantity of isotope held up in second containment barrier, } \\
\mathrm{Q}_{\mathrm{p}}(t)= & \text { quantity of precursor isotope held up in first containment } \\
& \text { barrier, } \\
\mathrm{U}_{\mathrm{p}}(t)= & \text { quantity of precursor isotope held up in second containment } \\
& \text { barrier, } \\
l= & \text { leak-rate constant for first containment barrier, } \\
m= & \text { leak-rate constant for second containment barrier, } \\
\lambda= & \text { decay constant for isotope being considered, } \\
\lambda_{\mathrm{p}}= & \text { decay constant for precursor isotope, } \\
\mathrm{N}(t)= & \text { total quantity of isotope existing at time } t, \\
N_{p}(t)= & \text { total quantity of precursor isotope existing at time t. }
\end{aligned}
$$


UNCLASSIFIED

ORNL-LR-DWG $72985 A$
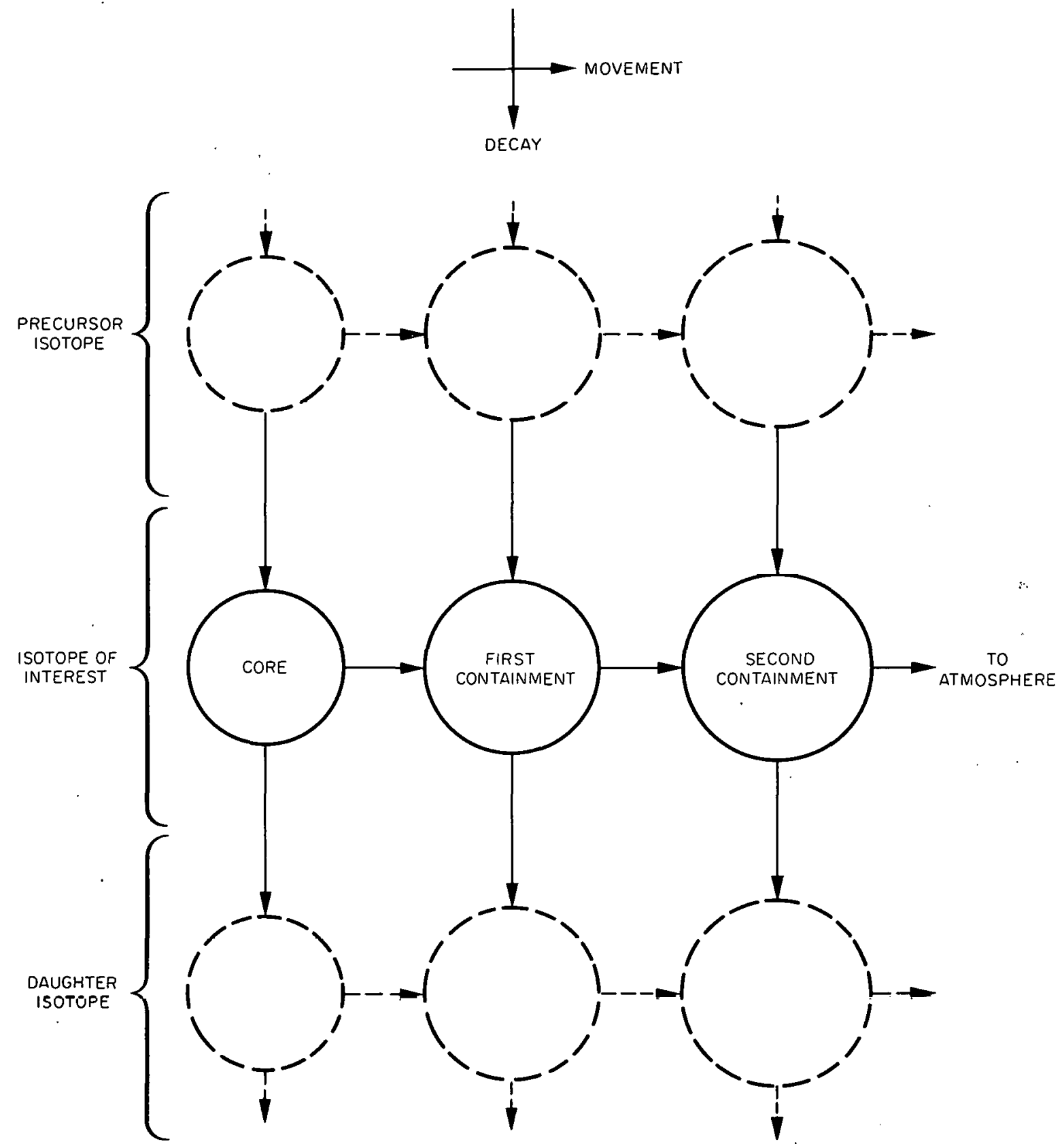

Fig. 10. Schematic Diagram of Three-Barrier Containment System.

The general problem of a three-barrier system was considered in ref. 8. As shown in ref. 8, if all precursor isotopes move through the system in the same manner as the isotope of interest or if there are no precursors, it is possible to separate the problems of mobility and decay. For this special case the leak rate to the atmosphere is given by 


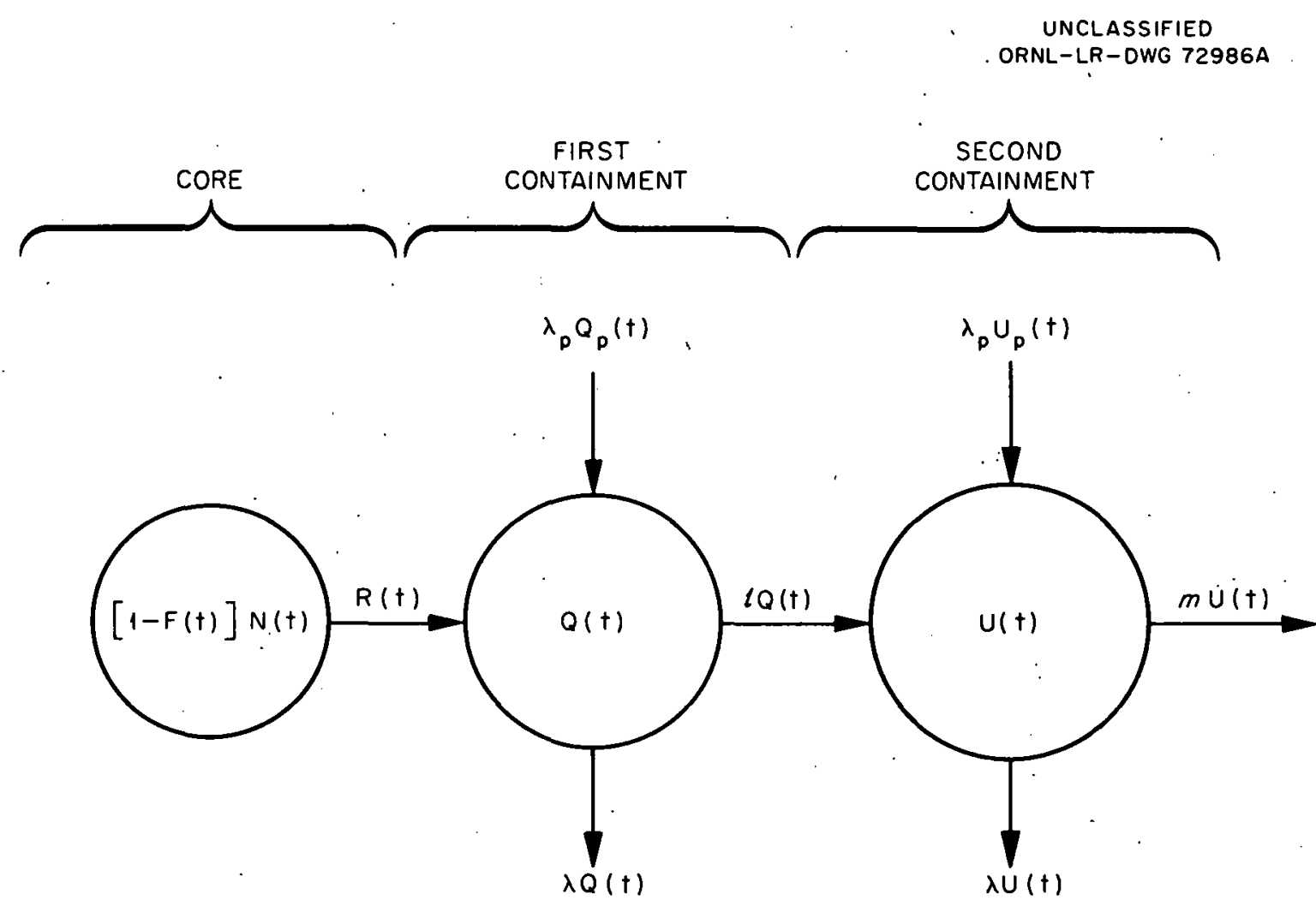

Fig. 1l. Schematic Diagram of Containment Rate Processes.

$$
m \mathrm{U}(\mathrm{t})=\frac{m l \mathrm{~N}(\mathrm{t})}{(m-l)}\left[m \mathrm{e}^{-m t} \int_{0}^{\mathrm{t}} \mathrm{e}^{m \tau} \mathrm{F}(\tau) \mathrm{d} \tau-l \mathrm{e}^{-l t} \int_{0}^{\mathrm{t}} \mathrm{e}^{l \tau} \mathrm{F}(\tau) \mathrm{d} \tau\right]
$$

where $\tau$ is the variable of integration.

The case of a reactor system with a single containment. vessel, which, upon initiation of an accident, releases some fraction, $f$, of a given fission product from the core was considered. It was assumed that leakage from the containment would be small enough so that little depletion would occur because of the leakage. For this simple case the leakage to the atmosphere is given by if $\mathrm{N}(\mathrm{t})$, and the leak rate given by Eq. (7) expressed as a fraction of the simple, single-containment case* is

*It should be noted that a distinction is made between the "singlecontainment" case and the "reference" case that was defined above. The reference release rate is based on case 1 power history and no decay, whereas the single-containment release rate is not limited to a particular power history, and decay is taken into account. 


$$
\begin{aligned}
\frac{m \mathrm{U}(\mathrm{t})}{l f \mathrm{~N}(\mathrm{t})}=\frac{m}{f(m-l)}\left[m \mathrm{e}^{-m \mathrm{t}} \int_{0}^{\mathrm{t}} \mathrm{e}^{m \pi} \mathrm{F}(\tau) \mathrm{d} \tau\right. & \\
& \left.-l \mathrm{e}^{-l t} \int_{0}^{\mathrm{t}} \mathrm{e}^{l \tau} \mathrm{F}(\tau) \mathrm{d} \tau\right]
\end{aligned}
$$

In order to calculate the relative release rate from $\mathrm{Eq}$. (8), it is necessary to evaluate $F(t)$. As indicated in Section $3, F(t)$ is given by

$$
F(t)=f E(t)
$$

where, as before, $f$ is the fraction of a fission product associated with exposed fuel that is released from the core as a gas and $E(t)$ is the fraction of the fissioned fuel exposed.

Figure 4 gives $E(t)$ for five different power histories, and the general shape of the E-curves suggests an empirical fit of the form

$$
\begin{array}{cc}
E(t)=0 & t \leqslant t_{0} \\
E(t)=1-e^{-\mu\left(t-t_{0}\right)} & t>t_{0},
\end{array}
$$

where $t_{0}$ is the time elapsed from start of accident to initial fuelelement failure and $\mu$ is the core release-rate parameter.

If the failure curves are approximated by Eq. (9),

$$
\begin{array}{rl}
F(t)=0 & t \leqslant t_{0} \\
F(t)=\left[1-e^{-\mu\left(t-t_{0}\right)}\right] f & t>t_{0} .
\end{array}
$$

By using Eq. (10) for $F(t)$, the relative leak rate given by Eq. (8) becomes:

$$
L(\theta)=\frac{k}{k-I}\left[\frac{\epsilon}{k-\epsilon} c^{-k \theta} \cdots \frac{\epsilon}{I-\epsilon} e^{-\theta}+\left(\frac{I}{I-\epsilon}-\frac{k}{k-\epsilon}\right) e^{-\epsilon \theta}\right],
$$

where

$$
\begin{aligned}
\mathrm{L}(\theta) & =\frac{m \mathrm{U}(\mathrm{t})}{l f \mathrm{~N}(\mathrm{t})}, \\
\theta & =l\left(\mathrm{t}-\mathrm{t}_{0}\right),
\end{aligned}
$$




$$
\begin{aligned}
& \kappa=\frac{m}{l}, \\
& \epsilon=\frac{\mu}{l} .
\end{aligned}
$$

The relative leak rate $\mathrm{L}(\theta)$, as given by Eq. (11), was determined for four different cases of power history and for both the normal and emergency reactor compartment ventilation systems. The results are shown in Figs. 12 and 13.

The information necessary to calculate $\mathrm{L}(\theta)$ is given in Table 4. To obtain the reactor compartment leak-rate constant $m$, it was assumed that only half of the compartment volume was exhausted by the ventilation system; thus the values of $m$ and therefore the leak rates are overestimated. The values of $\mu$ were obtained by fitting the empirical expression for $E(t)$ to the curves of Fig. 4 .

A special case of this generalized study of the ef'fect of system holdup is shown in Appendix $D$ in which the compartment concentration (and hence release rate) as a function of time is given as a function of the

Tahle 4, Tnformation Tised tin Saidsulate Reactor

\begin{tabular}{|c|c|c|c|c|}
\hline & Case 1 & Case 2 & Case 4 & Case 5 \\
\hline $\begin{array}{l}\text { Compartment volume } \\
\text { ventilated, } \mathrm{ft}^{3}\end{array}$ & $3 \times 10^{4}$ & $3 \times 10^{4}$ & $3 \times 10^{4}$ & $3 \times 10^{4}$ \\
\hline \multicolumn{5}{|c|}{$\begin{array}{l}\text { Compartment ventilation } \\
\text { rate, } \mathrm{ft}^{3} / \mathrm{min}\end{array}$} \\
\hline $\begin{array}{l}\text { Normal system } \\
\text { Emergency system a }\end{array}$ & $\begin{array}{l}4000 \\
200\end{array}$ & $\begin{array}{l}4000 \\
200\end{array}$ & $\begin{array}{l}4000 \\
200\end{array}$ & $\begin{array}{l}4000 \\
200\end{array}$ \\
\hline \multicolumn{5}{|l|}{$\dot{m}\left(\mathrm{day}^{-1}\right)$} \\
\hline $\begin{array}{l}\text { Normal system } \\
\text { Emergency system }\end{array}$ & $\begin{array}{l}192 \\
9.6\end{array}$ & $\begin{array}{l}192 \\
9.6\end{array}$ & $\begin{array}{l}192 \\
9.6\end{array}$ & $\begin{array}{l}192 \\
9.6\end{array}$ \\
\hline$l\left(\operatorname{day}^{-1}\right)$ & 0.015 & 0.015 & 0.015 & 0.015 \\
\hline$\mu\left(\operatorname{day}^{-1}\right)$ & 74.91 & 67.1 & 34.88 & 30.41 \\
\hline$t_{0}(\sec )$ & 500 & 1090 & 2450 & 3600 \\
\hline
\end{tabular}
Compartment Leakage 


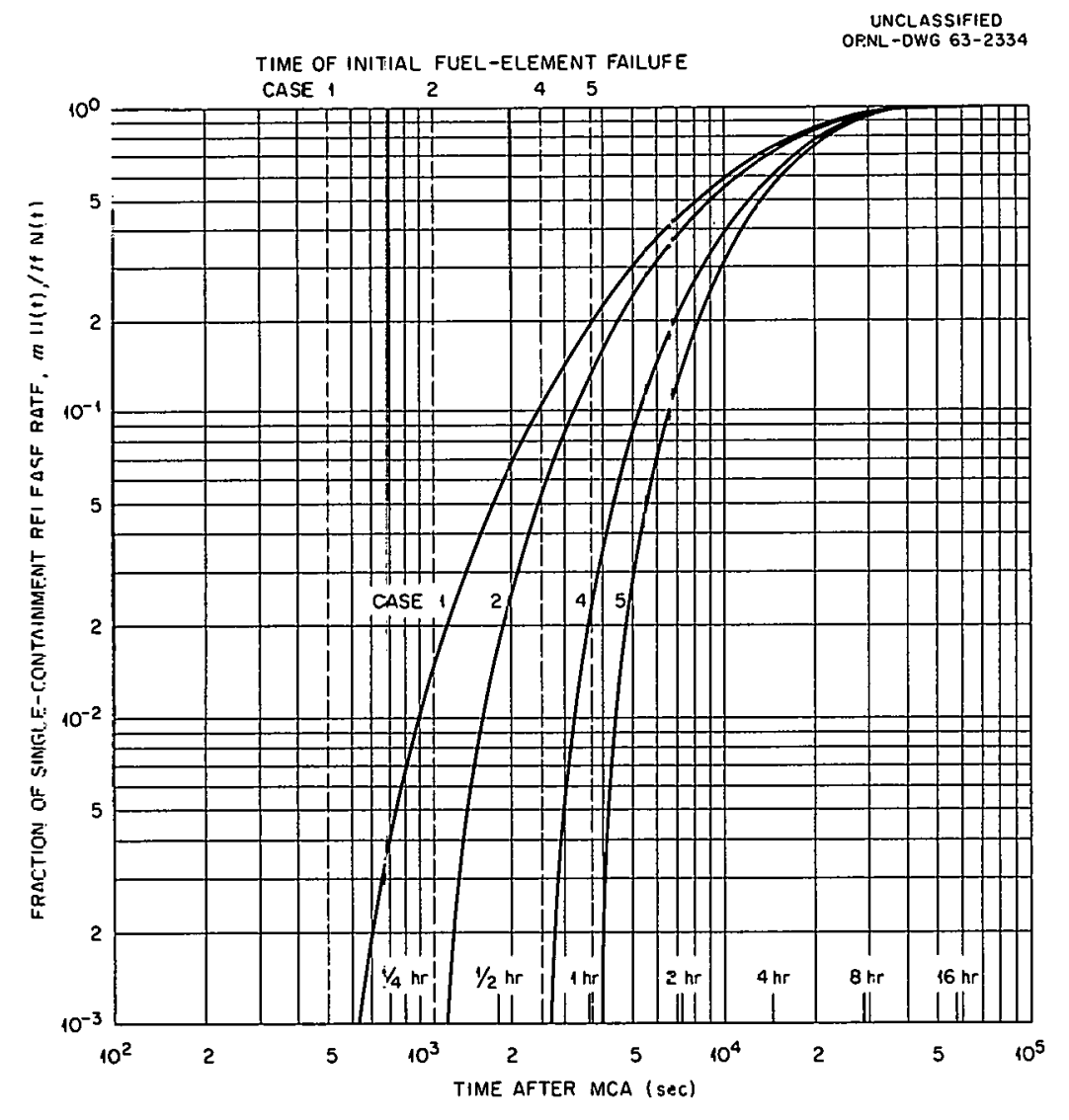

Fig. 12. Release Rate of Gaseous Fission Products from N.S. SAVANNAH Reactor Compartment, Emergency Ventilation.

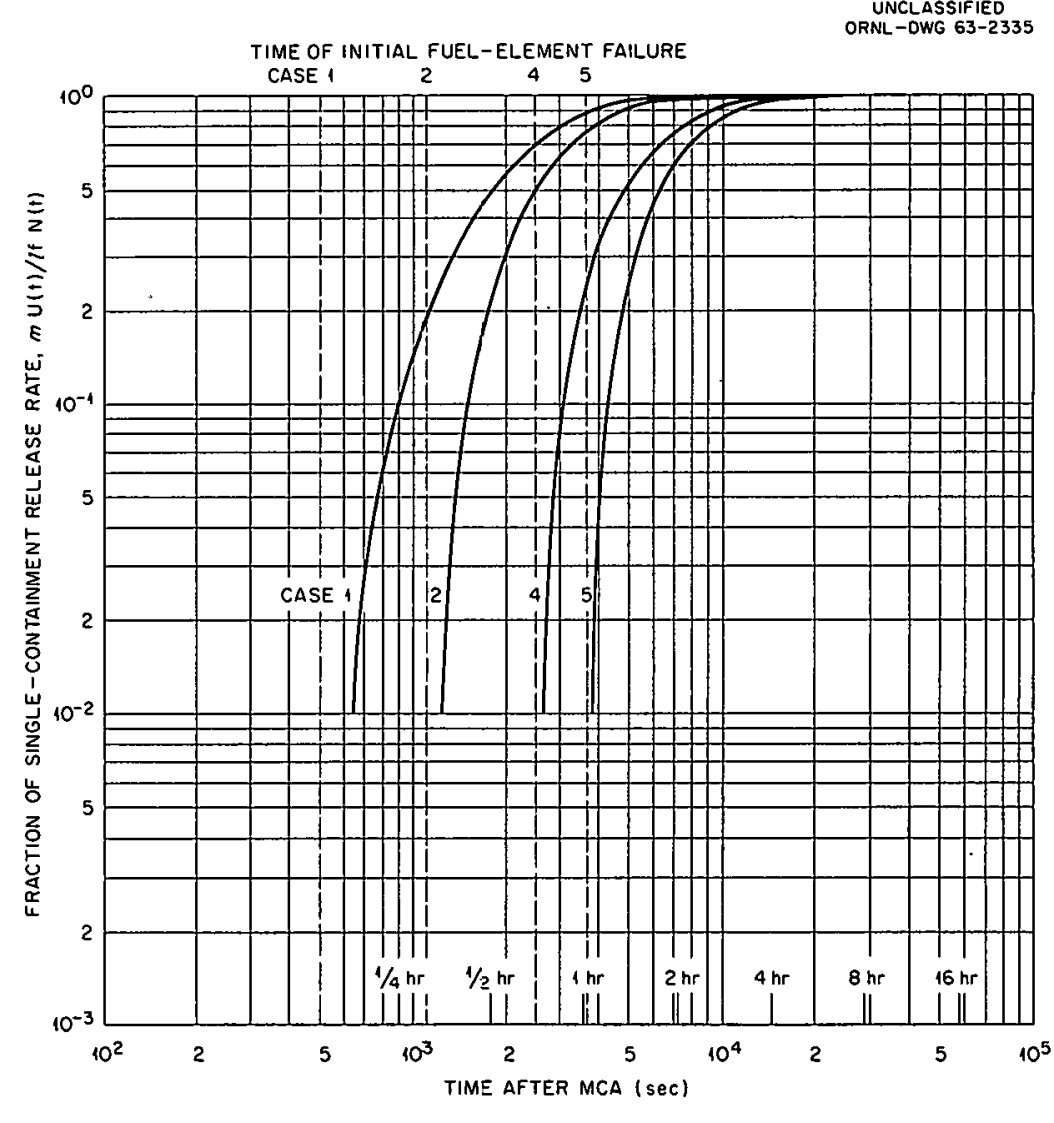

Fig. 13. Release Rate of Gaseous Fission Products from N.S. SAVANNAH Reactor Compartment, Normal Ventilation. 
ratio of the compartment volume to the ventilation rate. In this analysis the fission products were assumed to be released instantaneously from the fuel.

\section{Combined Effects of Decay and Holdup}

The decay of the noble gases and iodine isotopes was considered in Section 4. To obtain the release rate of radioactivity to the environment it was necessary to combine the decay information of Section 4 with the reactor compartment relative release rates given in Figs. 12 and 13. The combined effects of holdup and decay were best.illustrated by expressing the activity release rate as a fraction of the reference release rate:

$$
\text { Fraction of reference release rate }=\frac{l f \mathrm{~N}(t) \mathrm{L}(\theta)}{\text { lf } \mathrm{N}_{\mathrm{O}}} \text {. }
$$

The release rates of noble gas activity are shown in Figs. 14 and 15 . The release rates of the iodine isotopes are given by Figs. 16 through 23.

\section{EFFECT OF RELEASE MECHANISMS ON EXPOSURE}

The preceding sections cover various effects that would reduce the amount of radioactivity released during the accident. In this section the personnel exposures corresponding to the reduced activity releases are presented. The four reactor operating histories, cases 1, 2, 4, and 5, as defined in Section 2, were considered. The submersion exposure rate at $500 \mathrm{ft}$ from the reactor was computed for each of these power histories during the first $24 \mathrm{hr}$ following the accident, and a curve was prepared to permit interpolation to other distances. Several different sets of assumptions affecting the reactor compartment ventilation, fuel failure mechanism, and fission-product decay were made in each of these cases.

The calculations involved are tedious and time consuming, and therefore only the power history of case 2 was investigated further, since case 2 represents the situation to be expected during most port entries. 


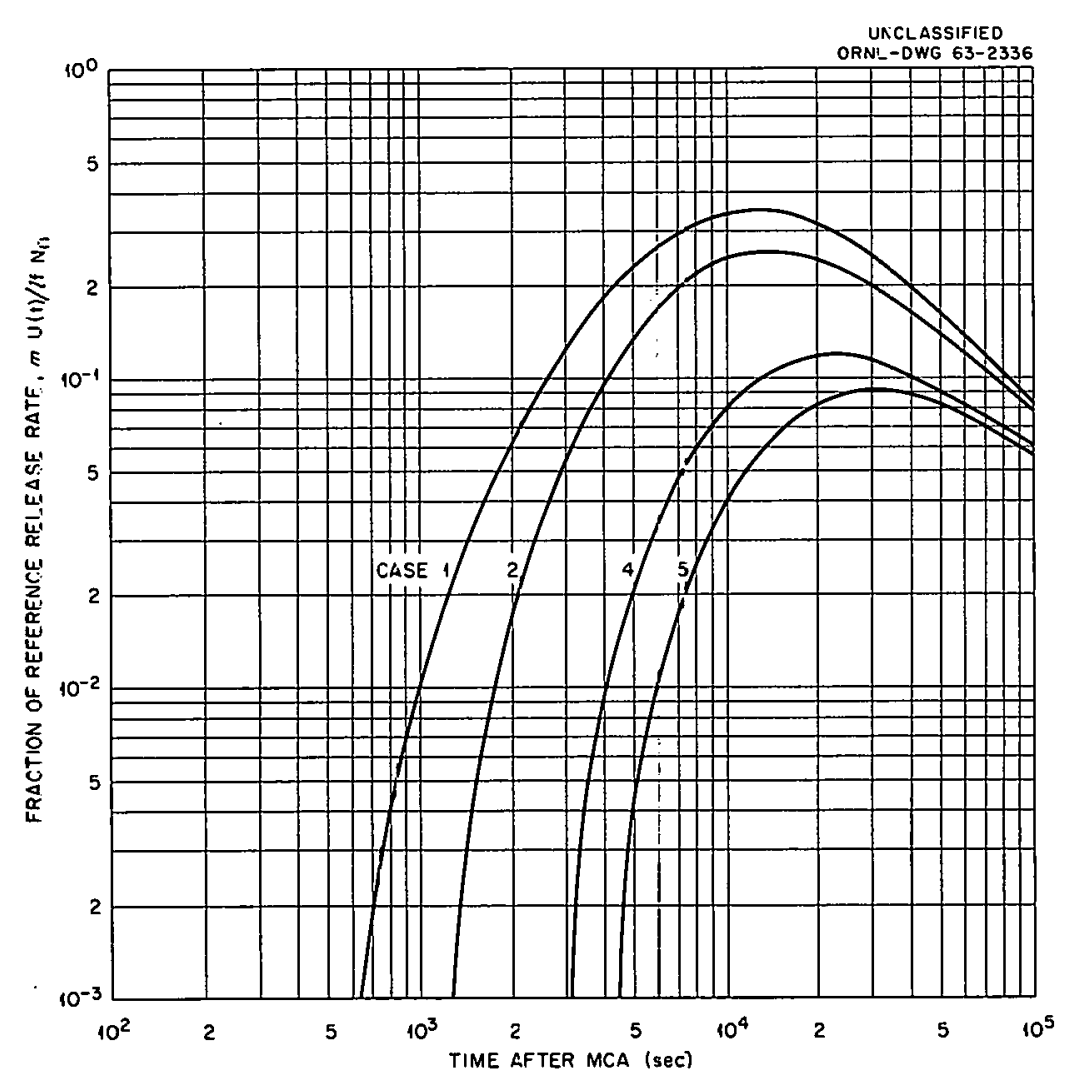

Fig. 14. Release Rate of Noble Gas Activity from N.S. SAVANNAH Reactor Compertment, Emergency Ventilation.

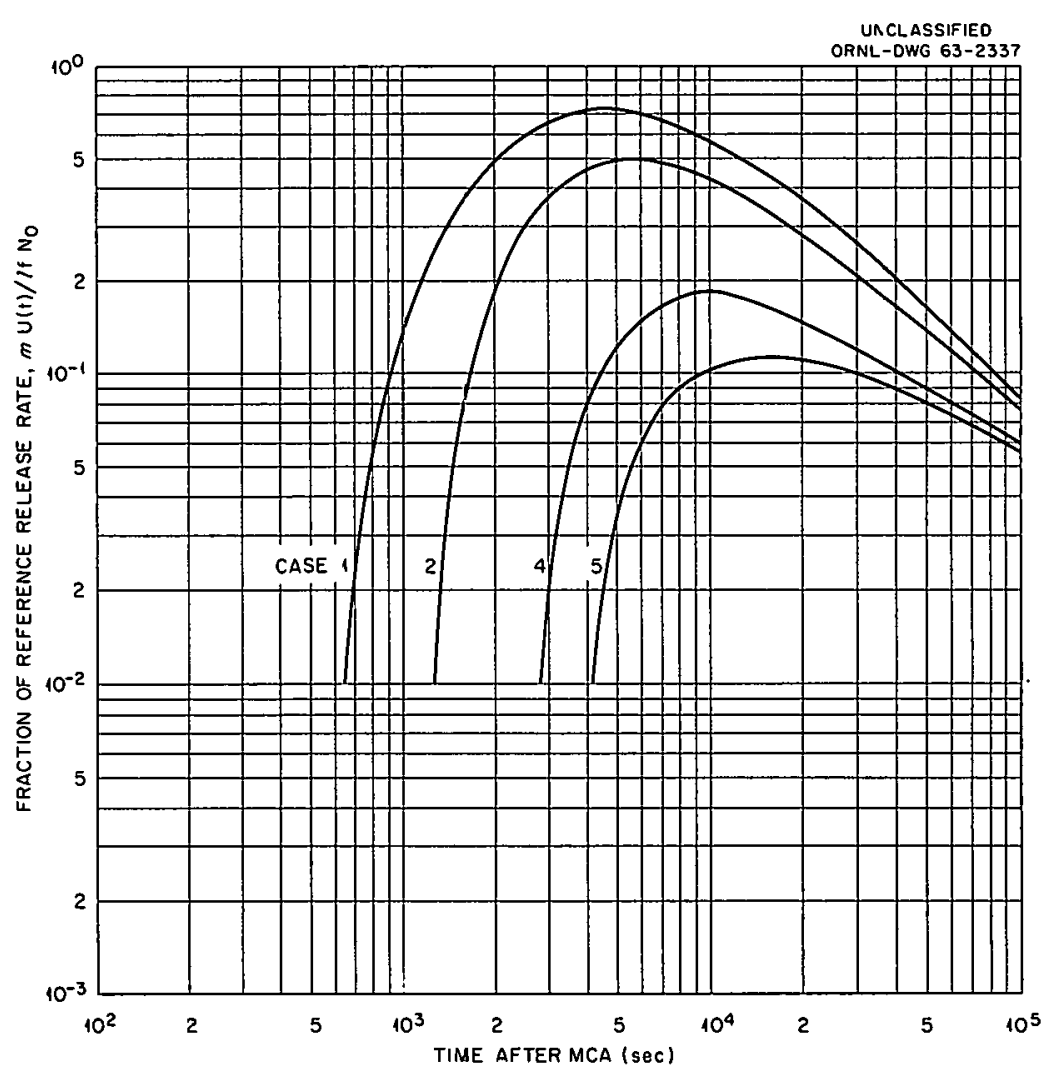

Fig. 15. Release Rate of Noble Gas Activity from N.S. SAVANNAH Reactor Compartment, Normal Ventilation. 


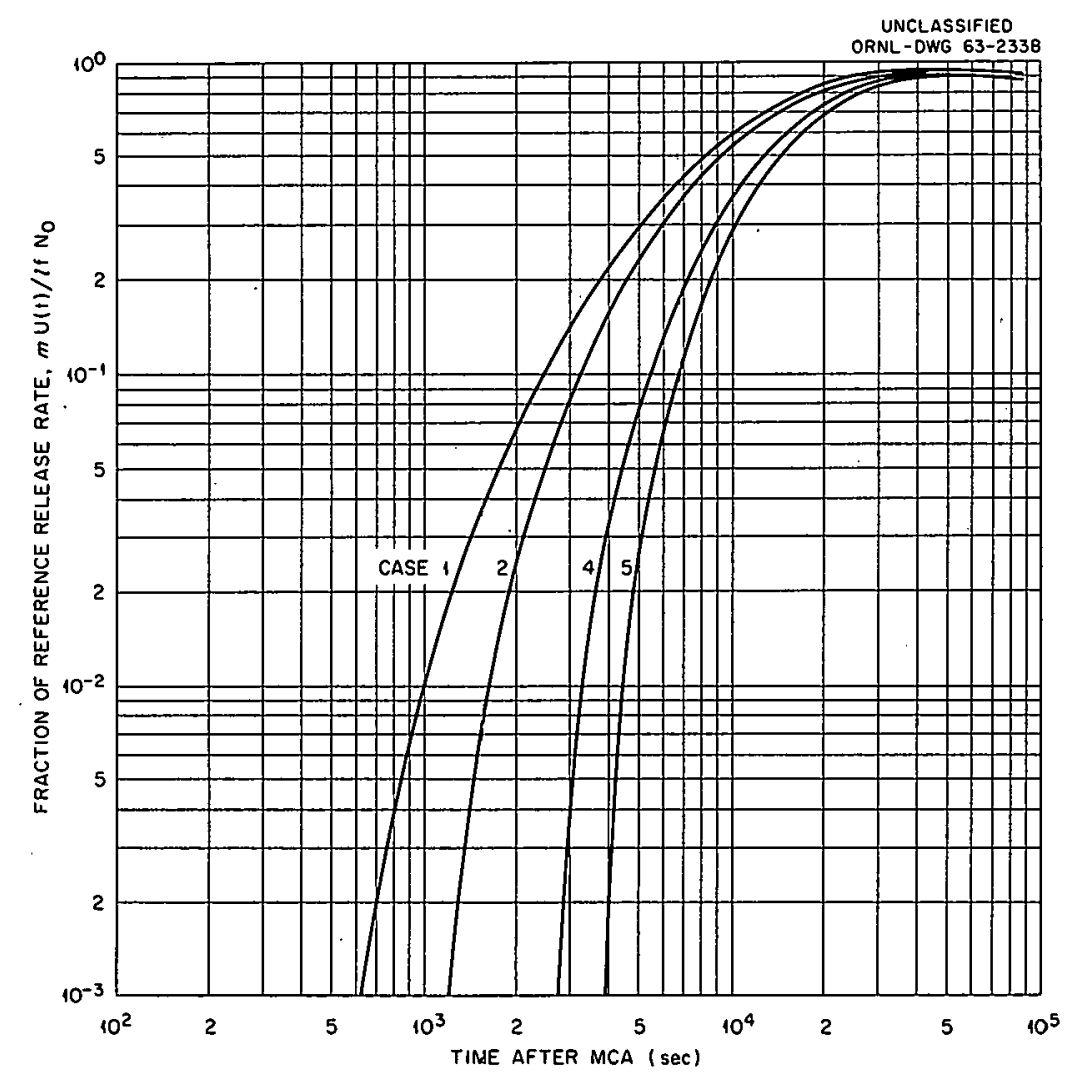

Fig. 16. Release Rate of $I^{131}$ from N.S. SAVANNAH Reactor Compartment, Emergency. Ventilation.

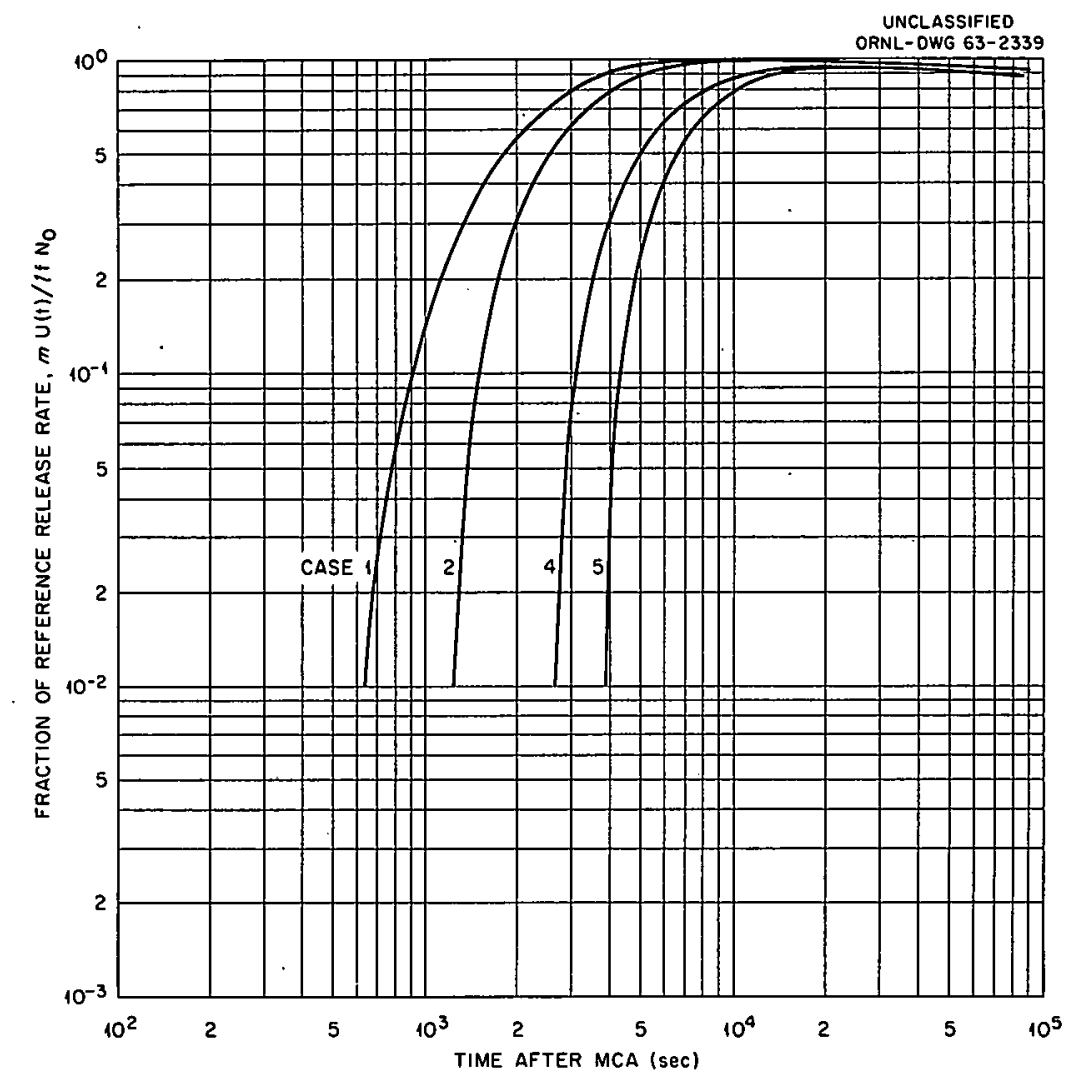

$\stackrel{N}{\infty}$

Fig. 17. Release Rate of $I^{131}$ from N.S. SAVAINIAH Reactor Compartment, Normal Ventilation. 


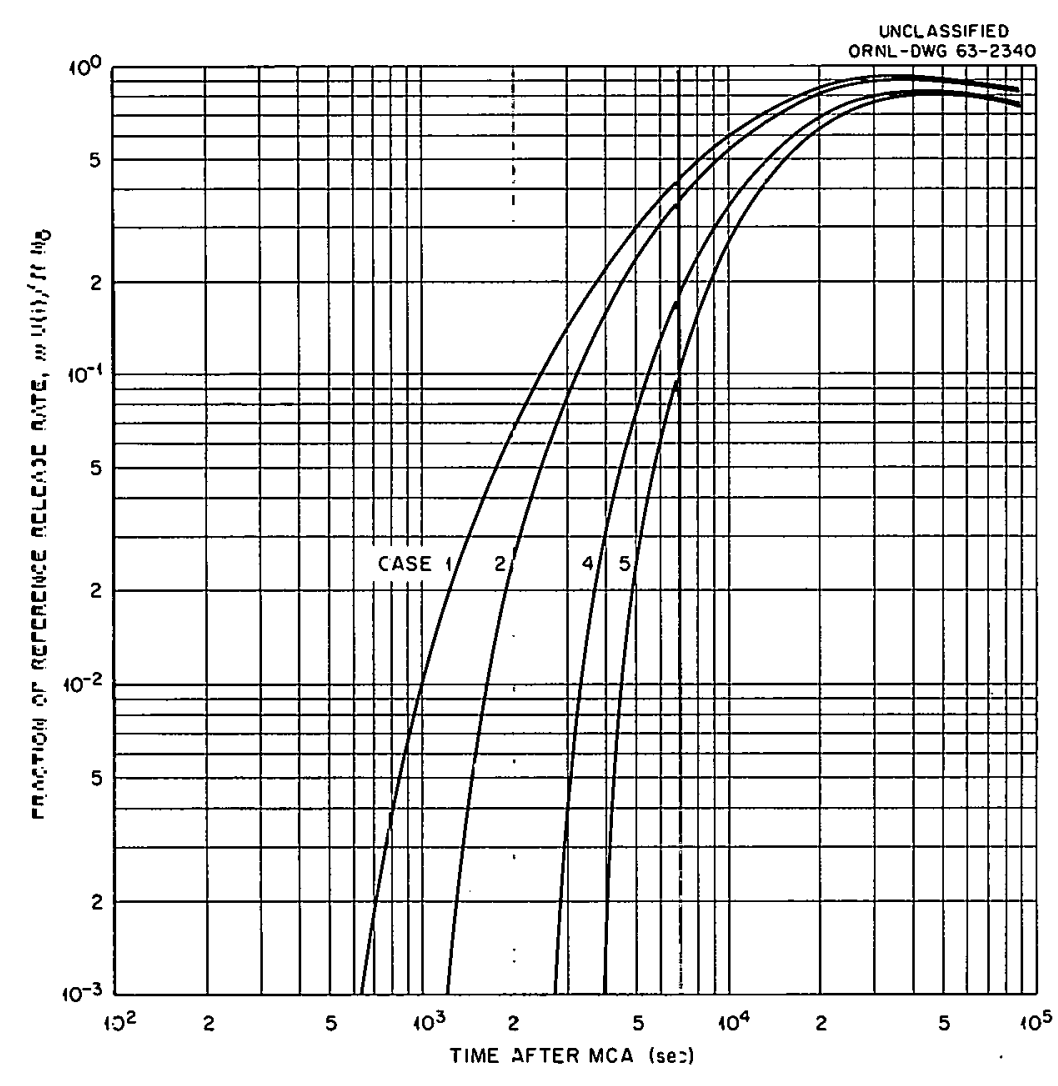

Fig. 18. Release Rate of $I^{132}$ from N.S. SAVANNIAH Reactor Compartment, Emergency Ventila广ion.

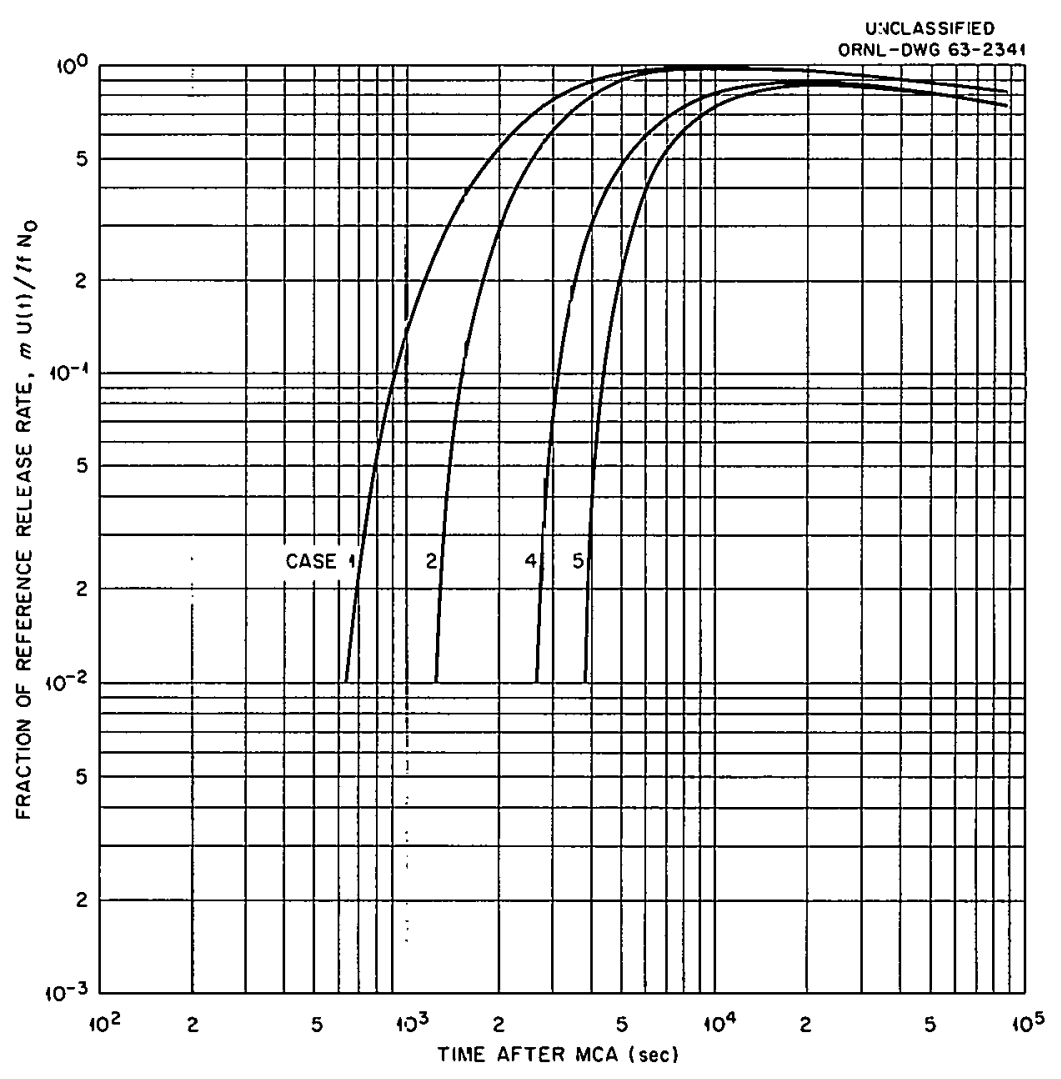

N 


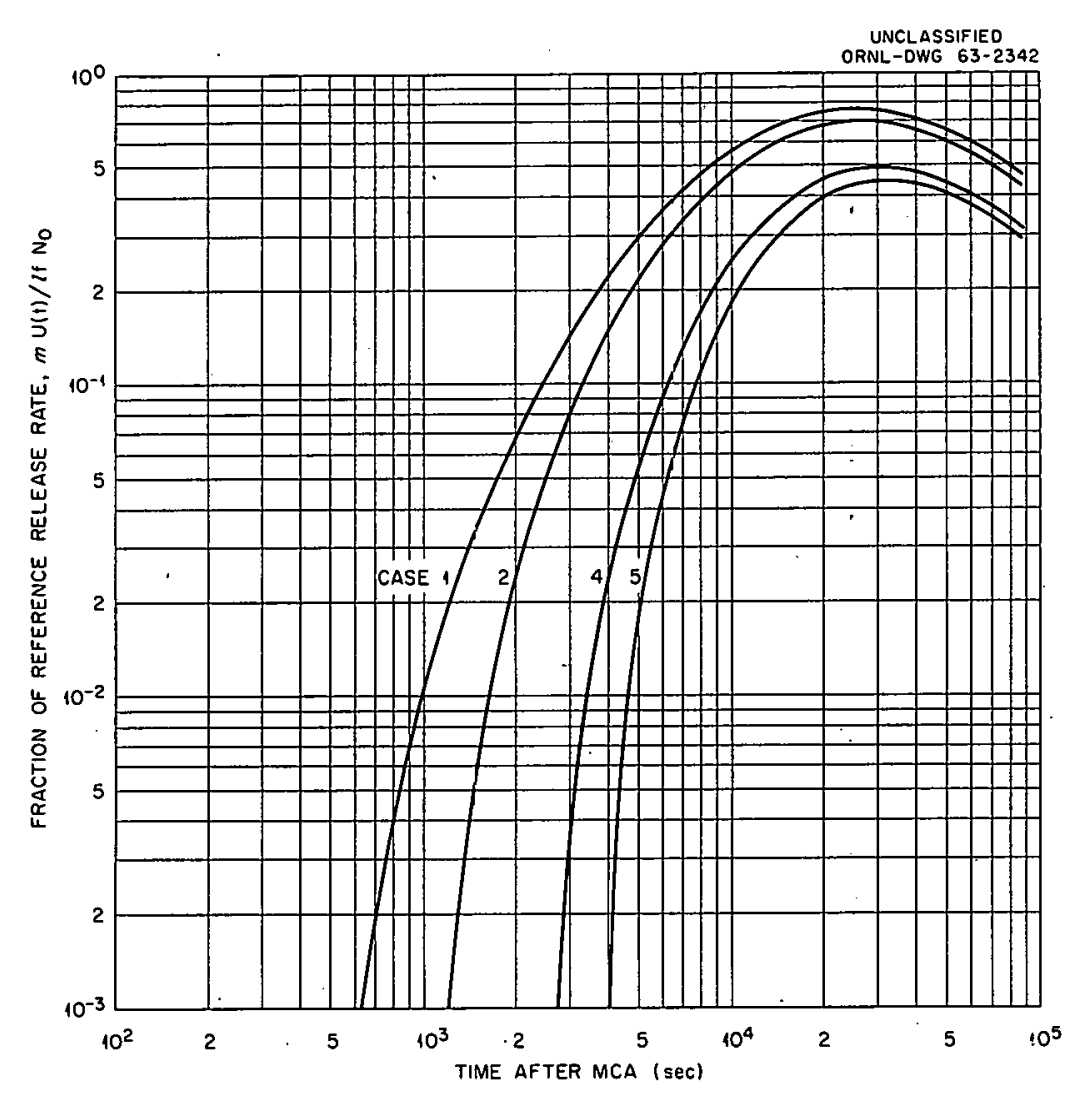

Fig. 20. Release Rate of $I^{133}$ from N.S. SAVANNAH Reactor Compartment, Emergency Ventilation.

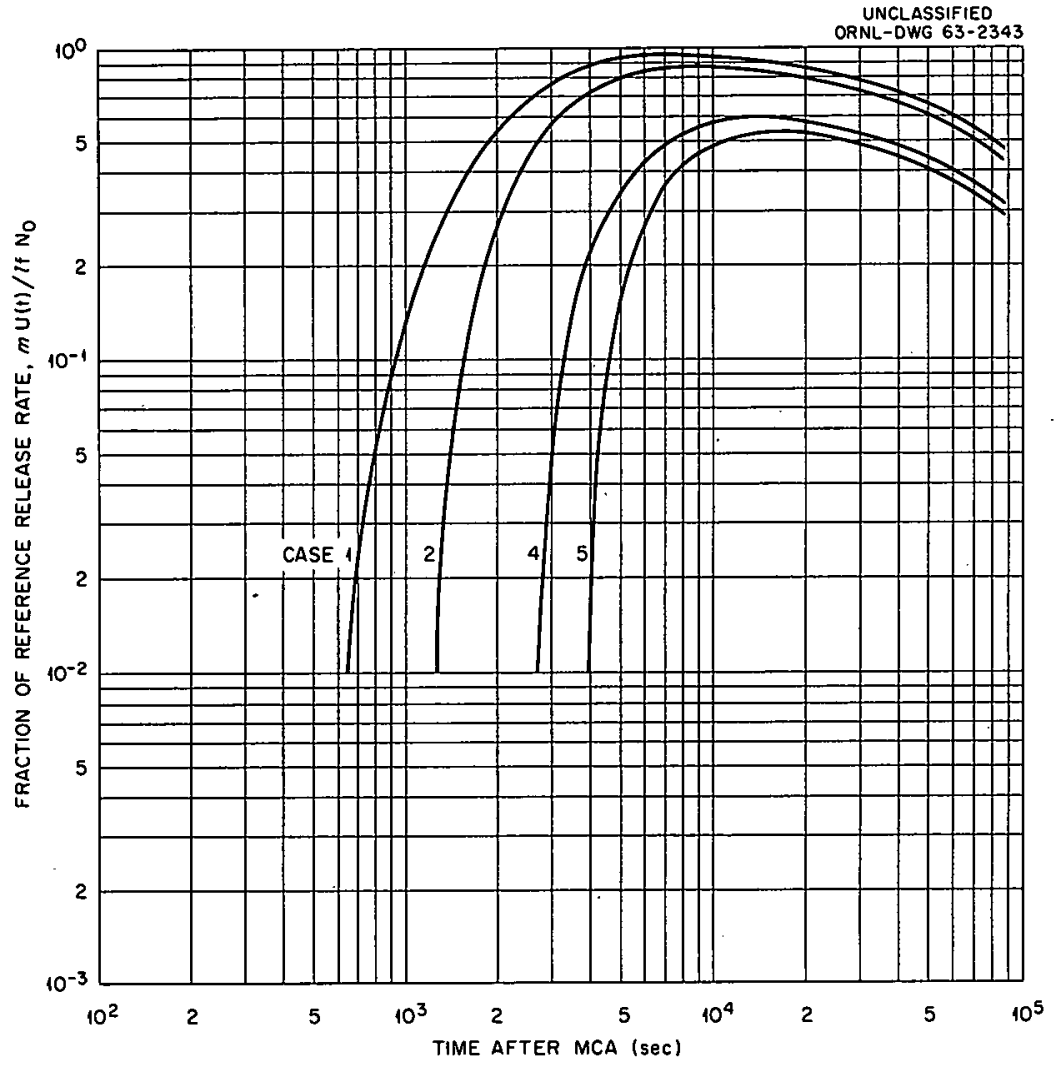

Fig. 21. Release Rate of $I^{133}$ from N.S. SAVANNAH Reactor Compartment, Normal Ventilation. 


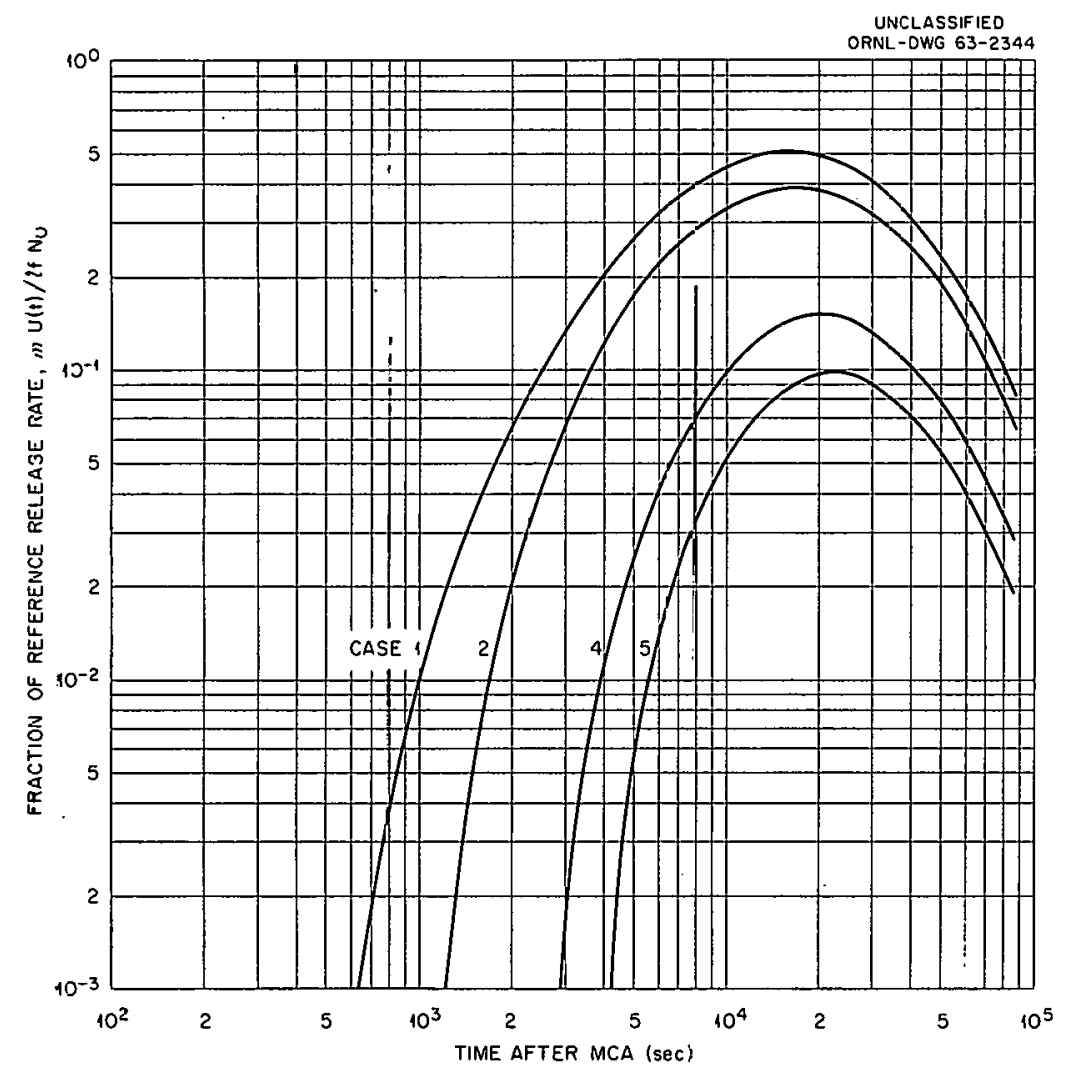

Fig. 22. Release Rate of $I^{135}$ from N.S.

SAVANIAH Reactor Compartment, Emergency Ventilaìn.

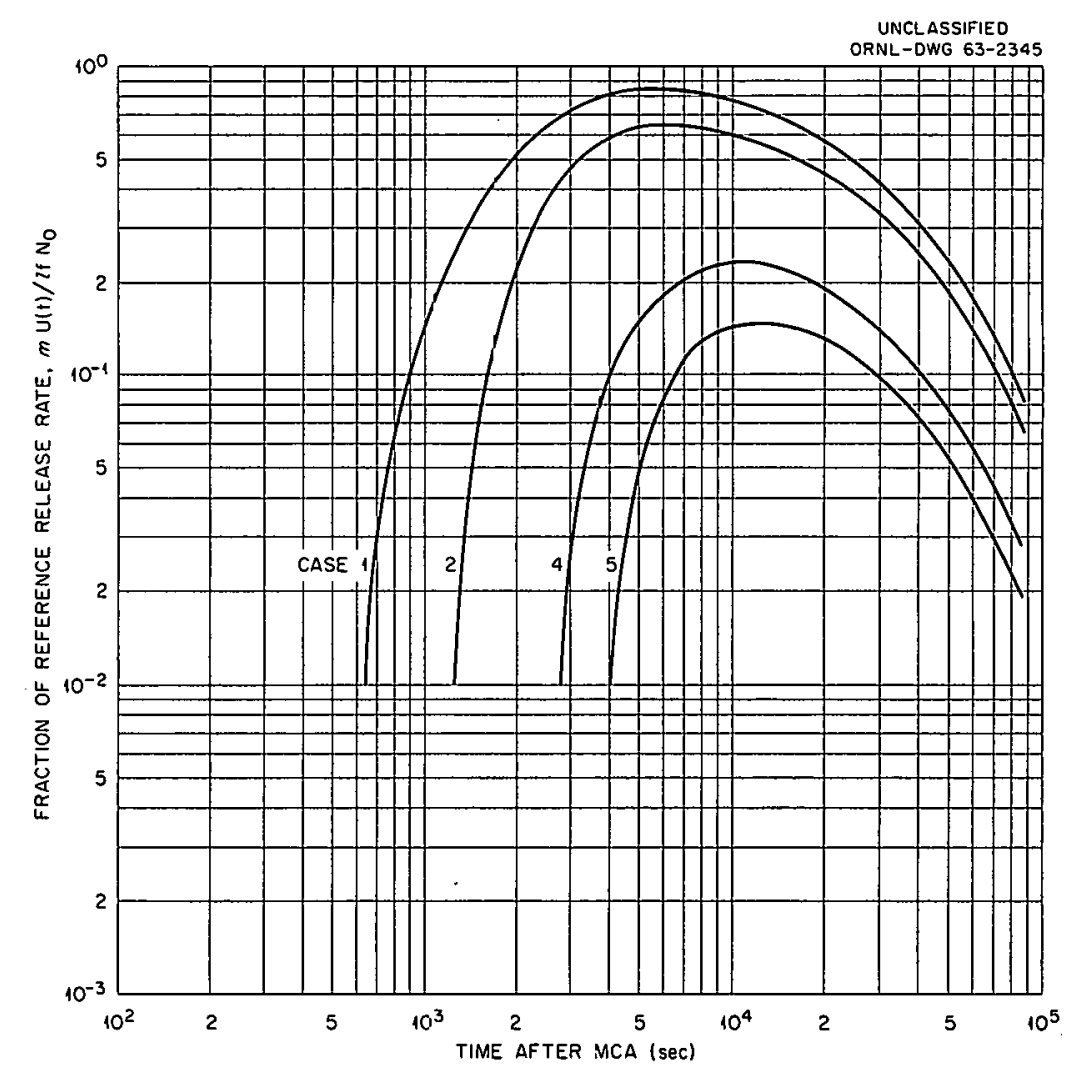

Fig. 23. Release Rate of $I^{135}$ from.N.S.

SAVANNAH Reactor Compartment, Normal Ventilation. 
The total integrated exposures at the site boundary and at the tug were calculated for this case, again under several different assumptions. It is believed that even though only a limited number of conditions was studied, sufficient information was developed to indicate that significant reductions in exposure result if the calculations are based on more realistic ground rules.

The reactor containment vessel of the N.S. SAVANNAH plant is enclosed by a secondary containment system that incorporates a filtered air exhaust system. The filtering efficiency for particulate fission products is expected to be at least 99.9\%. For this reason and because the release fraction of particulate fission products from the core is estimated as only $1 \%$, it is evident that exposure to volatile fission products would predominate. 4

\section{Assumptions Employed in Exposure Calculations}

Sections 3, 4, and 5 showed that more realistic assumptions concerning power history, fuel element failure, fission-product decay, and fission-gas holdup in the reactor compartment can reduce the estimates of activity release. Calculations to show what effect each of these individual considerations has on exposures for all values of some of the parameters involved would be voluminous. Therefore the following calculational modes and conditions were selected to illustrate some of the more interesting combinations of effects. Each of these modes may be considered for any power history.

Calculational Modes

Mode A. Continuous equilibrium activity release from the containment system was assumed commencing at the instant of the accident. Fission-product decay after the accident, the time required for the fuel elements to heat up and fail, and the holdup time provided by the reactor compartment were ignored. This mode, when considered in conjunction with the power history of case 1 , is the "reference case" that is typical of the conventional exposure calculations made for stationary reactors. 
Mode B. Mode B was identical to mode A, except that the decay of fission products between the instant of the accident and the time they entered the atmosphere was included. This provision for decay is somewhat conservative, since it ignores the decay during the time required for the activity to travel from the ship to the exposed personnel.

Mode C. In addition to fission-product decay as in mode $B$, the time required for fuel elements to fail and the holdup of the ventilation system were factored into the calculation for mode $C$. Of the various modes considered, mode $\mathrm{C}$ was thought to be closest to the conditions at a real accident. Where applicable, the exposure calculations were made for both the normal ventilation system and for the emergency ventilation system.

Fission-Product Release to Containment System

The following release fractions recommended for stationary reactors 9 were used to calculate the amounts of fission products released from the reactor to the containment shell during the accident:

$\begin{array}{lr}\text { Noble gases } & 100 \% \\ \text { Halogens } & 50 \% \\ \text { Solids } & 1 \%\end{array}$

An additional 50\% plate-out fraction for halogens in the containment shell was included, as proposed by the AEC. ${ }^{9}$

Filter Efficiency

Even though shipboard tests have shown somewhat higher filtering efficiencies for halogens, the following filter efficiencies were assumed in accordance with the conservative approach of these calculations :

$$
\begin{array}{ll}
\text { Normal ventilation system } & 90 \% \\
\text { Emergency vertilation system } & 99 \%
\end{array}
$$

No filtering was assumed for the noble gases.

Atmospheric Dilution Near the Ship

Because mobility after an accident is one of the important safety characteristics of a ship propulsion reactor, the exposure to the crew 
of a tug engaged in moving the ship was investigated. Analytical methods for calculating atmospheric dilution, such as Sutton's, 10 are not directly applicable to the short distance between the ship and tug. A dilution factor of 1000 was therefore assumed between the stack release point of the normal ventilation system and the tug. This value was based on a dilution factor of 100 between the stack release point and the ship's deck, as used in the Camden study, ${ }^{4}$ plus an additional dilution factor of 10 between the ship's deck and the tug. The corresponding dilution factor for the emergency ventilation system, which discharges from the top of the house, was taken as 100 .

Ventilation System Dilution and Source Elevation

The flow rates for the normal and emergency ventilation systems are 4000 and $2000 \mathrm{cfm}$, respectively. Of the 2000-cfm emergency ventilation flow, $200 \mathrm{cfm}$ is drawn from the reactor compartment and the remaining $1800 \mathrm{cfm}$ is diluent flow from the outside air. The concentration of fission products at the tug was calculated assuming uniform mixing of activity in the ventilation system air stream. The estimate of the concentration at the site boundary and beyond; on the other hand, assumed point source release at ground level. Ground-level release was assumed because some people might be inside buildings at about the same elevation as the actual elevated release point. Point source release was postulated because the flow rates of the ship's ventilation system are relatively small and have a negligible effect on the airborne fissionproduct concentration at the site boundary and points beyond. II

Calculational Method

Atmospheric Dispersion

The atmospheric dispersion of radioactivity from a ground-level release was calculated from Sutton's atmospheric dispersion equations. 10 Submersion Exposure

Previous calculations ${ }^{4}$ showed that the noble gases would be the main contributors to external exposure. The external exposure rate, D 
(in $\mathrm{rem} / \mathrm{hr}$ ), from submersion within a large cloud of radioactive material was estimated from the following expression, taken from ref. 4:

$$
D=9.4 \times 10^{-4} \mathrm{QE} \frac{X}{Q} \text {, }
$$

where

$$
\begin{aligned}
Q= & \text { (noble gas inventory at the time of the accident) } \times \text { (fraction } \\
& \text { released from the core) } \times \text { (fraction leaked per second from the } \\
& \text { containment vessel), } \\
E= & \text { effective gamma energy of noble gases at the time of the acci- } \\
& \text { dent } \\
= & 0.61 \mathrm{Mev}, \\
\frac{X}{Q}= & \text { dispersion, } \mathrm{sec} / \mathrm{m}^{3},
\end{aligned}
$$

and the value $9.4 \times 10^{-4}$ is the conversion factor needed to give the dose rate in rem per hour. Submersion exposures close to the source will be overestimated by this equation because of the effect of the . size of the finite cloud. All submersion exposures presented in this report are based on the assumption of an infinite cloud. The effect that consideration of the size of the finite cloud would have on the estimated exposures is discussed in Appendix $F$.

Mode A. For mode A activity release, $Q$ is the source strength of the activity released to the atmosphere in microcuries per second. The value of $Q$ is constant.

Mode B. For mode $B$, the dose is given by $D_{\text {mode } B}=n_{\text {mode } A} \times$ (fraction of reference energy release rate).

The fractions of reference energy release rate were taken from Fig. 5, and the exposure dose rates during the 24-hr period following the accident were computed.

Mode C.: Similarly, for mode c, the dnse is given by

$$
\left.\mathrm{D}_{\text {mode } \mathrm{C}}=\mathrm{n}_{\text {mode } \mathrm{A}} \times \text { (fraction of reference release rate }\right) \text {. }
$$

The fractions of reference release rate were taken from Figs. 14 and 15. Again, the exposure dose rates during the $24-\mathrm{hr}$ period following the accident were computed. 
Thyroid Exposure

Previous calculations ${ }^{4}$ showed that the iodine isotopes would be the main contributors to thyroid exposure. The integrated thyroid dose $\left(T I D_{\text {thy }}\right.$ ) from iodine inhalation is given by

$$
\operatorname{TID}_{\text {thy }}=\mathrm{DBR} \frac{X}{Q} \int_{0}^{t} Q d t
$$

which was adapted from the work of Cottrell et al. ${ }^{4}$ In this expression

$$
\begin{aligned}
Q= & \text { (iodine inventory at time of accident) } \times \text { (fraction released } \\
& \text { from core) } \times \text { (fraction not plated out) } \times \text { (fraction leaked per } \\
& \text { second from the containment vessel) } \times \text { (fraction passed by the } \\
& \text { iodine filter), } \\
t= & \text { time elapsed after accident, sec, } \\
D= & \text { the exposure from } 1 \mu \text { of activity (values for the isotopes of } \\
& \text { interest are listed in Appendix } \mathrm{E}),
\end{aligned}
$$

$\mathrm{BR}=$ breathing rate, taken as $500 \mathrm{~cm}^{3} / \mathrm{sec}$,

$\frac{X}{Q}=$ aispersion, $\mathrm{sec} / \mathrm{m}^{3}$.

For Mode A, Q, the strength of the source released to the atmosphere (in curies/sec), is constant, so

$$
\int_{0}^{t} Q d t=Q t
$$

Thyroid exposures were not calculated for Mode B. The effect of fission-product decay is expected to be minor during the first few hours after the accident because of the relatively long half-lives of $I^{131}$ and $I^{133}$, the main contributors.

For Mode C,

$\mathrm{TID}_{\text {thy, mode } \mathrm{c}}=\mathrm{TID}_{\text {thy, mode } \mathrm{A}} \frac{\mathrm{I}}{\mathrm{t}} \int_{0}^{t}\left(\begin{array}{r}\text { fraction of reference } \\ \text { release rate }\end{array}\right) \mathrm{dt}$. The integral was evaluated numerically from Figs. 16 through 23 for the four iodine isotopes of interest. 


\section{Results of Exposure Calculations}

Results of the submersion exposure calculations are shown in Figs. 24 through 30 for both the normal and the emergency ventilation systems. Submersion exposure dose rates at $500 \mathrm{ft}$ are shown in Figs. 24 through 27 for cases 1, 2, 4, and 5 during the 24-hr period after the accident. The individual total integrated dose in $24 \mathrm{hr}$ after the accident is shown in Fig. 28 for case 2 at $500 \mathrm{ft}$. Figures 29 and 30 show the individual total integrated dose in $24 \mathrm{hr}$ after the accident for case 2 at the tug.

Results of the thyroid exposure calculations are shown in Figs. 31 through 34 for both the normal and the emergency ventilation systems. The individual total integrated dose to the thyroid at $500 \mathrm{ft}$ in $24 \mathrm{hr}$ after the accident is shown in Figs. 31 and 32, while Figs. 33 and 34 contain this information for the tug. If values of the downwind doses are desired at distances other than $500 \mathrm{ft}$, the 500-ft exposure should . be multiplied by the distance factor, as shown in Fig. 35.

Inasmuch as the distance at which an individual would receive 25 rem in $2 \mathrm{hr}$ following the accident is one of the cornerstones of the criteria for both nuclear ships and stationary reactors, it was instructive to determine this distance for several of the cases and modes of interest to ship operation. The results are presented in Table 5.

For mode $\mathrm{C}$ there was a difference in the exposure depending upon which ventilation system was in use. No such difference showed up in the calculations for modes $A$ and $B$, as both of these modes assumed groundlevel source release with no holdup and effectively excluded the differences between the two systems.

Table 5. Exclusion Radii Based on a Whole-Body Submersion Dose of $25 \mathrm{rem}$ in $2 \mathrm{hr}$ at Site Boundary

Assumptions

\begin{tabular}{ll}
\hline Case 1, mode A, the "reference case" & 475 \\
Case 2, mode A & 410 \\
Case 2, mode B & 360 \\
Case 2, mode C & \\
Normal ventilation & 245 \\
Emergengy verililabidas & 105 \\
\hline
\end{tabular}

Txclusion Radius

(ft)

475

410

245 


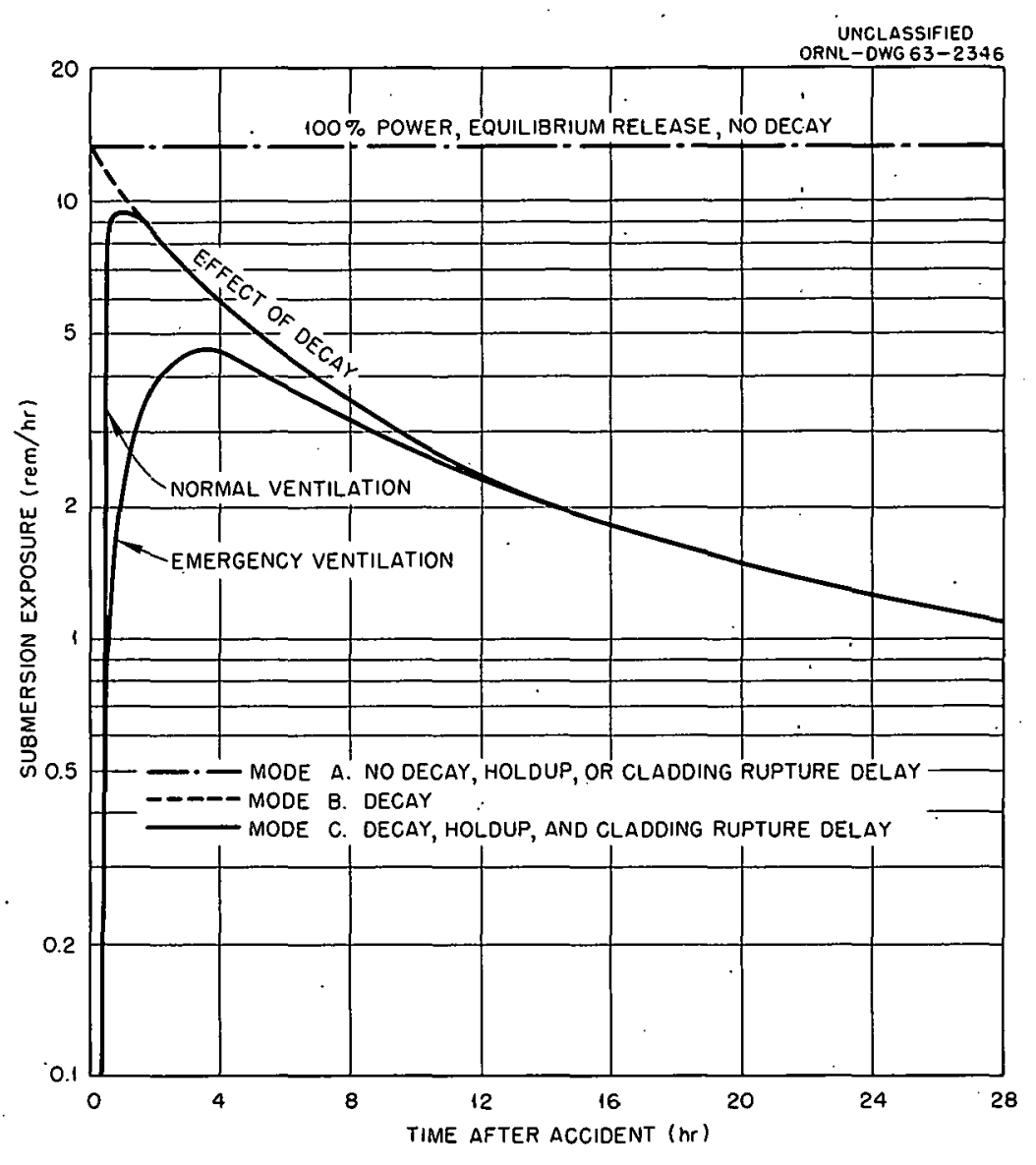

Fig. 24. Submersion Exposure Rate at $500 \mathrm{ft}$, Case 1 .

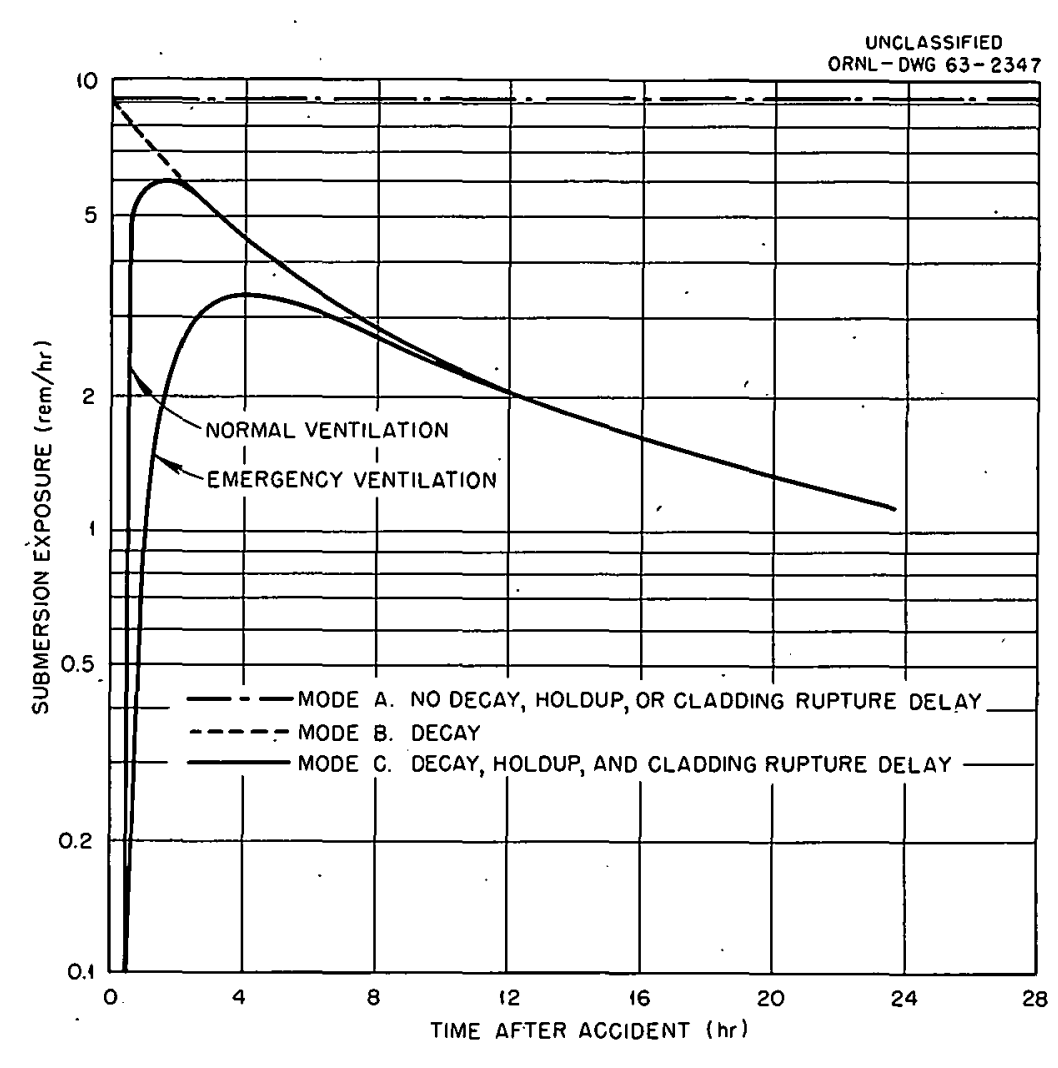

Fig. 25. Submersion Exposure Rate at $500 \mathrm{ft}$, Case 2. 


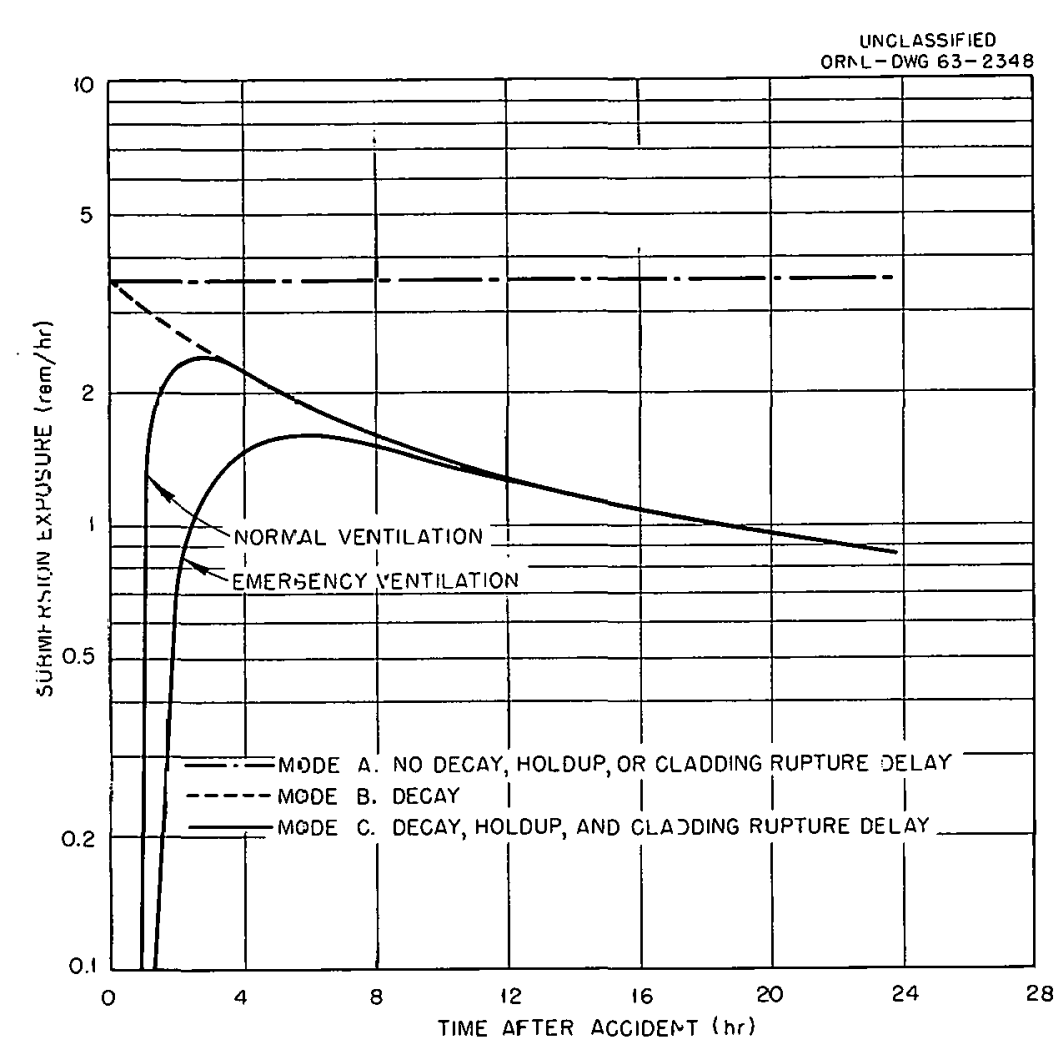

Fig. 26. Sukmersion Exposure Rate at $500 \mathrm{fi}$, Case 4 .

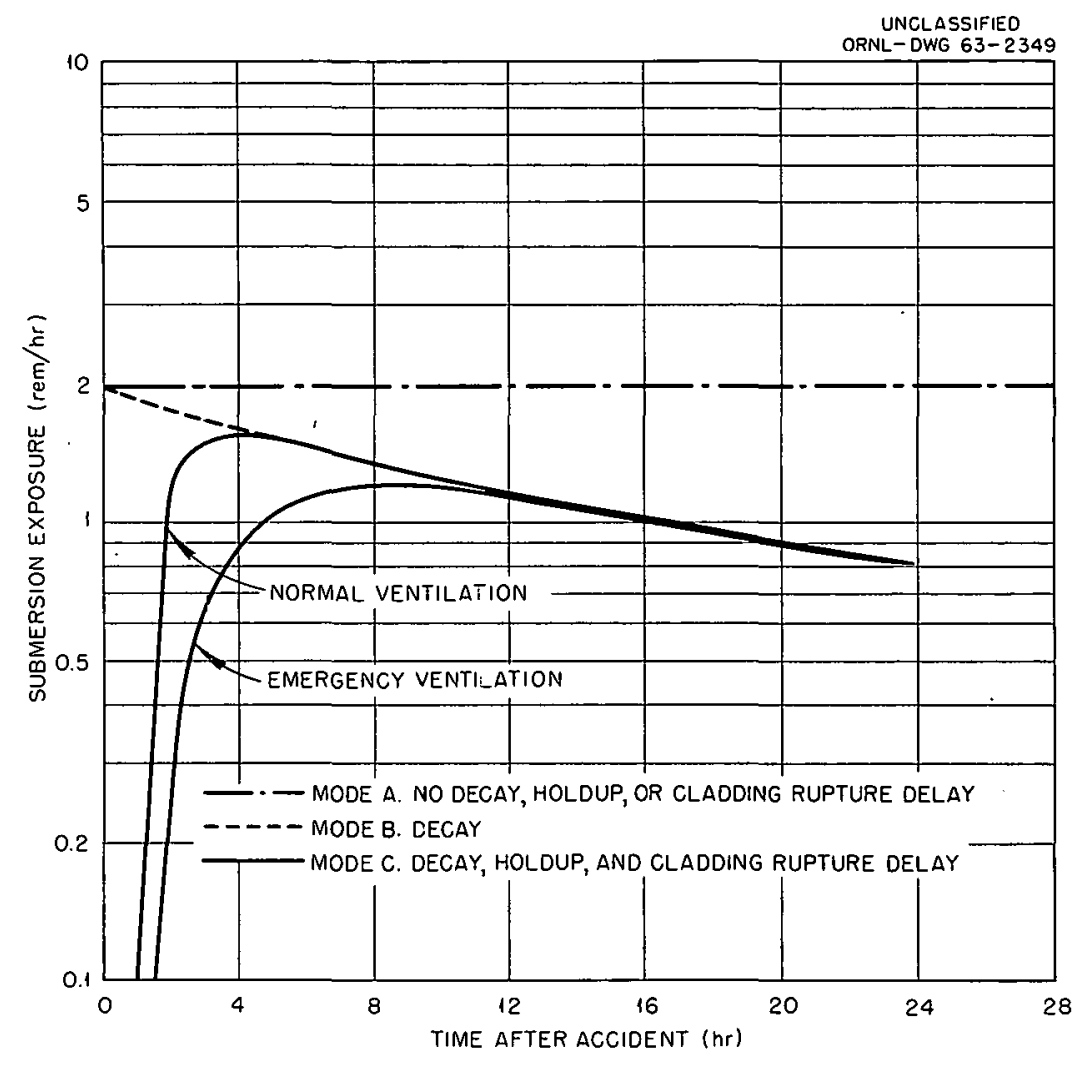

Fig. 27. Submersion Exposure Rate at $500 \mathrm{ft}$, Case 5. 


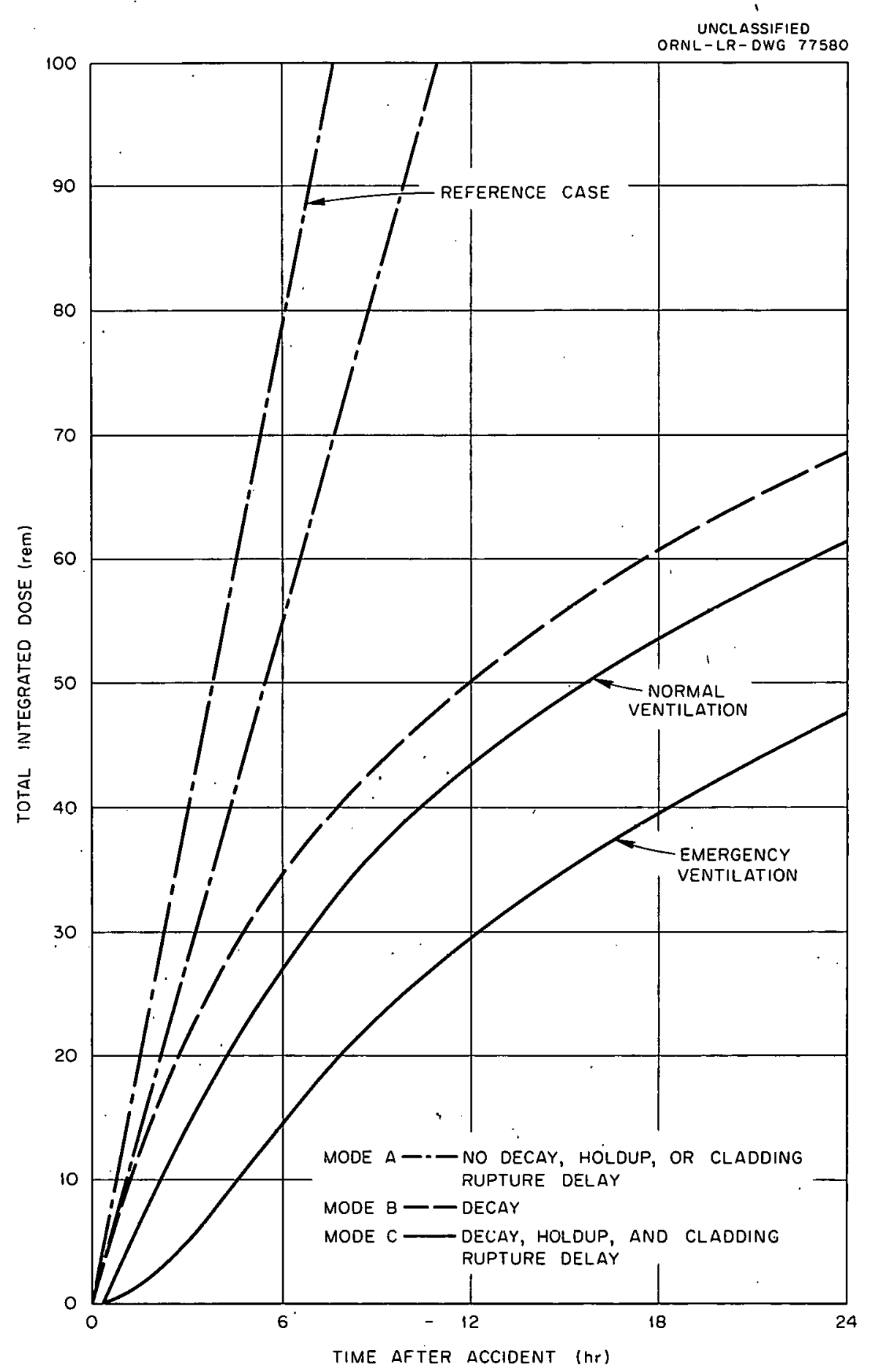

Fig. 28. Total Integrated Submersion Exposure Dose at $500 \mathrm{ft}$, Case 2. 


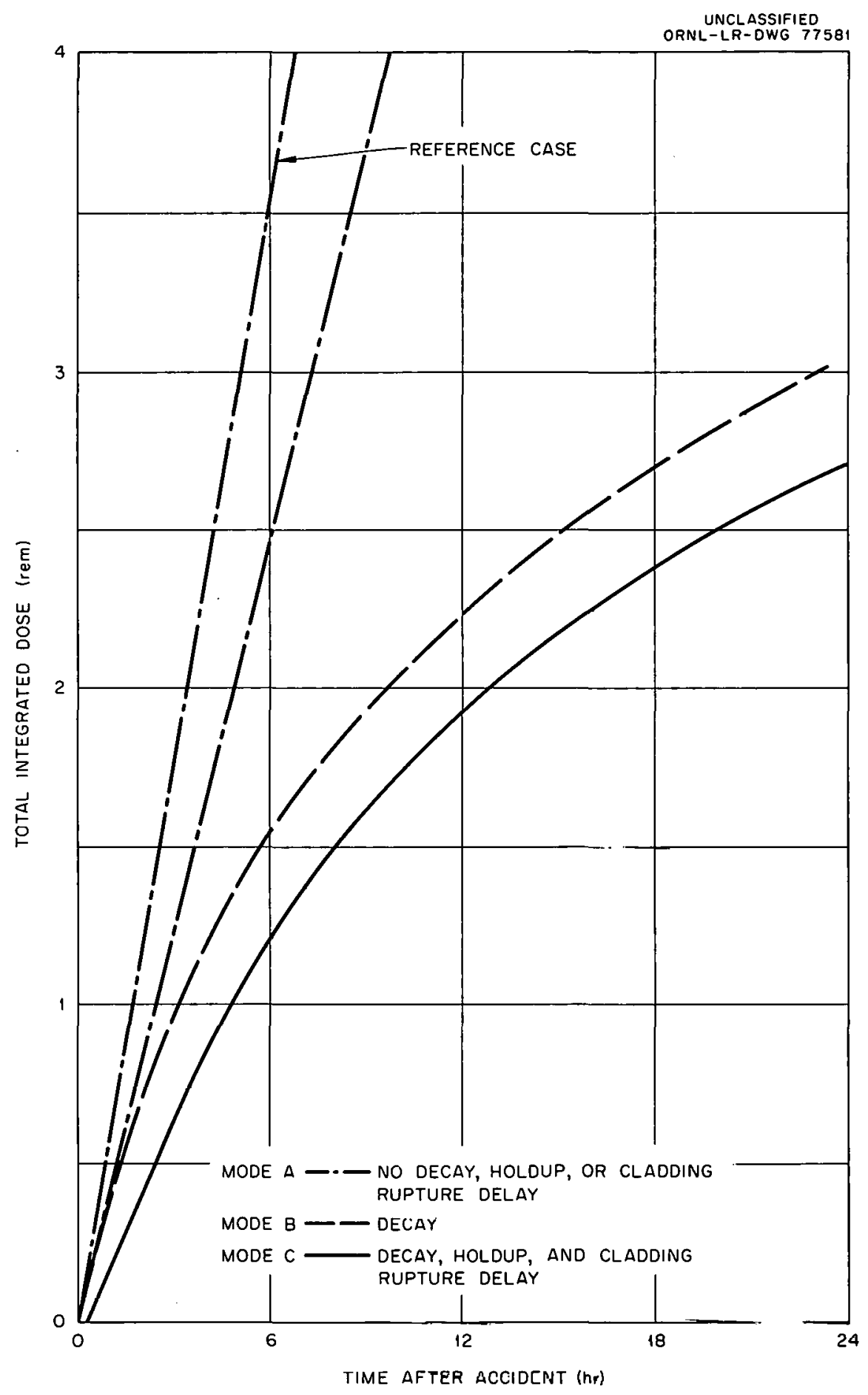

Fig. 29. Total Integrated Submersion Exposure Dose at Tug, Case 2, Normal Ventilation. 


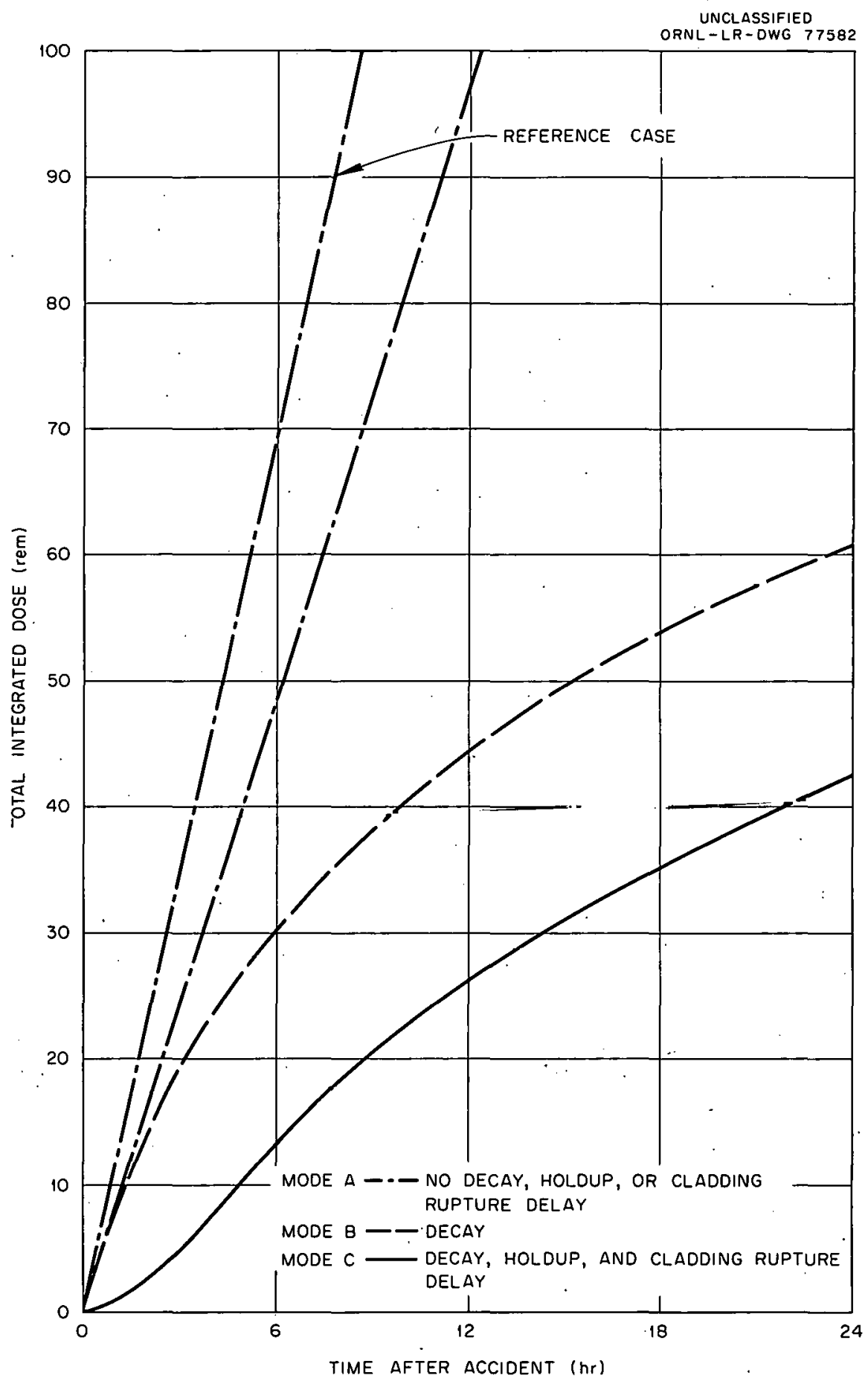

Fig. 30. Total Submersion Exposure Dose at Tug, Case 2, Emergency Ventilation. 


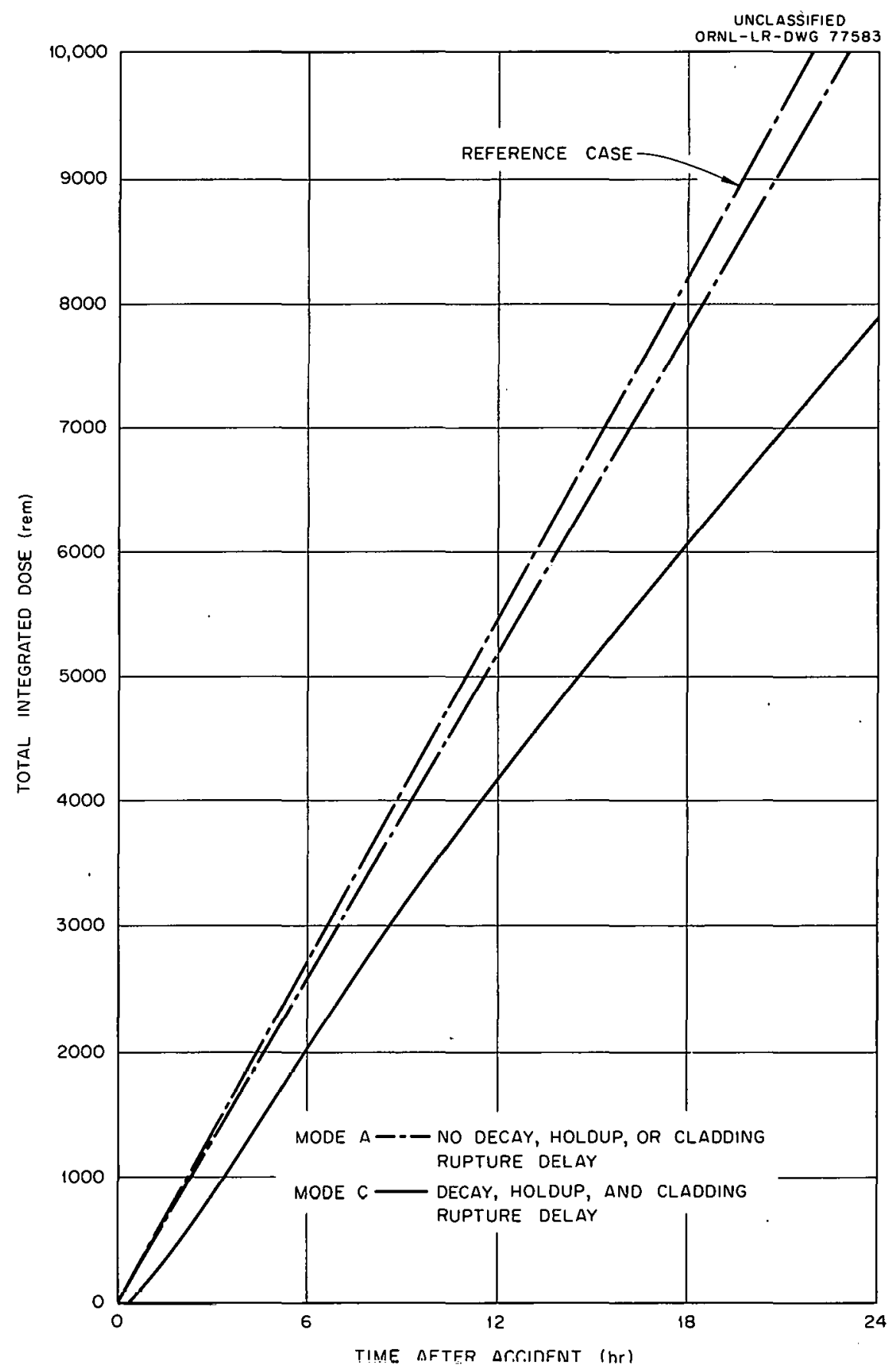

Fig. 31. Total Integrated Thyroid Exposure Dose at $500 \mathrm{ft}$, Case 2, Normal Ventilation. 


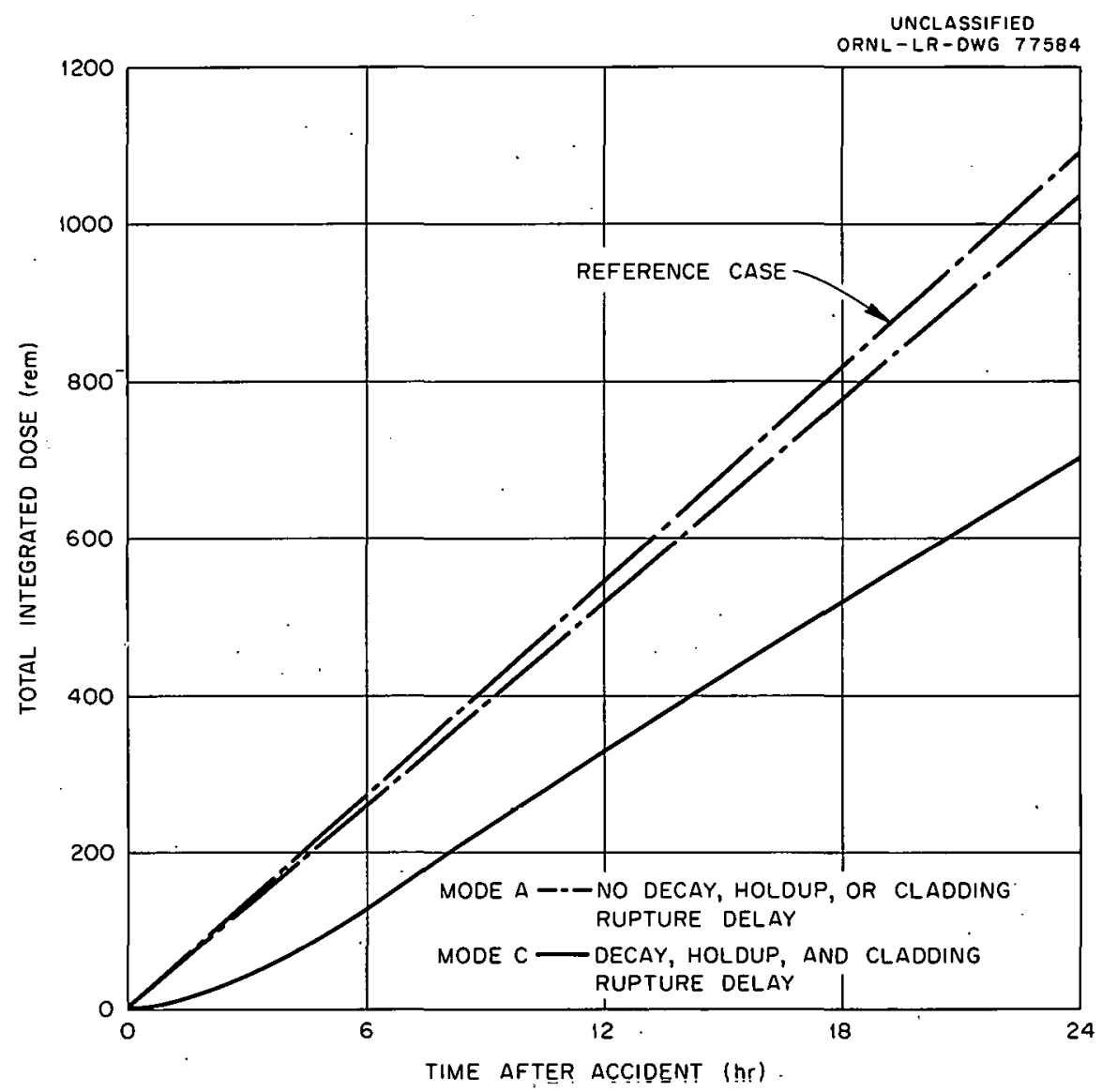

Fig. 32. Total Integrated Thyroid Exposure Dose at $500 \mathrm{ft}$, Case 2, Emergency Ventilation.

\section{DISCUSSION}

\section{Implications of Exposure Calculatione}

Various mechanisms have been evaluated, as mentioned above, and shown to have a significant effect on the activity release. Since the alternate release mechanisms investigated had somewhat interdependent effects on exposure, these effects were grouped in the three modes discussed in Section 6. These modes were then compared with a reference case and with each other to show trends. Since integrated exposures are mainly of interest for time-dependent activity releases, exposure rates were calculated only for whole-body submersion at one location ( $500 \mathrm{ft}$ ), as shown in Figs. 24 and 27. The effect of decay was of importance for all power 


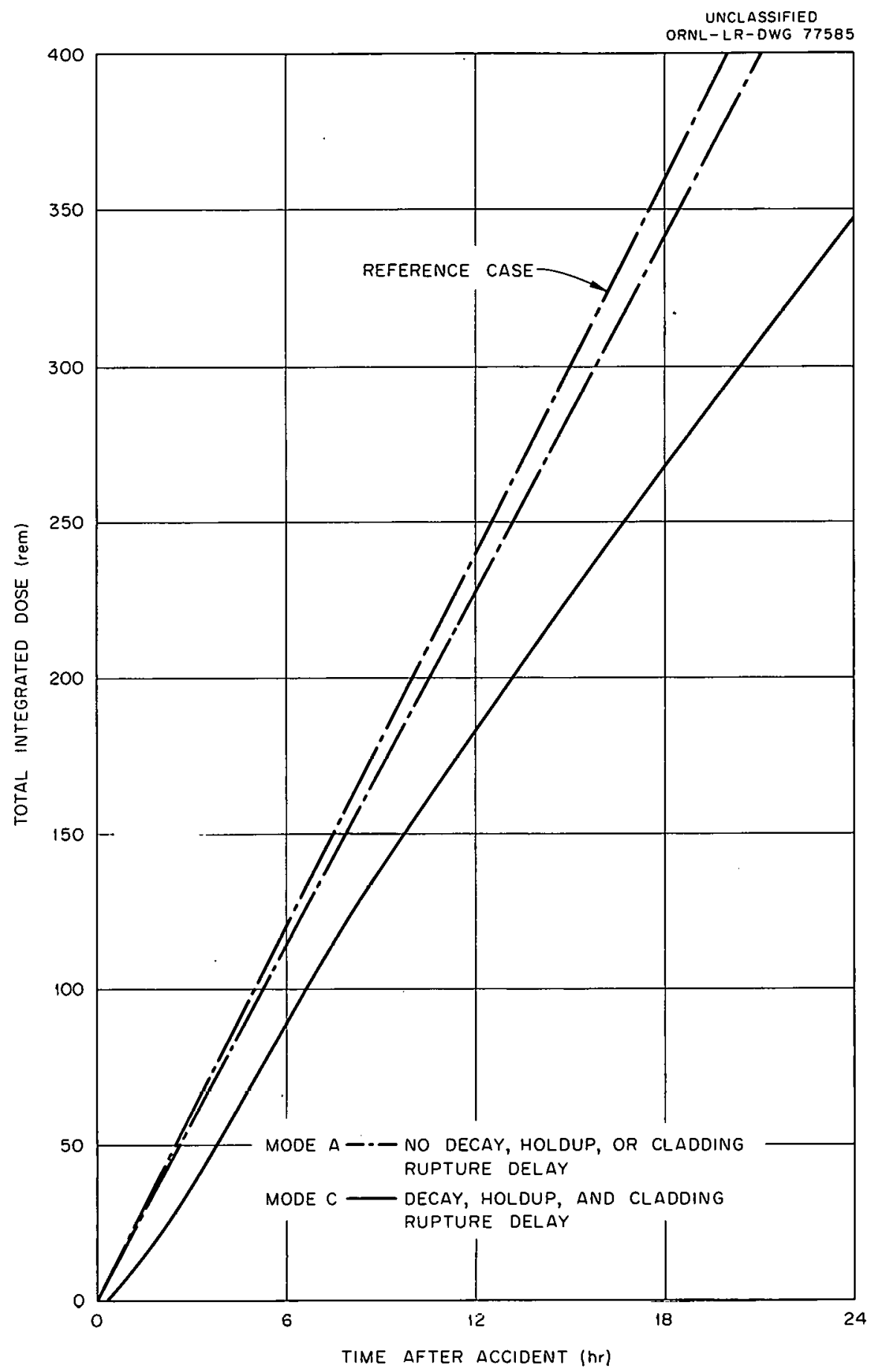

Fig. 33. Total Integrated Thyroid Exposure Dose at Tug, Case 2, Normal Ventilation. 


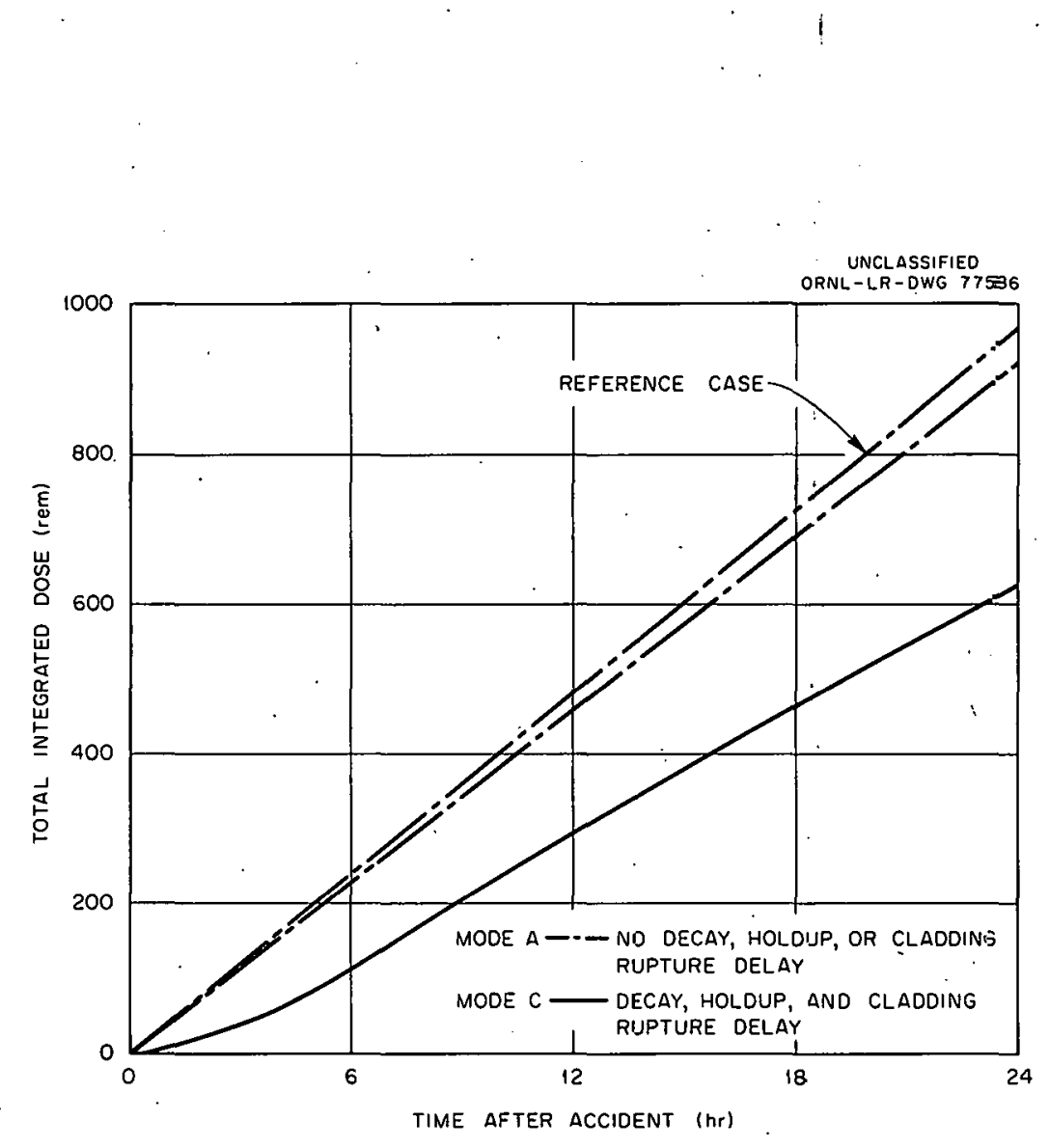

Fig. 34. Total Integrated Thyroid Exposure Dose at Tug, Case 2, Emergency Ventilation.

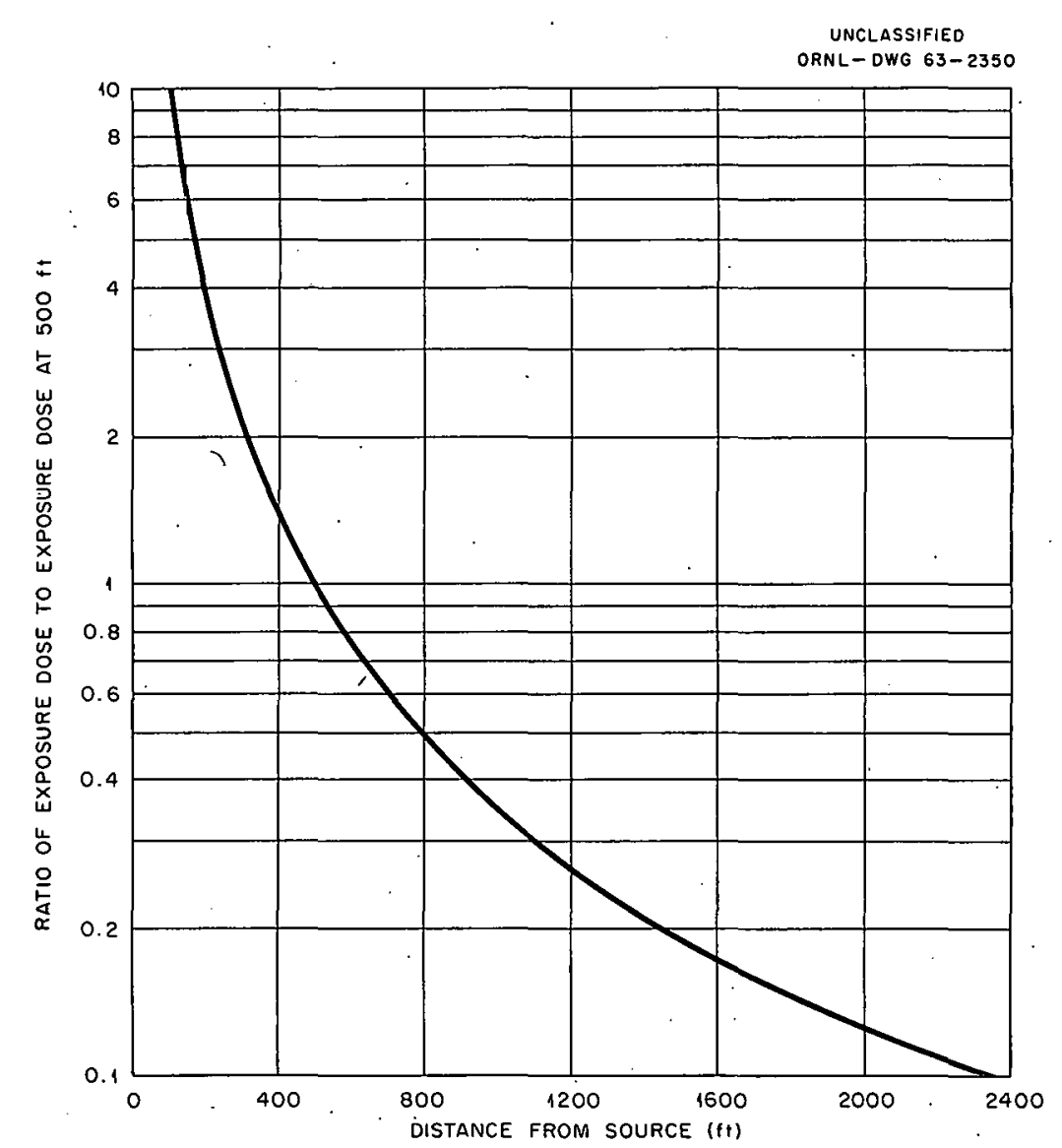

Fig. 35. Relative Exposure Along Plume Centerline During Ground Release. 
histories considercd but. was greatest where no reduction in reactor power prior to the accident was assumed; for this case the exposure rate was reduced by a factor of about 1.0 within one day after the accident. It was further noted that consideration of both the delay in cladding failure and the ventilation system holdup, as illustrated by the difference between modes $B$ and $C$, affected exposure rates the most for the shorter time periods after the accident. For example, in case 2 this effect vanished altogether within $2 \mathrm{hr}$ with the normal ventilation system operating and $12 \mathrm{hr}$ with the emergency ventilation system operating.

The reduction in dose rate afforded by the emergency ventilation system was greater and prevailed for longer periods than the corresponding effect of the normal ventilation system in all cases. This was to be expected because the scavenging flow rate of the emergency system is low and a longer time is rcquired for the activity in the reactor compartment to approach equilibrium.

Integrated Submersion Exposure

Submersion exposures at $500 \mathrm{ft}$ are shown in Fig. 28 for case 2, which is for a power history representative of a typical port entry. Exposures for the reference case are included for comparison. As a measure of the time available to evacuate areas adjacent to the site, the exposure times required to receive a 25-rem whole-body dose at $500 \mathrm{ft}$ can be compared for the various modes considered. If the previous power history is taken into account, the time required to receive 25 rem increases from about $2 \mathrm{hr}$ (the reference case) to $2.6 \mathrm{hr}$ (case 2, mode A). If, in addition, decay of the fission-product activity is considered (case 2, mode B), this time increases to $3.6 \mathrm{hr}$. Further, if the ventilation system holdup and the time needed for the cladding to fail are considered, about 5.4 aild $10 \mathrm{hr}$, respertively, would elapse with the normal and emergency ventilation systems. The latter time is five times as long as the time computed for the referencc case.

Equivalent reductions were predicted in the submersion exposures aboard the tug, as shown in Figs. 29 and 30. It may be noted that the exposures calculated for the emergency ventilation system are considerably larger than those obtained for the normal vertilation system. This 
is the result of the atmospheric dilutions assumed between the ship and the tug, as discussed in Section 6. According to this model, the atmospheric concentration of fission products varies inversely with the ventilation system flow rate. On the other hand, a large flow rate from the reactor compartment will decrease the holdup afforded by the compartment, as shown in Fig. 28. A solution to these contradictory requirements may be provided by a ventilation system that draws a rather small amount of air from the reactor compartment (perhaps a flow just sufficient to. maintain a negative pressure) and then dilutes this stream with a large volume of relatively clean air drawn from the atmosphere.

\section{Integrated Thyroid Exposure}

The use of more realistic assumptions has less effect on thyroid exposures than on submersion exposures. As a measure of the time avai.1able to evacuate areas adjacent to the site i.t is of interest to compare the exposure times required to receive $300 \mathrm{rem}$ to the thyroid at $500 \mathrm{ft}$. (This exposure represents a hazard comparable to a 25-rem whole-body dose.)

The normal ventilation condition was considered first, and it was found, as shown in Fig. 31, that under the referonce case cuilulliurs a 300-rem exposure would be received in $0.7 \mathrm{hr}$. Taking into account the case 2 power history increases this time only to about $0.8 \mathrm{hr}$. This is because the operating time at reduced power $(5 \mathrm{hr})$ is short compared with the half-lives of the more important isotopes of iodine. If decay, normal ventilation system holdup, and the time needed for the cladding to fail are considered, the exposure time required to receive 300 rem to the thyroid at $500 \mathrm{ft}$ becomes $1.4 \mathrm{hr}$, or twice the time computed for the reference case. At the tug, the times for the reference case, case 2 mode $A$, and case 2 mode $\mathrm{C}$ were found to be 15, 15.8, and $20.4 \mathrm{hr}$, respectively. These values were obtained from Fig. 33.

Turning to the emergency ventilation calculation, it should be recalled that an iodine filter efficiency of $99 \%$ was assumed, a factor of 10 higher than that of the normal system filters. As a result, the exposures at $500 \mathrm{ft}$ calculated for the emergency system are about a factor of 10 lower than corresponding exposures obtained for the normal ventilation system. It is shown in Fig. 32 that, under the reference case 
conditions, 300 rem would be received at $500 \mathrm{ft}$ in $6.5 \mathrm{hr}$. The corresponding numbers for case 2 mode $A$, and case 2 mode $C$ are 7 and $11.1 \mathrm{hr}$, respectively, increases of $7 \%$ and $70 \%$ over the reference case. The times required to receive 300 rem to the thyroid at the tug showed similar increases over the reference case, as shown in Fig. 34.

Exclusion Distances

A further illustration of the effects of release mechanisms on exposures is shown in Table 5, Section 6, which lists the exclusion radii needed to limit submersion exposure following the accident to 25 rem in $2 \mathrm{hr}$. While the exclusion radius for the reference case is $475 \mathrm{ft}$, consideration of case 2 power history and mode $\mathrm{C}$ release mechanisms reduces this distance to $245 \mathrm{ft}$ and $105 \mathrm{ft}$ for the normal and emergency ventilation systems, respectively. It should be noted that Sutton's atmospheric diffusion model ${ }^{10}$ probably is not valid for these short distances (since the concentration approaches infinity as the distance approaches zero); however, it is the model recommended in the AEC's site criteria and is used here in lieu of a better analytical model.

\section{Justification of Mechanisms Evaluated}

The calculations described above demonstrated that several mechanisms operate to delay and reduce the activity release from the N.S. SAVANNAH containment system following the maximum credible accident. Exposures calculated on the basis of these mechanisms were substantially less than exposures calculated for the same accident but employing standard techniques. Inasmuch as the calculational procedures employed here have not been generally accepted by the licensing and regulating authorities, a discussion of the following specific issues is appropriate: (1) power history, (2) core failure sequence, (3) decay of fission products, and (4) holdup effect of reactor compartment.

\section{Power History}

The operating power history of a reactor immediately prior to the maximum credible accident would have a significant effect on both the 
time to core failure and the activity available for release. The latter effect would be most significant in cases where the noble-gas exposures were controlling. For nuclear ships there is some justification for assuming a power level less than full power for purposes of the accident analysis. This justification is based on the inherent operating characteristics of ships in and near harbors where the accident would have the greatest consequences.

In the analysis given here, a power requirement of $50 \%$ power for 5 hr was considered to be representative of typical port entry operations. This power requirement was based on a review of the anticipated power requirements for the harbors of New York and Seattle. Nevertheless, it is recognized that there may be some ports for which the above assumptions concerning power history would not be conservative. It is suggested, however, that, if necessary, an administratively imposed reduction to 50\% power for $5 \mathrm{hr}$ prior to docking would not place a severe limitation on ship operation.

\section{Core Failure Sequence}

Most hazards analyses are based on instantaneous core meltdown as a convenient, conservative assumption, even though in reality such meltdown would be impossible to attain. If it is assumed that the maximum credible accident in the N.S. SAVANNAH is, indeed, the loss-of-coolant accident, the time to fission-product release is a function of the preaccident temperature of the fuel, the afterheat within the fuel, the physical properties of the fuel, and such heat-removal mechanisms as might exist. For the calculations described here no credit was taken for heat transfer, and all releasable fission products were assumed to be released from the fuel when any portion of the cladding reached the cladding melting temperature. Nevertheless, calculations which were performed on this basis indicate that, depending upon the prior operation, $10 \mathrm{~min}$ to $\mathrm{I} \mathrm{hr}$ is required before the initiation of cladding melting, and considerably longer times are required for the melting of a significant fraction of the core. Thus, in the event of such an accident, the initial exposures, that is, the exposures during the first $10 \mathrm{~min}$ to $\mathrm{l} \mathrm{hr}$ after the accident, will be virtually nil. In order to assure that such 
time intervals are available, however, other accident sequences by which a core meltdown may occur more rapidly, for example, a nuclear excursion, must be excluded.

As is well known, the long time constant of $\mathrm{UO}_{2}$ fuel elements in combination with the Doppler coefficient of low-enrichment systems provides a very effective inherent safety mechanism for reactors of the N.S. SAVANNAH type. This has been demonstrated by both theoretical and experimental investigations. For example, startup accident analyses have been performed by General Electric ${ }^{12}$ for three types of light-water reactors. The three reactors were characterized by their fuel elements, as follows: (1) uranium-aluminum alloy, highly enriched, in aluminumclad fuel plates; uranium-zirconium alloy, highly enriched, in zirconiumclad fuel plates; and $\mathrm{UO}_{2}$, slightly enriched, in zirconium-clad rods. The results of the analyses indicated that, even with an initial reactor period of $4.34 \mathrm{msec}$, the $\mathrm{UO}_{2}$ fuel elements remained well below the melting temperature of the zirconium cladding. With the same initial period, the other two cores suffered extensive fuel-element melting.

Experimental evidence of the effectiveness of the Doppler coefficient in preventing damage to $\mathrm{UO}_{2}$ fuel elements is also available. SPERT I tests were conducted on a core made up of fuel rods from the N.S. SAVANNAH critical experiment. ${ }^{13}$ Self-limiting power-excursion tests, initiated by step insertions of reactivity, were performed over a wide range of initial asymptotic reactor periods from $30 \mathrm{sec}$ to $3.2 \mathrm{msec}$. Power excursions with asymptotic periods as short as $3.2 \mathrm{msec}$ were successfully quenched by the Doppler effect without core damage. The implication of the results of these tests is summarized well in ref. 13, as follows:

"The fact that the core was able to sustain without damage a 3.2-msec period self-limiting power excursion, which requires a step reactivity insertion in excess of $\$ 2$, implies the following:

"(a) In order to obtain a minimum period of $3.2 \mathrm{msec}$ in a ramp-induced, self-limiting power excursion, an estimated ramp rate of about $8 \mathrm{\$} / \mathrm{sec}$ is required for a sufficient time to inject at least $\$ 2$ reactivity into the system. This ramp rate is perhaps a factor of 50 or more greater than that obtainable in a rod withdrawal accident f'rom most control rod drive systems presently in use. The 8 \$/sec rate also may 
cover any reasonable fuel loading accident in an oxide reactor.

"(b). Whereas no damage occurred in the oxide core for a 3.2-msec step test, the same test in a plate-type, watermoderated reactor would in all likelihood result in substantial fuel plate melting and in mechanical damage by transient steam pressures. That damage occurs in the one case and not in the other appears to be a consequence of the rapidity with which heat in the plate-type core is transferred from the meat to the cladding, and thence (after the cladding surface temperature has risen substantially above the saturation point), transferred quickly to the water. The sudden violent boiling that occurs gives rise to the destructive transient pressures, and, as a result of the decreased plate surface heat transfer coefficient, to the subsequent increase in surface temperature up to the melting point. On the other hand, an oxide fuel rod core with an adequate Doppler coefficient need not depend on heat transfer to effect shutdown, and its low heat transfer rate is advantageous in the event of a severe power excursion in helping to maintain the fuel rod cladding temperature near the saturation point and in suppressing rapid steam formation and consequently violent pressures. The implication of these results is that a rodtype oxide core may be safer than a plate-type core for a research reactor; and also may provide the basis for an efficient burst facility."

Based on the demonstrated effectiveness of the Doppler effect in preventing core damage during a nuclear excursion, it appears that there is good justification for excluding this type of accident in considering possible core failure sequences.

\section{Fission-Product Decay}

The decay of fission products following a maximum credible accident determines both the afterheat in the reactor and the amount of any given isotope in existence. Inasmuch as reactor accidents are commonly evaluated by assuming equilibrium full-power operation, the release processes are such that iodine (or, in some instances, strontium) exposures are controlling. There has been little incentive to consider radioactive decay processes in such evaluations. In the case of a mobile reactor such as the N.S. SAVANNAH, both these situations may be altered to such an extent that decay processes could have a significant effect on the 
resulting exposures and, hence, siting considerations. The new situation for the IN.S. SAVANNAH arises from two independent factors: (1) the power level immediately prior to docking may be substantially less than full power for a significant fraction of a day, and (2) the containment system filters are sufficiently effective in restricting the release of iodine and particulate matter so that the submersion dose from noble gases is controlling. The effect of fission-product decay in the former case is obvious, that is, it gives longer times to core melting following reduced power operation. The effect of decay on the submersion exposure is also significant, inasmuch as most noble gases have relatively short half-lives.

It should be noted that, since the noble gases have a more rapid decay rate than the halogens, situations could exist in which the noble gases were initially controlling but subsequently decayed and the iodine became controlling. It is also pertinent to observe that while effective filters for the noble gases may be employed, such filters are much more cumbersome than filters of comparable efficiency for halogens and particulate matter, so the submersion exposure from noble gases represents a convenient design point.

Holdup Effect of Reactor Compartment

The volume of the reactor compartment is sufficiently large that, if uniform mixing of the containment vessel leakage is assumed, the effective holdup time in the compartment would be significant. This holdup effect is especially important for emergency ventilation because of the relatively low exhaust rate. Of course, uniform mixing throughout the. whole containment volume would not be a good assumption because of the partial separation of the compartment into a lower and an upper void. For this reason the calculations given here were based on the assumption that only half of the compartment volume was available for mixing; uriform mixing in this volume was assumed. Actually the degree of mixing is impossible to establish without experimental evidence. One complicating feature of the mixing problem is that the degree of mixing probably depends to a large extent on the location of the leak from the containmert. vessel. Containment vessel leakage is likely to be distributed 
among the numerous penetrations, most of which are located in the lower void. Since the normal ventilation. system exhausts from the lower void, the degree of conservatism associated with the mixing assumption may be questionable when the normal system is operating. The emergency system exhausts from the upper void, and therefore it is felt that the mixing assumption is a reasonable representation of the system performance.

\section{Other Pertinent Factors}

In addition to the factors discussed above, there are several others that have a significant bearing on the hazards evaluation of nuclear ship operation in harbors. While the factors discussed here have not been specifically analyzed in this report, it is important to understand their relationship to the overall safety evaluation. Such factors include:

1. ability to remove ship from dock after the maximum credible accident,

2. performance of filters and compartment ventilation systems,

3. implications of total population exposure,

4. proximity and resulting exposure of passengers and visitors aboard or near ship, and

5. effect of radioactive cloud size on submersion exposure.

Ability to Remove Ship from Dock After Accident in the Time Required

The question of the feasibility of ship removal was considered only insofar as the resulting exposures to the remaining ship's crew and tugboat personnel were concerned. The problems of ability to evacuate visitors aboard ship or at dockside, availability of tugboats, emergency planning to effect the removal of the ship, etc., are covered by the Port Analysis Report that is prepared for each port to be visited (see refs. 14-18 for such reports on the ports of Savannah, Norfolk, Panama Canal, Seattle, and San Francisco). The exposures calculated herein are all centerline downwind values that could be reduced orders of magnitude by the simple expedient of stationing crew members and positioning the tugboat upwind of the source. Even the centerline downwind submersion exposures (see Figs. 29 and 30) are, however, within the acceptable emergency exposure limits for many hours, those from the normal ventilation system 
with its elevated discharge being a factor of $\$ 20$ lower than those from the emergency system. The thyroid exposure at the tugs (Figs. 33 and 34) would be considerably greater than the submersion exposure regardless of which ventilation system was employed, since the assumed efficiencies of the iodine filters in the normal and emergency systems have been conservatively set for the interim operating period at 90 and $99 \%$, respectively. Since the criterion for thyroid exposure is $300 \mathrm{rem}$ as opposed to $25 \mathrm{rem}$ for whole-body submersion, it is apparent that the submersion exposure is controlling in most cases; however, thyroid exposures of this magnitude should and, in this case, can be avoided by providing shipboard and tugboat personnel with respiratory protection, such as face masks with charcoal canisters, when operating under such emergencies. Normal practice would also require that, where possible, emergency operating personnel would remain upwind of the source.

Performance of the Filters and Compartment Ventilation Systems

Heretofore most reactor containment systems have consisted of a single containment envelope. For boiling-and pressurized-water reactors, the envelope was commonly a steel pressure shell. The N.S. SAVANNAH containment system consists not only of such a steel shell but also the ventilated reactor compartment within which the steel container is located. Hence it is essential that the compartment integrity be monitored with the same care as that for the steel shell and also that the efficiency of the compartment discharge filters and the operability of the ventilation system be demonstrated and continuously maintained in a manner comparable to that required to assure the continued integrity of the steel shell. More specifically, no significant activity may be permitted to leave the reactor compartment except through the normal or emergency ventilation systems, which are provided with iodine and particulate matter filters.

In the present study iodine filter efficiencies of at least 90 and 99\% were assumed for the normal and emergency ventilation systems, respectively. Actually, the efficiencies of these two filters have been repeatedly checked and shown to be greater than the prescribed minimum values. It may be anticipated that, following the review of the initial operation of the N.S. SAV̈ANNAH, the assumed efficiencles fur line rilters 
in both of these systems will be increased. This could have an important bearing on the dock facilities at which the N.S. SAVANINAH would be permitted to berth. Once the iodine and particulate matter had been effectively attenuated by filtration, the noble gases would be controlling and, if a further reduction in accident exposures was desired, it would be necessary to provide for attenuation of the noble gas activity. Removal of the noble gases by filtration might also be considered, although before such a scheme would be practical it would be necessary to reduce the volume by, for example, the installation of an annular shell immediately outside the steel containment shell that would be maintained at a slight negative pressure by the low flow in question.

\section{Implications of Total Population Exposure}

The data presented here indicate the effect of various processes and mechanisms on activity release and hence upon exposures from the N.S. SAVANNAH maximum credible accident. It"was shown in Table 5, Section 6 , that these processes permit the exclusion radius to be reduced in the cases cited from 475 to $105 \mathrm{ft}$, with similar reductions in the controlled-zone boundary. It appears from these studies that the distance requirements for nuclear ship berths should be attainable within existing regulations, if, where necessary, a case could be made for the validity of one or more of the mechanisms described here. In any event, because of the proximity of population centers to most important ship berthing areas, it is generally impossible for the berthing areas to fulfill the population center distance stipulation of the Reactor Site Criteria. ${ }^{1}$ In lieu of this stipulation, a total population exposure criterion of $2 \times 10^{6}$ man-rem has been proposed, 4 and, as indicated in Appendix E, it would be possible for a nuclear ship such as the N.S. SAVANNAH to fulfill this criterion if the maximum credible accident were to occur in the New York Harbor. It is true, of course, that the site boundary exposures and the total population exposures would not be independent, so for a given site (or berth) when one exposure increases (or decreases) the other also increases. Furthermore the establishment of a 24-hr limit (because of the assumed removal of the ship) in the determination of the controlledzone boundary has the effect of reducing the area that can be subjected 
to a high (up to $25 \mathrm{rem}$ ) exposure, with the result (as indicated by the population exposures for New York Harbor given in Appendix E) that even for ports with high population densities the total population exposure (of persons outside the controlled zone) does not approach the $2 \times 10^{6}$ man-rem criteria in $24 \mathrm{hr}$. The concept of the total population exposure would thus appear to have more meaning as applied to stationary reactor site evaluations because the low population distance is so great that large numbers of people may be concentrated immediately beyond. Even in berth evaluation, however, the concept is useful, since it serves as an index to measure the number of persons who may be admitted to the immediate vicinity of the ship. In the case of Savannah Harbor, people in the immediate vicinity would account for 383,000 man-rem, or over $70 \%$ of the total estimated population exposure.

Implicat1ons of Limited Time in Port

The fact that a nuclear vessel is in any one port only a small percentage of the time has a direct bearing on the probability of the occurrence of the accident in that port; however, this probability is only one of many that could be associated with the occurrence of the maximum credible accident at any place or time, none of which are included in hazards calculations. Hazards evaluation technology will have to become much. more refined than it is at the present before probability factors can be meaningfully evaluated in such an analysis.

Proximity and Resulting Exposure of Passengers and Visitors Aboard Ship

The existence of members of the public, passengers and visitors, either aboard or at dockside constitutes an exposure potential that has no significant counterpart in a stationary power plant. The tentative criteria on port operation of the N:S. SAVANNAH proposed by the Maritime Administration suggested that such persons be evacuated before they had received more than a 25-rem whole-body dose or a 300-rem thyroid exposure. $^{2}$ If these exposure criteria are accepted as reasonable, the real question is whether it is feasible to carry out the evacuation of these persons before they would receive an excessive exposure. Since the delay 
in activity release due to the time to cladding melting and the holdup in the reactor compartment defer the time to maximum activity release for several hours (see Figs. 14 through 23), the required evacuation is feasible, even if carried out in up to $2 \mathrm{hr}$ with the evacuated persons downwind (see Figs. 28 to 34). Furthermore, if the actual finite cloud size were considered, a substantial reduction would result in the submersion exposures previously calculated on the basis of a uniform concentration equivalent to the Sutton ${ }^{10}$ centerline downwind concentration (see the following section). Actually, emergency evacuation procedures would be such that times in downwind concentrations would be minimized, and the evacuation should be effected in much less than $2 \mathrm{hr}$.

\section{Effect of Radioactive Cloud Size on Exposure}

Whereas most submersion exposure calculations have assumed an infinite radioactive cloud of uniform concentration, the data in Appendix $E$ indicate that, at distances close to the source, submersion exposures will be overestimated by from one to two orders of magnitude. This is of particular importance to nuclear installations such as the N.S. SAVANIVAH for which the submersion exposure is controlling and which require some operating personnel to remain close by following an accident. The exposures to persons being evacuated may also be substantially less than would otherwise be calculated.

\section{CONCLUSIONS}

In estimating the activity released from the N.S. SAVANVAH in the maximum credible accident, there is reasonable justification for including the influence of reduced power operation during port entry, delay in transport of containment vessel leakage through the reactor compartment, and radioactive decay following the accident. The combined effects of these factors, when treated in a conservative manner, reduce calculated exposures by approximately an order of magnitude for the situations of interest. Although this reduction is not large compared with that afforded by the primary attenuating mechanisms, that is, containment vessel holdup, iodine filtration, and atmospheric dilution, it 
: may be important in assessing the feasibility of evacuating personnel from the immediate vicinity of the ship and of moving the striken ship to a remote anchorage.

A reduction in power during port entry would affect both the time to core failure and the activity available for release. A power history consisting of continuous full-power operation followed by $5 \mathrm{hr}$ of operation at $50 \%$ of full power (case 2 ) gives a reasonable approximation of the fission-product inventory at the time of docking under typical port entry conditions. This reduction decreases the noble gas (gamma energy) inventory to about two-thirds of the full-power value and increases the time between loss-of-coolant and initial c.ladding failure by at least several minutes. The delay in cladding failure has a significant effect on the activity release rate at short times. At times longer than about $1 \mathrm{hr}$, however, the conservative heat transfer model used indicates that the cladding of most of the rods would have failed with either power.. regime.

Radioactive decay following the accident would be an important factor in alleviating the noble gas exposure hazard. On the other hand, the radioiodine release rate would not be appreciably reduced by decay because of the relatively long half-lives of the important isotopes $I^{131}$ and $\mathrm{I}^{133}$.

It is desirable and practical to provide particulate matter and iodine filtration of the air exhausted from the reactor compartment so that the controlling exposure would be that from noble gases. Tris conditinn is usual.ly a convenient design point in view of the difficulty of removing noble gases from air streams. An iodine removal efficiency of 99\% or better is needed for this purpose.

The reactor compartment would delay the release of activity to the environment and permit particulate matter and iodine filtration to be accomplished prior to release. The compartment delay is significant if it san be assumed that there will be uniform mixing of containment vessel leakage with a large fraction of the compartment volume. The reduction in exposure rate would be most pronounced during the period when concentrations in the compartment were building up to equilibrium values, 
but there would be a corresponding reduction in accumulated exposures at longer times.

Maximum benefit from reactor compartment delay would be obtained if (1) the compartment exhaust rate were the minimum required to maintain the compartment at negative pressure, (2) there were assurance of uniform mixing within the compartment or that flow patterns in the compartment were such that containment vessel leakage would not pass directly to the exhaust without a comparable time delay, (3) a large flow of diluting air were drawn from the atmosphere to reduce the concentration of fission products near the discharge point, and (4) the discharge point were elevated to provide additional atmospheric dilution before exposure of nearby personnel.

Considerations of reduced power during port entry, radioactive decay, and delay in release appreciably reduce the calculated exposures in the maximum credible accident. If it is assumed that the emergency. ventilation system is operating, the present calculations indicate the following for case 2 with respect to the reference case:

1. The 2-hr submersion dose at the tug or at $500 \mathrm{ft}$ downwind is reduced by a factor of about 10, the major contribution being delay in the reactor compartment.

2. The 24-hr submersion dose at 500 ft downwind is reduced by a factor of about 7, with radioactive decay being the principal contributor.

3. The 2-hr thyroid dose is reduced by a factor of about 3.5, and the 24-hr thyroid dose by a factor of 1.5 .

4. The exposure time for receiving a 25-rem whole-body dose is increased by a factor of about 5 to about $10 \mathrm{hr}$.

5. The exclusion radius (for 25 rem in $2 \mathrm{hr}$ ) is reduced by a factor of 4 to about $100 \mathrm{ft}$.

6. The exposure rate is lowest immediately after the accident, reaches a maximum in about $4 \mathrm{hr}$, and then gradually decreases, reaching half the maximum value at about $16 \mathrm{hr}$ after the accident.

If the normal ventilation system is operating, the exposure reductions are less pronounced. This is due to the higher flow rate and consequent shorter time delay in the reactor compartment and to the fact 
that thyroid exposures are controlling as a result of the comparatively low iodine-removal efficiency assumed for this system.

The calculated exposures are sufficiently low and the calculations retain sufficient conservatism that there is good assurance that personnel will not receive an excessive dose while the ship is being moved to a remote anchorage. The use of respiratory protection and of radiation monitoring to assist in positioning personnel engaged in the move would be advisable and would further reduce exposures. 


\section{PAGES 62 to 64 WERE INTENTIONALLY LEFT BLANK}




\author{
Appendix A \\ DIFFERENCES BETWEEN N.S. SAVANNAH AND \\ STATIONARY POWER PLANTS
}

The differences ${ }^{19}$ that have some bearing on the relative safety of nuclear ships and most stationary power plants have been identified. The N.S. SAVANNAH power plant is either possessed of or provided with these features by virtue of the marine environment, with the result that it has several significant differences from a stationary reactor of comparable size. The design and operation of a nuclear vessel, as well as safeguards analysis and evaluation, should take into account each of these differences, insofar as possible. Their probable effects on the health and safety of the general public are discussed here.

\title{
The "Population Center Distance"
}

Facilities that meet the needs of large ships exist only at large ports. Therefore if nuclear vessels could not be berthed in major ports, their commercial usefulness would be seriously curtailed. On the other hand, while there are obvious economic advantages to the location of stationary power reactors near population centers, such considerations are not (at the present time, at least) overriding. Hence the recently approved Reactor Site Criterial established certain minimum distances by which a power reactor should be separated from population centers. Such separation distances are incompatible with nuclear vessels. In order to compensate for the proximity to population centers, the N.S. SAVANNAH not only is provided with an additional containment barrier, but also it can be removed from the dock to an isolated anchorage. Environmental analyses of various ports have shown how effective the N.S. SAVANINAH containment is expected to be. The maximum individual exposure at the site boundary and the total population exposure in the event of an accident would be well below the values considered acceptable for stationary power plants, even if relatively long removal times were considered. 
Characteristics of the Area Surrounding the Ship Berth.

In addition to the proximity to population centers, ship berths may be expected to be characterized by relatively small exclusion areas and high population densities in the immediate vicinity of the exclusion, or controlled, area boundary. Since nuclear ships will be expected to utilize existing berthing facilities, insofar as possible, the "effective" exclusion area that could be associated with any berth would only be that which might "happen" to exist. Other things being equal, it would be desirable to select the berth which afforded the greatest exclusion area. The N.S. SAVANNAH is designed, however, so that in the event of the maximum credible accident, the exposures at comparable distances from the reactor are orders of magnitude less than those in most stationary power plants. Furthermore, should the exposure at the site boundary tend to exceed the specified limit because of the small size of the exclusion area, the potential exposure could be reduced by restricting the operating history of the ship prior to berthing. 20-24

\section{Proximity of Some Members of the Public to the Reactor}

The crew of a nuclear ship is the counterpart of the operating staff of a stationary power plant. As far as routine exposures and dockside accidents are concerned, the ship's crew belongs in the category of radiation workers and would be subject to occupational exposure limits as defined by the ICRP. ${ }^{25}$ Similarly, passengers on nuclear ships are presumably regarded, as far as routine exposures are concerned, in the same light as "members of the public living in the neighborhood of controlled areas." Furthermore, when at dockside it should be possible to evacuate passengers so that no passenger would receive more than 25 rem to the whole body or 300 rem to the thyroid in the event of an accident. On the other hand, when at sea, the passengers wili be subject to much the same risks as the crew, just as the passengers and crew share the same risks in a conventional ship. It should be noted that the Reactor Site Criterial make no specific requirements for operating personnel safety in the event of an accident. Furthermore, visitors to a stationary 
nuclear facility assume some of the risks of the operating personnel. Somewhat similarly, passengers on a nuclear vessel forego their status as members of the public at large and assume some of the risks of the operating personnel. On the other hand, the safety features of the N.S. SAVANNAH, most significantly the multiple containment provisions, provide a degree of protection of the crew, as well as the passengers, which is not required or generally found at stationary reactors, and which should be capable of limiting the resulting exposure to less than 25-rem whole body or 300-rem thyroid.

\section{Effect of Operating Power History}

Stationary nuclear power plants normally. operate at or near design power as much of the time as possible. The operating power on a nuclear ship will be reduced to about 50\% of normal operating power as it approaches a harbor and will be further reduced to the hotel load of about 15\% immediately after berthing. Thus the magnitude of the potential activity release and the time before the activity is released are both improved with time following the reduction of power prior to entering a port. Should some particular situation require an even further reduction in potential activity release, this could be accomplished by further reductions in power for longer times.

\section{Removal of Ship to a Remote Anchorage}

In the siting of stationary power reactors the zone outside the exclusion area must be so sparsely populated that it can be evacuated in such a manner that no one will receive exposures in excess of 25 -rem whole body. The evacuation time is $2 \mathrm{hr}$ at the inner boundary of the zone and intinity at its outer perimeter. One of the biggest single safety advantages of a nuclear ship power plant over its stationary counterpart lies in the fact that the ship is mobile. Thus, in the event of an accident, or in anticipation of an accident in which fuel element melting is expected, the ship may be removed from its berth to a predetermined, remote anchorage. 
Release to the Hydrosphere

A ship is always subject to accidents that conceivably could result in its being sunk. Thus, should the maximum credible accident and the ship sinking occur simultaneously, the activity would be released to the water. From the standpoint of the dose to the surrounding population, this would undoubtedly be preferable to the uncontrolled release of activity to the atmosphere, since, as was shown in the Camden site study, 26 the resulting activity concentration in the Delaware River at Camden would barely exceed maximum permissible values if only the steel containment shell was effective in limiting the release of activity. Values of the hydrospheric dispersion parameters for various harbors are given in the respective site reports. The subject is not discussed further here because the hazards are less significant than those from atmospheric dispersion of the same activity.

\section{Accidents as a Consequence of Plant Mobility}

Accidents caused either by the motion of a nuclear vessel or other ships have no reasonable counterpart in stationary reactor operation. Such accidents would include power plant failures induced by ship motion, vibrational fatigue, storms, ship collisions, and groundings. Safety factors to preclude the possibility of such failures were factored into the design of the plant. While it cannot be concluded that such mechanisms cannot contribute to an accident, insofar as possible the design minimizes the possibility. It is regarded as incredible that these mechanisms can act simultaneously to cause the maximum credible accident and rupture a containment barrier in port. Furthermore, while the possibility of ship accidents increases in harbor waters because of the traffic density, the probability of accidents of sufficient severity to release activity actually decreases as the ship enters the harbor and approaches its berth because of the restriction on permissible speeds in harbor areas. Specifically, the N.S. SAVANNAH is designed 27 so that no credible accident in harbor waters could either (1) produce the maximum credible accident or (2) rupture the pressure containment vessel, 
although such an accident is conceivable when the ship is on the high seas.

\section{Electrical Power}

In a stationary power plant, reliable power may be obtained from lines to a number of grid systems, in addition to an emergency station. Aboard ship, however, no external sources are available and emergency power must be provided from self-contained power sources. The continued opcration of the blower's in the ventilation system is of course dependent upon the reliability of the electrical power supply. Emergency power is available to these blowers from the emergency diesel system, as well as from the auxiliary diesel generators.

In addition to the normal power supply from the turbine-generators, the two auxiliary diesel generators can supply $1500 \mathrm{kw}$ on a normal basis or more than $1800 \mathrm{kw}$ for periods of at least $2 \mathrm{hr}$ through either or both of the two main power buses. The 300-kw emergency diesel generator can supply the reactor emergency cooling system through separate buses and would be automatically switched to furnish power to all vital loads, such as reactor compartment ventilation, primary pumps, etc., if the normal or auxiliary power sources failed. Like the auxiliary diesel generators, it is rated for 125\% output for a minimum of $2 \mathrm{hr}$. Control power is supplied at all times from a battery-backed floating bus. Twin sets of motor-driven inverters and alternators, either of which can supply the total bus load, assure uninterrupted battery charge maintenance and availability of control power.

\section{Evacuation of the Ship at Sea}

Abandoning the ship at sea is not necessarily feasible or less hazardous than radiation exposure. Emergencies on the high seas are conceivable in which it might be considered less hazardous to remain aboard ship even in the face of certain radiation exposure. This would be less applicable to ships at herths or even in harbor waters. Some 
conditions, such as storms, might impair the ease with which the passengers and crew could be removed.

Time in Port

A ship would visit many ports and would be expected to be in any one port only a small fraction of the time. In a stationary power plant the surrounding population is subjected to the full potential of an accident approximately 90\% of the time. On the other hand, the port population is not subject to any exposure potential when the ship is not in port.

\section{Ship Compartmentalization}

Considerations of seaworthiness and safety against sinking dictated that the containment vessel be housed in a watertight compartment that is adequately reinforced to maintain the integrity of the ship's hull under all sea conditions. This compartment is provided with two independent ventilation systems, each containing provisions for removal and entrapment of exhausted airborne radioactivity, and is maintained at a slight negative pressure with respect to the atmosphere. One of the ventilation systems is operated from the ship's emergency electrical supply, and thus effective activity removal is independent of the operation of the ship's power plant. The compartment constitutes a complete second containment shell surrounding the inner vessel.

Since the reactor compartment is watertight, it would be possible in the event of a primary piping rupture to flood this compartment partially in order to cool the containment vessel and reduce the pressure inside at an increased rate, thereby minimizing fission-product leakage to the atmosphere. This procedure would have an added advantage in that some of the leaking activity would be adsorbed in the water; however, the compartment ventilation system would eventually be rendered inoperable. An inexhaustable supply of coolant is assured because cooling external to the containment vessel can utilize the adjacent sea 
water. Flooding of the reactor compartment could be easily accomplished by a fire boat, if available.

\section{Collision Protection}

To maximize the protection afforded the primary containment vessel against penetration by collision, the hull of the ship in the vicinity of the reactor was strengthened 27 by increasing the thickness of deck plates and by placing a layered steel and redwood collision barrier immediately outboard of the reactor compartment. This additional reinforcement not only renders the containment vessel invulnerable to penetration by all existing merchant ships at harbor speeds but also substantially improves the resistance of the reactor compartment to failure. 
Appendix B

FISSION-GAS RELEASE DURING OPERATION

An analysis was made of the pressure buildup in the fuel rods because of fission-product gases leaving the $\mathrm{UO}_{2}$-fueled matrix during the lifetime of the core. The purpose of the analysis was to determine the temperature at which the cladding could be expected to fail in a temperature transient following a loss-of-coolant accident. The release of fission gases from the fuel into the volume provided by the open pores of the $\mathrm{UO}_{2}$ pellets and the free volume of the fuel element was calculated based on recently obtained data for the pellet temperature distribution and rare-gas release. A degree of conservatism was maintained by using the most reasonable pessimisitic data available. It was found that $2 \%$ of the rare-gas inventory would be released during the lifetime of the core in the highest flux region at the midplane of the central rod. The conservative simplifying assumption was therefore made that $2 \%$ release could be expected from all the fuel elements in the core.

Since a high fraction of release has been found to occur in $\mathrm{UO}_{2}$ undergoing grain growth, the extent of grain growth in the N.S. SAVAivivH fuel was estimated by comparison with suitably correlated experimental data. It was found that grain growth would not occur in the peak power region of the core, which has a peak-to-average power ratio ${ }^{28}$ of 3.75 during 69-Mw operation.* Power operation in excess of 21\% above $69 \mathrm{Mw}$ would be required to initiate grain growth. Without grain growth, reasonably accurate estimates of the rare-gas release in the relatively lowdensity ( 91 to $93 \%$ theoretical) pellets used in core 1 of the N.S. SAVANNAH reactor could be obtained by use of the Booth model.29,30 In this model, the $\mathrm{UO}_{2}$ compact is assumed to be composed of microspheres that communicate with the atmosphere through open pores.

The pressure buildup in the fuel sheath was calculated using $2 \%$ rare gas, iodine, cesium, and rubidium release added to the partial-pressure contribution of the initial 1 atm of helium fill gas. The volume filled

*The axial ratio is 1.5 ; the radial, 2.0 ; and the local, 1.25 . 
by this gas mixture that contributes to the stress on the cladding was taken as the open porosity of the $\mathrm{UO}_{2}$ plus the free volume between the pellets and the stainless steel cladding with end caps in place.

The tangential cladding stress caused by the internal pressure buildup was compared with data obtained in stress-rupture experiments performed at ORNL, and it was concluded that the stress was sufficiently low that the fuel elements would not fail until the cladding temperature approached $2550^{\circ} \mathrm{F}$, which is the melting point of stainless steel.

\section{Discussion of the Conductivity Integral}

In order to estimate the amount of fission-gas release during operation, it was necessary to investigate the existence of grain growth because of the high fractional release reported in regions of grain

growth. For this study, experimental data were scanned to find the lowest heat rate that would yield grain growth, and the result was compared with the heat rate in the N.S. SAVANNAH reactor. The parameter used for the comparison was

$$
\int_{T_{S}}^{T} g g k(T) d T,
$$

where

$$
\begin{aligned}
\mathrm{K}= & \text { thermal conductivity of the } \mathrm{UO}_{2}, \\
\mathrm{~T}_{\mathrm{S}}= & \text { surface temperature of pellet, } \\
\mathrm{T}_{\mathrm{gg}}= & \text { temperature of structural change in } \mathrm{UO}_{2} \text {, that is, grain growth, } \\
& \text { in this case. }
\end{aligned}
$$

This parameter bears the following relationship to the linear heat rate in a solid, cylindrical pellet: ${ }^{31}$

where

$$
\int_{T_{S}}^{T_{C}} r_{(}(T) d T=\frac{W}{4 \pi},
$$

$$
\begin{aligned}
T_{c} & =\text { central temperature, } \\
W & =\text { linear heat rate of the fuel element }(\mathrm{w} / \mathrm{cm})
\end{aligned}
$$


Since parameter (B.I) does not require detailed knowledge of the thermal conductivity and is independent of the pellet radius, it is useful for. comparison of experimental results. In order to determine the existence of grain growth in the N.S. SAVANNAH reactor fuel, it was necessary only to show that the following inequality was satisfied:

$$
\int_{T_{s r}}^{T_{c r}} K(T) d T<\int_{T_{s e}}^{T_{g g}} K(T) d T+\int_{T_{s r}}^{T} s e ~ K(T) d T,
$$

where

$$
\begin{aligned}
& \mathrm{T}_{\mathrm{sr}}=\text { pellet surface temperatures in the reactor under study, } \\
& \mathrm{T}_{\mathrm{cr}}=\text { pellet central temperature in the reactor, } \\
& \mathrm{T}_{\mathrm{gg}}=\text { grain-growth temperature, } \\
& \mathrm{T}_{\mathrm{se}}=\text { pellet surface temperature measured experimentally. }
\end{aligned}
$$

The value of the conductivity integral is

$$
\int_{\mathrm{T}_{\mathrm{sr}}}^{\mathrm{T}} \mathrm{cr} \mathrm{K}(\mathrm{T}) \mathrm{dT}=23.4 \mathrm{w} / \mathrm{cm}
$$

at $69 \mathrm{Mw}$ for the midpoint of the central fuel element, which has a peakto-average flux ratio of 2 radially, 1.5 axially, and 1.25 locally, yielding a peak-to-average ratio of 3.75 .

\section{Determination of the Pellet Surface Temperature}

In order to compare the calculated value with the experimental value, the surface temperature of the pellet must be known. This is dependent on the heat flux, cladding thickness, temperature difference between the cladding outer surface and the cooling water, temperature of the water cooling the exterior of the cladding, and the interface thermal conductance between the pellet and the cladding. The following values were used for this analysis:

Peak heat flux*

Cladding thickneșs
$243,000 \mathrm{Btu} / \mathrm{hr} \cdot \mathrm{ft} \mathrm{t}^{2}$

0.035 in.

*Derived from 69-Mw operation and a peak-to-average flux ratio of 3.75 . 
Water temperature 8

$509^{\circ} \mathrm{F}$

Cladding to water temperature dif- $\quad 11^{\circ} \mathrm{F}$

ference

Thermal conductivity ${ }^{32}$ of type 304 stainless steel at $520^{\circ} \mathrm{F}$

Interface thermal conductance

$10.7 \mathrm{Btu} / \mathrm{hr} \cdot \mathrm{ft} t^{2}$

$1000 \mathrm{Btu} / \mathrm{hr} \cdot \mathrm{ft} \mathrm{t}^{2} \cdot{ }^{\circ} \mathrm{F}$

$0.567 \mathrm{w} / \mathrm{cm}^{2} \cdot{ }^{\circ} \mathrm{C}$

The interface thermal conductance is difficult to evaluate analytically because of the fracturing of the $\mathrm{UO}_{2}$ during irradiation and the subsequent uncertainty in the gap thickness to be used in thermal conductivity calculations. Experiments have been performed, as reported in ref. 31, for correlating gap conductance deduced from observations of grain growth and melting of $\mathrm{UO}_{2}$ samples in metal sheaths. Some of these data are presented in Fig. B.I as a function of the ratio of diametral

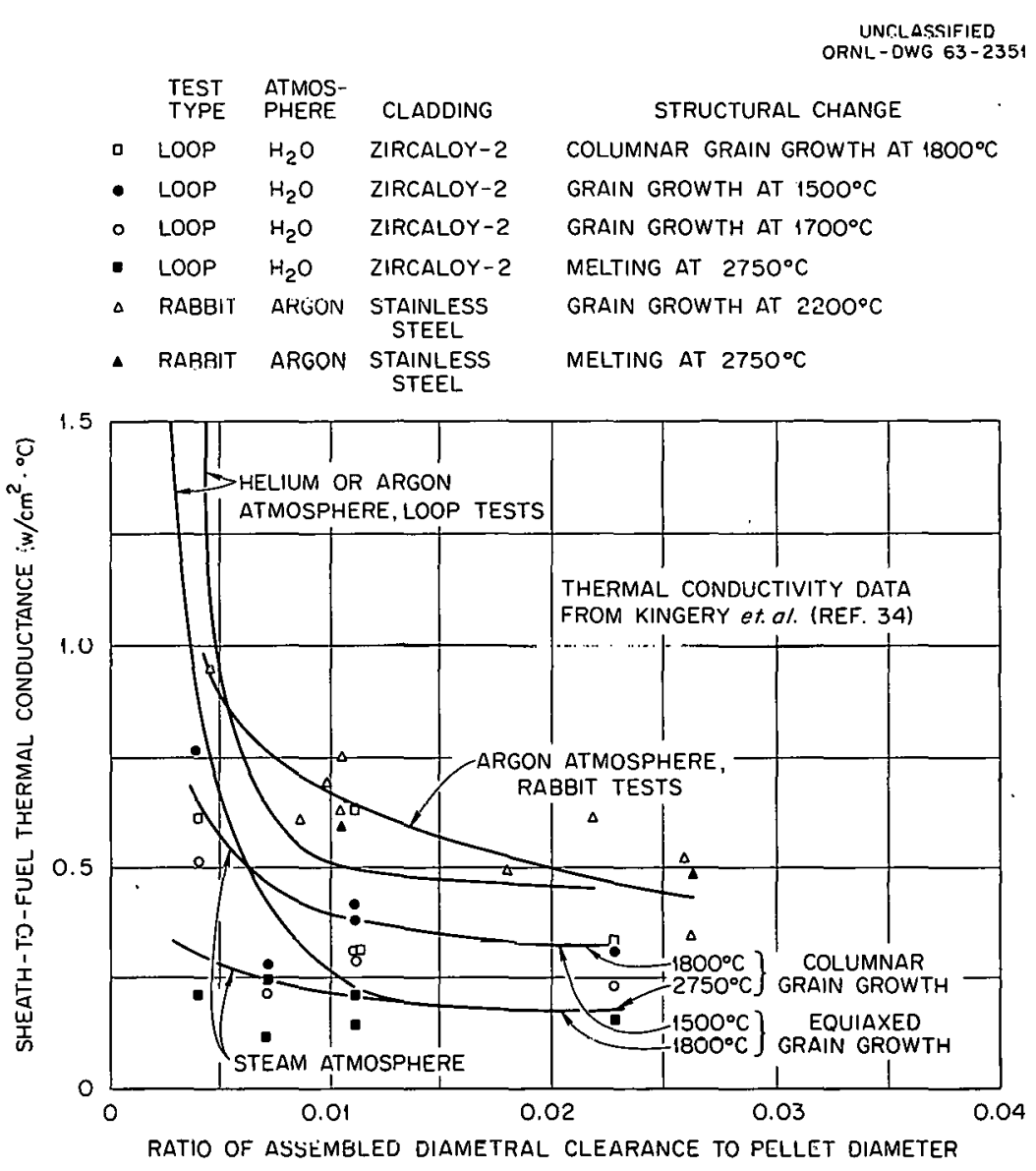
34).

Fig. B.1. Effect of Clearance on Gap Conductance (taken from ref. 
clearance to the pellet diameter; as assembled. For an assembled clearance ratio of 0.01 , approximately the value for the N.S. SAVANNAH fuel, it can be seen from Fig. B.I that a sheath-to-fuel thermal conductance of $0.567 \mathrm{w} / \mathrm{cm}^{2} \cdot{ }^{\circ} \mathrm{C}\left(1000 \mathrm{Btu} / \mathrm{hr} \cdot \mathrm{ft}^{2} \cdot{ }^{\circ} \mathrm{F}\right)$ lies in the low region of the range of data from experiments with stainless steel-clad fuel. Based on these values, the surface temperature of the peak power pellet was found to be $432^{\circ} \mathrm{C}$, or $809^{\circ} \mathrm{F}$.

\section{Use of the Conductivity Integral}

Although $\int_{T_{S}}^{T_{g g}} \mathrm{~K}(\mathrm{~T}) d \mathrm{~T}$ is a function of the linear heat rate alone, evaluation of one of the limits of integration when the other is known requires knowledge of the thermal conductivity, $K(T)$. The central pellet temperature is shown in Fig. B.2 as a function of the conductivity integral $^{33}$ for thermal conductivity data ${ }^{34-36}$ applicable when the bottom limit of the integral is $100^{\circ} \mathrm{C}$. It is apparent from Fig. B.2 that for a given linear heat rate the temperature of the upper limit of integration increases as the thermal conductivity decreases. Although the Kingery. ${ }^{34,35}$ data are probably the most reliable, the Hedge and Fieldhouse 36 data were used here because of the extra conservatism imparted to the analysis; that is, if grain growth were not found using the Hedge and Fielohouse data, it would not be found using any of the other data.

Thus the inequality of Eq. (B.3) would be

$$
\int_{432^{\circ} \mathrm{C}}^{\mathrm{T}} \mathrm{cr}(\mathrm{T}) \mathrm{dT}<\int_{\mathrm{T}_{\mathrm{se}}}^{\mathrm{T}} \mathrm{gg} K(\mathrm{~T}) \mathrm{dT}+\int_{432^{\circ} \mathrm{C}}^{\mathrm{T}} \mathrm{se}(\mathrm{T}) d \mathrm{~T}
$$

The last term can be found from Fig. B.2 by breaking it into two parts, as follows:

$$
\int_{432^{\circ} \mathrm{C}}^{\mathrm{T}} \mathrm{se}(\mathrm{T}) \mathrm{dT}=\int_{100^{\circ} \mathrm{C}}^{\mathrm{T}} \mathrm{se}(\mathrm{T}) \mathrm{dT}-\int_{100^{\circ} \mathrm{C}}^{432^{\circ} \mathrm{C}} \mathrm{K}(\mathrm{T}) \mathrm{dT} .
$$

The experimental data ${ }^{31}$ for $\int_{T_{S e}}^{T_{g g}} K(T)$ dT for six experiments with helium fill gas in the gap clearance and 21 experiments with argon fill gas were scanned to find the lowest value of the integral that yielded 


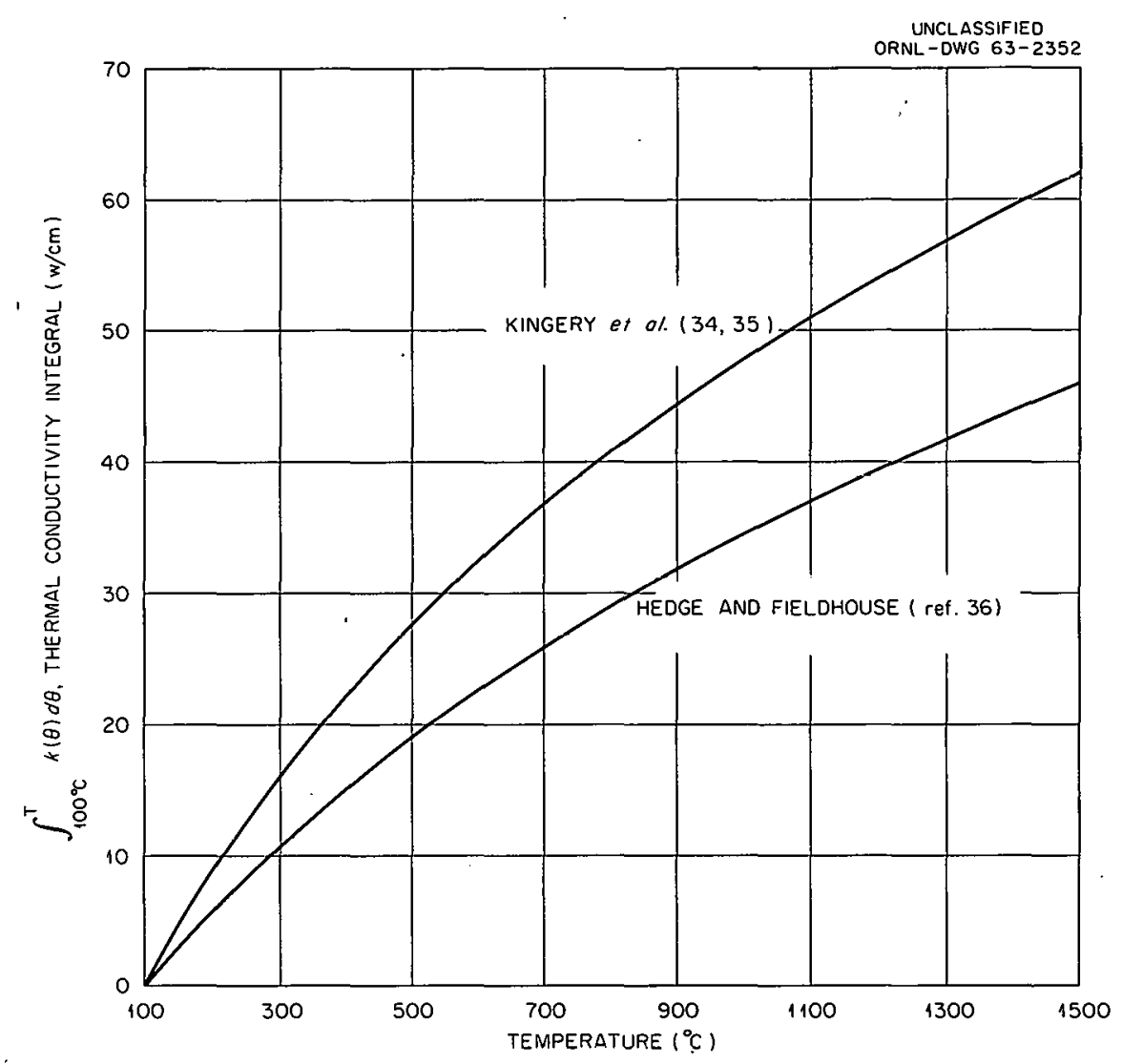

Fig. B.2. Central $\mathrm{UO}_{2}$ Pellet Temperature as a Function of the Thermal Conductivity Integral Based on the Thermal Conductivity Data of References 35 and 36 .

grain growth within the pellet. This value was found to be $23.8 \mathrm{w} / \mathrm{cm}$. The surface temperatures in this experiment was deduced to be $650^{\circ} \mathrm{C}$ using Hedge and Fieldhouse data. ${ }^{36}$ Substituting the values obtained from Fig. B.2 into Eqs. (B.3) and (B.4) yielded

$$
\int_{432^{\circ} \mathrm{C}}^{\mathrm{T}} \mathrm{cr}(\mathrm{T}) \mathrm{dT}=23.8+21-16=28.8 \mathrm{w} / \mathrm{cm} \text {. }
$$

Since

$$
\int_{432^{\circ} \mathrm{C}}^{\mathrm{T}} \mathrm{cr}(\mathrm{T}) \partial \mathrm{II}=23.4 \mathrm{w} / \mathrm{cm}
$$

for the pellet in the highest flux region of the N.S. SAVAINIAH reactor, the inequality of Eq. (B.3) is satisfied and grain growth does not occur. 


\section{Calculation of Fission-Gas Release}

Having established that the high rates of release associated with grain growth do not occur under normal operating conditions, an estimate was made of the amount of fission gases that would diffuse out of the $\mathrm{UO}_{2}$ into volumes within the fuel rod, since these gases would contribute to the internal pressure and would be released immediately upon failure of the cladding. For the relatively low-density pellets of core I (91 to $93 \%$ of theoretical density), the Booth ${ }^{30}$ model should give reasonable estimates.

The Booth model is based on the assumption that the compacted and sintered $\mathrm{UO}_{2}$ pellet can be idealized as a compact of many microspheres with the voids between interconnected and communicating with the free volume within the cladding. The radius of these spheres is taken as:

$$
a=\frac{3 d}{s},
$$

where

$a=$ radius of equivalent microsphere, $\mathrm{cm}$,

$\mathrm{d}$ = fraction of theoretical density,

$S=$ total surface area per unit volume $\left(\mathrm{cm}^{2} / \mathrm{cm}^{3}\right)$.

Thus, mathematical solutions of Fick's second law, ${ }^{37}$ with appropriate boundary conditions should represent the rate of diffusion of fission products from $\mathrm{UO}_{2}$.

The diffusion equation for a fission product produced at a constant rate at a constant temperature without radioactive decay is

$$
\frac{\partial C}{\partial t}=D\left(\frac{\partial^{2} C}{\partial r^{2}}+\frac{2}{r} \frac{\partial C}{\partial r}\right)+B,
$$

where

$\mathrm{C}=$ concentration of fission products as a function of radius and time, $r=$ radial position in sphere,

$t=$ time,

$D=$ diffusion coefficient,

$\mathrm{B}=$ rate of production. 
The solution for the fraction, $f$, of the given fission product released in time, $t$, is ${ }^{38}$

$$
f=1-\frac{6 a^{2}}{90 D t}+\frac{6}{\pi^{4} D t} \sum_{n-1}^{\infty} \frac{1}{n^{4}} \exp \left(-n^{2} \pi^{2} D t a^{2}\right) .
$$

For $f<0.57$, corresponding to values of the ratio

$$
\frac{\pi^{2} \mathrm{Dt}}{\mathrm{a}^{2}} \leqslant 1
$$

and the valuc of $f$ is given by the approximation

$$
f=4\left(\frac{D t}{\pi a^{2}}\right)^{1 / 2}-\frac{3 D t}{2 a^{2}} .
$$

Again, the second term is negligible for values of

$$
\frac{\pi^{2} D t}{a^{2}}<0.01
$$

For nonisothermal conditions, the pellet must be subdivided into radial zones of constant temperature and Eq. (B.8) must be applied for each zone. This is necessary because of the strong temperature dependence of the diffusion coefficient $D$, as expressed by

$$
D=D_{\text {ref }(T)} \exp (-Q / R T),
$$

where

$$
\begin{aligned}
D & =\text { the diffusion coefficient, } \\
D_{\text {ref }(T)} & =\text { the diffusion coefficient at a reference temperature, } \\
Q & =\text { activation cnergy, } \\
\mathrm{R} & =\text { gas constant, } \\
I & =\text { temperature, degrees absol.12te. }
\end{aligned}
$$

'I'he procedure, while tedisus, has been performed by Robertson and his co-workers, and their results are presented in Fig. B.3, which was taken from ref. 39. The data were obtained for a pellet surface temperature of $400^{\circ} \mathrm{C}$ and present fractional release of xenon as a function of 


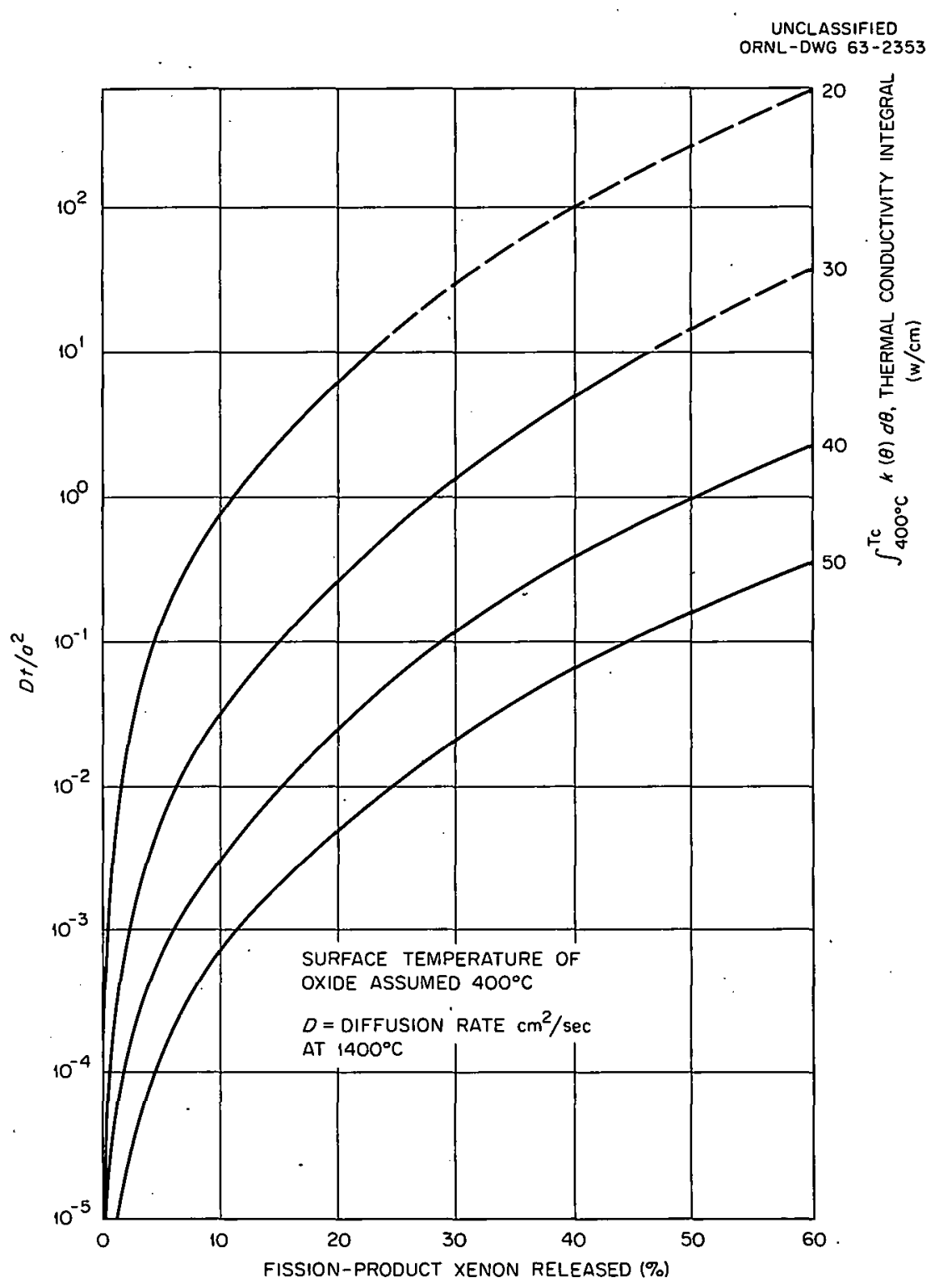

Fig. B.3. Fractional Release of Xenon in a Cylindrical $\mathrm{UO}_{2}$ Fuel Element as a Function of Thermal Rating, Time, and Diffusion Rate (Taken from ref. 39, Courtesy, American Institute of Mining, Metallurgical, and Petroleum Engineers, Inc.).

$\mathrm{D}_{1400^{\circ} \mathrm{C}}^{\prime}$ and $\int_{400^{\circ} \mathrm{C}}^{\mathrm{T} e} \mathrm{~K}(\mathrm{~T}) \mathrm{dT}$, where $\mathrm{D}_{1400^{\circ} \mathrm{C}}^{\prime}$ is the value of $\mathrm{D} / \mathrm{a}^{2}$ at $1400^{\circ} \mathrm{C}$, and $t$ is the time of irradiation. The data of Fig. B.3 were based on an activation energy of $46,000 \mathrm{cal} / \mathrm{g} \cdot \mathrm{mole}$, compared with the more commonly accepted value of $71,000 \mathrm{cal} / \mathrm{g} \cdot \mathrm{mole}{ }^{31}$ This difference had the effect of overestimating the release at temperatures below $1400^{\circ} \mathrm{C}$, and therefore gave a degree of conservatism to the data of Fig. B.3 when applied to the 
N.S. SAVANNAH reactor. The conductivity integral of the reactor was adjusted to the $400^{\circ} \mathrm{C}$ surface temperature condition for use with the data of Fig. B. 3 by the following relation:

$$
\int_{400^{\circ} \mathrm{C}}^{T_{C}} K(T) d T=\int_{432^{\circ} \mathrm{C}}^{T_{C}} K(T) d T+\int_{400^{\circ} \mathrm{C}}^{432^{\circ} \mathrm{C}} K(T) d T,
$$

where the last term can be found from Fig. B.2 as follows:

$$
\int_{400^{\circ} \mathrm{C}}^{432^{\circ} \mathrm{C}} \mathrm{K}(\mathrm{T}) \mathrm{dT}=\int_{100^{\circ} \mathrm{C}}^{432^{\circ} \mathrm{C}} \mathrm{K}(\mathrm{T}) \mathrm{dT}-\int_{100^{\circ} \mathrm{C}}^{400^{\circ} \mathrm{C}} \mathrm{K}(\mathrm{T}) \mathrm{dT} \text { : }
$$

Based on the conservative data of Hedge and Fieluhouse, ${ }^{36}$ this adds 1.2 w/cm to the N.S. SAVANNAH reactor value of $23.4 \mathrm{w} / \mathrm{cm}$, yielding

$$
\int_{400^{\circ} \mathrm{C}}^{\mathrm{T}} \mathrm{C}(\mathrm{T}) \mathrm{dT}=24.6 \mathrm{w} / \mathrm{cm}
$$

for use with the data of Fig. B.3. This procedure for correction to a $400^{\circ} \mathrm{C}$ surface temperature yields the correct central temperature but underestimates the surface temperature. Since the central portions of the pellet release by far the largest amounts of fission gas, this discrepancy is negligible.

'I'he value of $D_{1400^{\circ} \mathrm{C}}^{\prime}$ used was $2.8 \times 10^{-11} \mathrm{sec}^{-1}$ (ref. 40), as determined experimentally for N.S. SAVANNAH fuel, and t was $6.52 \times 10^{7} \mathrm{sec}$, based on full-power operation at $69 \mathrm{Mw}$ for a core life of 52,000 Mwd. Substituting these values and reading from Fig. B.3 yields a release value of approximately 2\% for the peak power pellet in the reactor. 'l'he release could have been mapped as a function of core power distribution, but for this core it was assumed that the whole core released the same fraction as the peak power pellet, thus giving a further degree of conservatism in the results.

\section{Pressure Buildup and Cladding Stress in Fuel Rod}

The fission gases that are released to open pores and thence to the free volumes within the fuel sheath contribute to the internal pressure. In calculating the steady-state pressure, it is necessary to include the 
effect of the higher temperature within the open pores in the pellets by a relationship of the form

$$
p=\frac{n R}{\int_{V_{i}} \frac{d V_{i}}{\mathrm{~T}_{i}}}
$$

where

$$
\begin{aligned}
\mathrm{p} & =\text { pressure } \\
\mathrm{n} & =\text { number of moles of fission gas released, } \\
\mathrm{R} & =\text { gas content, } \\
\mathrm{V}_{i} & =\text { volume of gas experiencing temperature } \mathrm{T}_{i} \cdot
\end{aligned}
$$

The temperature becomes essentially isothermal within a short time after the loss-of-coolant accident because of the leveling of the temperature profile caused by the decrease in heat generation and the removal rate. Thus it can be assumed that all the gas is at a uniform temperature at any given time after the accident.

The total pressure is the sum of the partial pressures of each nuclide :

$$
p_{t}=\sum_{i=1}^{n} p_{i}
$$

and

$$
p_{i}=\frac{n_{i} R T}{v}
$$

where

$$
\begin{aligned}
& n_{i}=\text { number of moles of element } i \\
& V=\text { open pore volume plus free volume. }
\end{aligned}
$$

The open pore volume was found to be approximately $7 \%$ of the pellet volume from Fig. B.4. Thus the total open porosity per rod would be $10.1 \mathrm{~cm}^{3}$, as found from

$$
\mathrm{V}=0.07\left[\frac{\mathrm{m}}{(0.91) \rho_{t d}}\right] \frac{\mathrm{I}}{\mathrm{N}},
$$




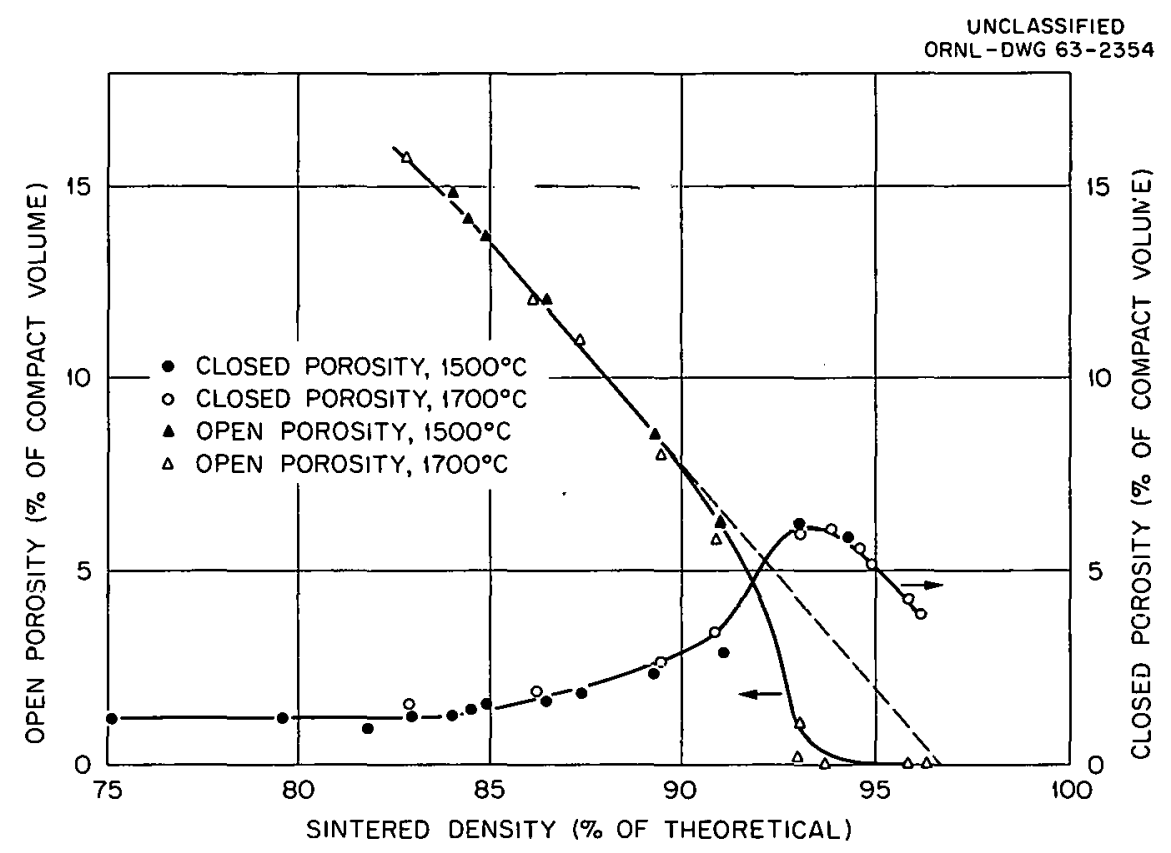

Fig. B.4. Porosity as a Function of Density for ADU Oxide Pressed to $65 \%$ of Theoretical Density and Sintered in Hydrogen (Taken from J. Belle and B. Lustman, pp. 442-515 in "Fuel Elements Conference, Paris," TID7546, Book 2, March 1958).

where

$$
\begin{aligned}
\mathrm{m} & =\text { mass of the fuel in the core }=7.555 \times 10^{6} \mathrm{~g}, \\
\rho_{\mathrm{ld}} & =\text { theoretical density, } \sim 10.97 \mathrm{~g} / \mathrm{cm}^{3}, \\
\mathrm{~N} & =\text { number of rods in the core }=5248 .
\end{aligned}
$$

'i'he free volume was taken from values given from ref. 41 for test fuel elements with the free volume increased by the clearance area times the length difference between the core fuel elements and the test element (27.5 in.), which yielded an additional free volume of $5.55 \mathrm{~cm}^{3}$. Thus the total free volume per rod was taken as $15.65 \mathrm{~cm}^{3}$ per rod.

The internal pressure in the highest power pin would therefore be

$$
p_{\text {tot }}=p_{h e}+p_{f p} \text {, }
$$

with

$$
p_{h e}=p_{f i l l} \frac{T}{T_{f i l l}} \text {, }
$$


and

$$
p_{f p}=\frac{\sum_{i=1}^{n} Y_{i} \text { Ff }}{6.02 \times 10^{23}} \frac{R T}{V_{t o t}}
$$

where

$$
\begin{aligned}
\mathrm{p}_{\text {he }}= & \text { partial pressure of helium fill gas, atm, } \\
\mathrm{p}_{\mathrm{fp}}= & \text { summed partial pressures of long-lived and stable fission } \\
& \text { gases, atm } \\
\mathrm{p}_{f i l l}= & \text { pressure of fill gas before operation, atm, } \\
\mathrm{T}_{\mathrm{fill}}= & \text { temperature of fill gas when rod was filled, }{ }^{\circ} \mathrm{K}, \\
\mathrm{T} & =\text { temperature of fuel element during transient, }{ }^{\circ} \mathrm{K}, \\
\mathrm{R} & =\text { gas constant, atm. } \mathrm{cm}^{3} / \mathrm{g} \cdot \mathrm{mole}, \\
\mathrm{Y} & =\text { yield of isotope } \mathrm{i}, \text { atoms per fission, } \\
\mathrm{F} & =\text { number of fissions during lifetime of core in central pin, } \\
\mathrm{f} & =\text { fraction of long-lived and stable 1sotopes released. } \\
\mathrm{The} & \text { following values were used in evaluating Eqs. (B.16), (B.17), }
\end{aligned}
$$
and (B.18):

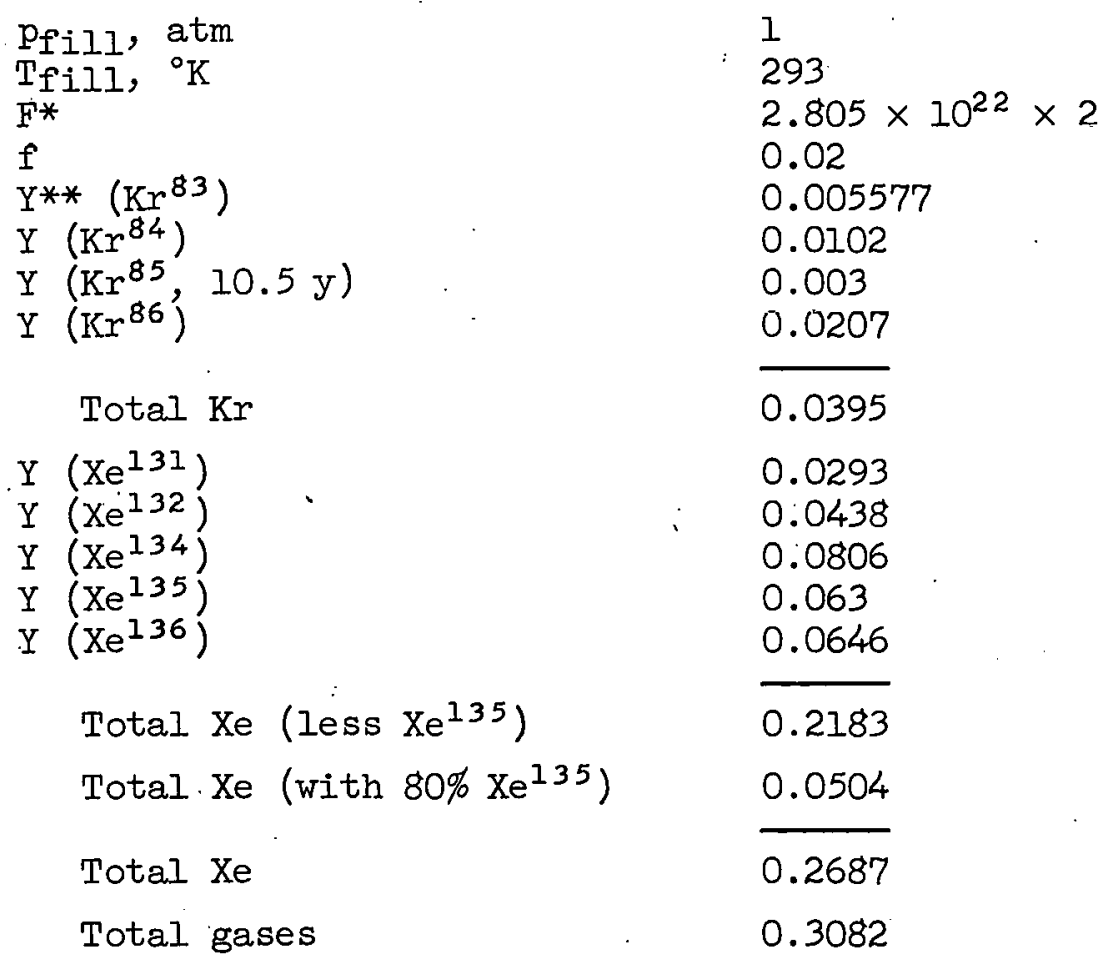

*The number of fissions for the central pin was taken as 2 times that of the average pin based on the radial peak-to-average flux distribution.

**Fractional yield values taken from refs. 42 and 43 . 


$$
\begin{array}{ll}
\mathrm{Y}\left(\mathrm{Rb}^{85}, \text { stable }\right) & 0.012 \\
\mathrm{Y}\left(\mathrm{Rb}^{87}, 6.2 \times 10^{10} \mathrm{y}\right) & \underline{0.027} \\
\text { Total. Rb } & 0.039 \\
\mathrm{Y}\left(\mathrm{I}^{127}\right) & 0.0025 \\
\mathrm{Y}\left(\mathrm{I}^{129}\right) & \underline{0.0100} \\
\text { Total I } & 0.0125 \\
\mathrm{Y}\left(\mathrm{Cs}^{133}\right) & 0.065 \\
\mathrm{Y}\left(\mathrm{Cs}^{135}\right) & 0.062 \\
\mathrm{Y}\left(\mathrm{Cs}^{137}\right) & \underline{0.059} \\
\text { Total Cs } & 0.186
\end{array}
$$

The contributions of iodine, rubidum, and cesium were considered at temperatures above their respective boiling points. The results are shown in Fig. B. 5 converted to units of pressure and temperature.

The cladding stress as a function of temperature was determined by taking the results derived above and presented in Fig. B.5 and using them

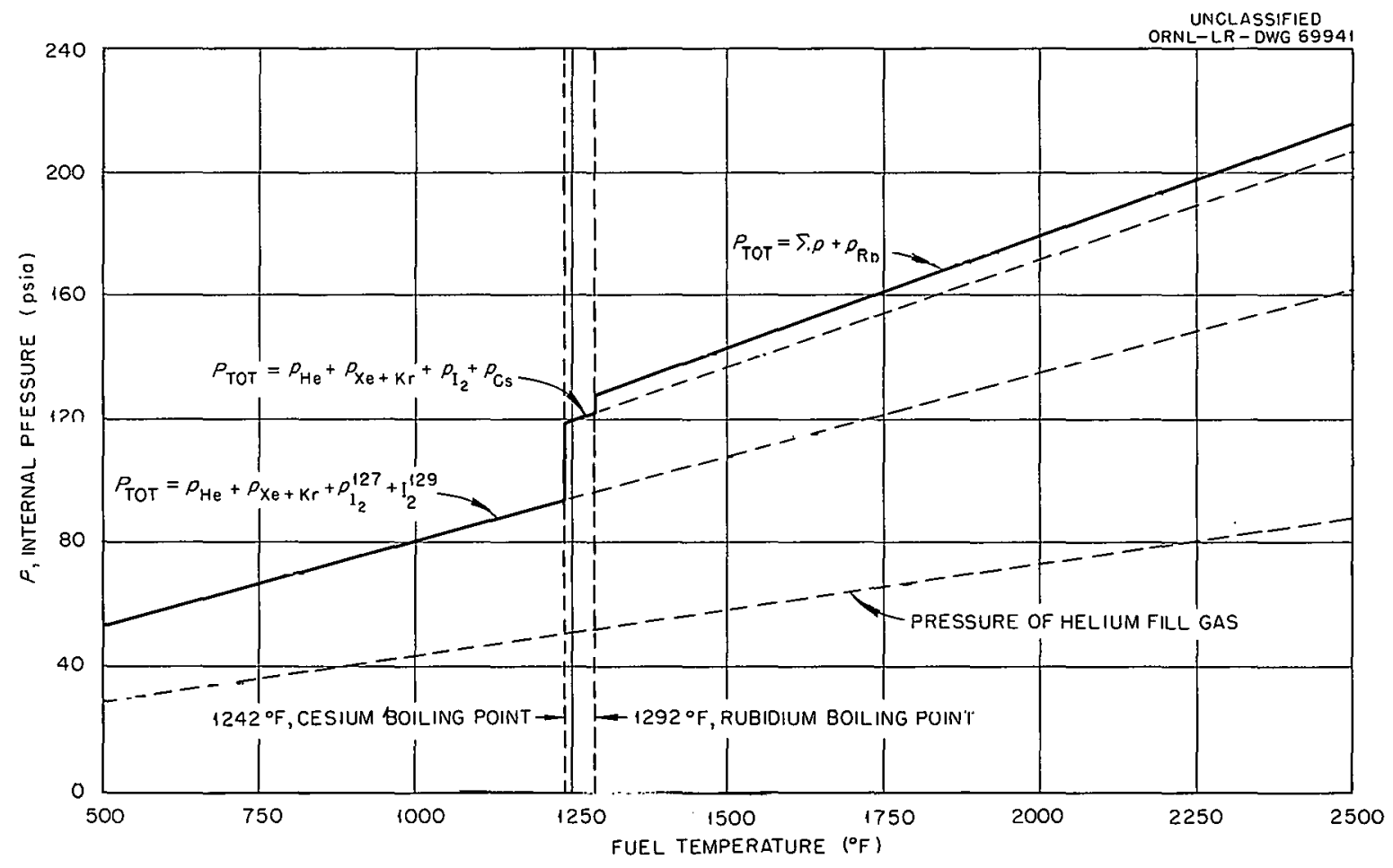

Fig. B.5. Internal Pressurè in Peak Power Fuel Pin vs Temperature Based on 2\% Rare Gas Release and $2 \% \mathrm{Cs}$, I, Rb Reledse, with End of Core Life at 52,000 Mwd of operation at $69 \mathrm{Mw}$. 
to calculate the tangential cladding stress, as follows:

$$
\sigma_{t}=\frac{\Delta \mathrm{P} \mathrm{d}}{2 \mathrm{t}}
$$

where

$$
\begin{aligned}
\sigma_{t} & =\text { tangential cladding stress, psi, } \\
\Delta P & =\text { pressure differential across cladding }\left(p_{\text {internal }}-p_{\text {ambient }}\right), \text { psi } \\
d & =\text { inside diameter of cladding, } 0.430 \mathrm{in.}, \\
t & =\text { thickness of cladding, } 0.035 \mathrm{in} .
\end{aligned}
$$

Substitution of the above values into Eq. (B.19) yielded

$$
\sigma_{\mathrm{t}}=6.15 \Delta \mathrm{P} \text {. }
$$

Computations were made using the internal pressures given in Fig. B.5 and an assumed ambient pressure of 14.7 psia. The results are shown in Fig. B.6.

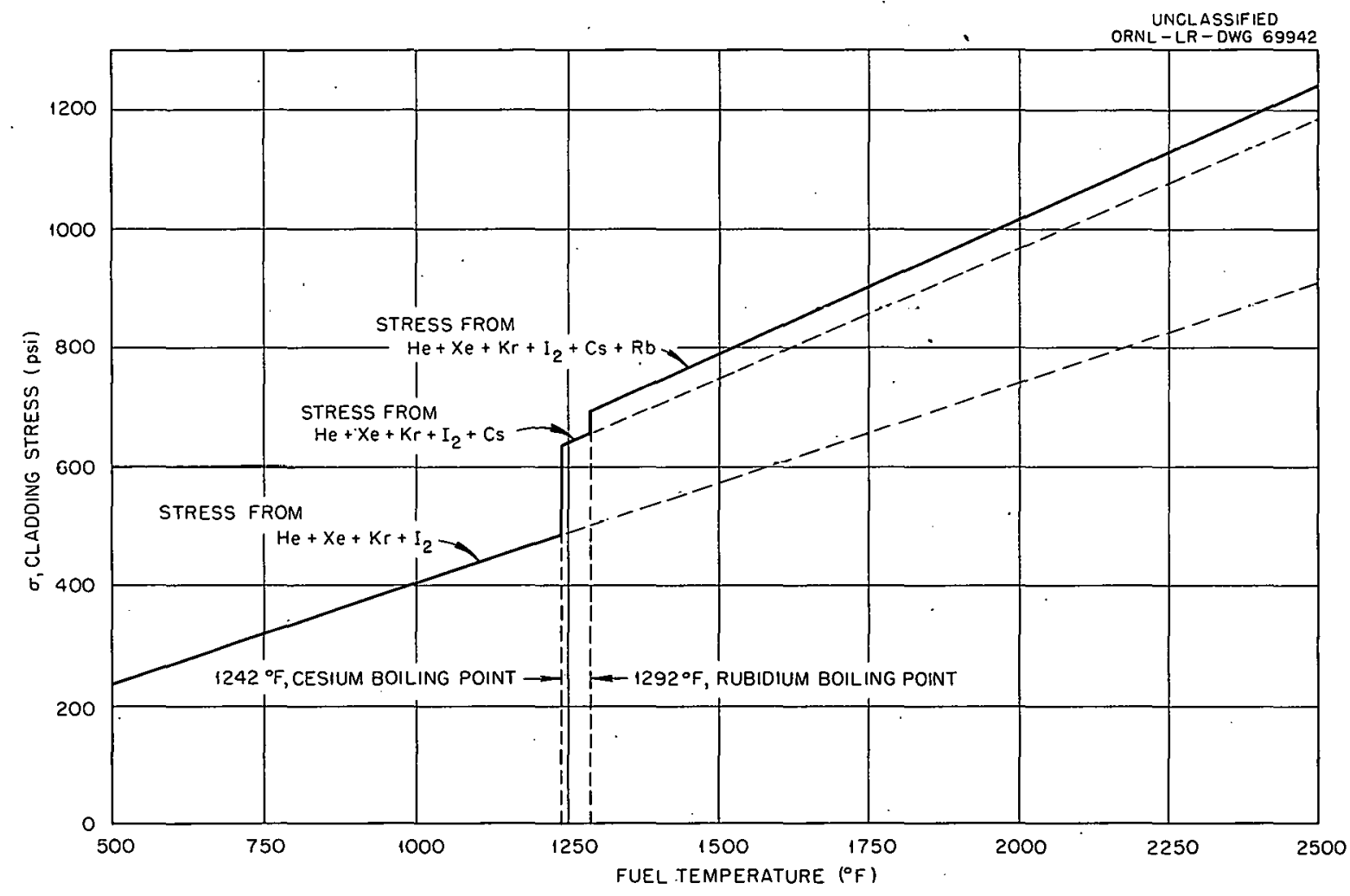

Fig. B.6. Tangential Cladding Stress in Peak Power Fuel Pin at 14.7-psia Ambient Pressure from $2 \%$ Release of $\mathrm{Xe}, \mathrm{Kr}, \mathrm{I}^{127}+\mathrm{I}^{129}, \mathrm{Cs}$, and $\mathrm{Rb}$, with End of Core Life at 52,000 Mwd of Operation at $69 \mathrm{Mw}$. 
Fuel Element Failure Criterion

The tangential stress vs time to rupture, as determined in experiments performed at the Oak Ridge National Laboratory with type 304 stainless steel, 44 is shown in Fig. B.7. The highest temperature data available show that at $2200^{\circ} \mathrm{F}$ and a cladding stress of 1100 psi (obtained from Fig. B.6), the time to failure is $2880 \mathrm{sec}$. Since the cladding temperature would be rising at the rate of $2^{\circ} \mathrm{F} / \mathrm{sec}$, it would attain a temperature of $2200^{\circ} \mathrm{F}$ within $1000 \mathrm{sec}$ after the accident. A temperature of $2550^{\circ} \mathrm{F}$ would be reached in an additional $175 \mathrm{sec}$. It is apparent that the cladding would not fail before it reached $2200^{\circ} \mathrm{F}$, but it might fail at any time after that. It can be concluded that the use of the original Babcock \& Wilcox data for the fraction of core fuel elements reaching $2550^{\circ} \mathrm{F}$ as a function of time does not overestimate the time to failure for any given fuel element by more than $175 \mathrm{sec}$. Since this period is small compared with the time values in other parts of this analysis, the cladding was considered to fail upon reaching a temperature of $2550^{\circ} \mathrm{F}$. This analysis permitted the use in the present hazard calculation of the original

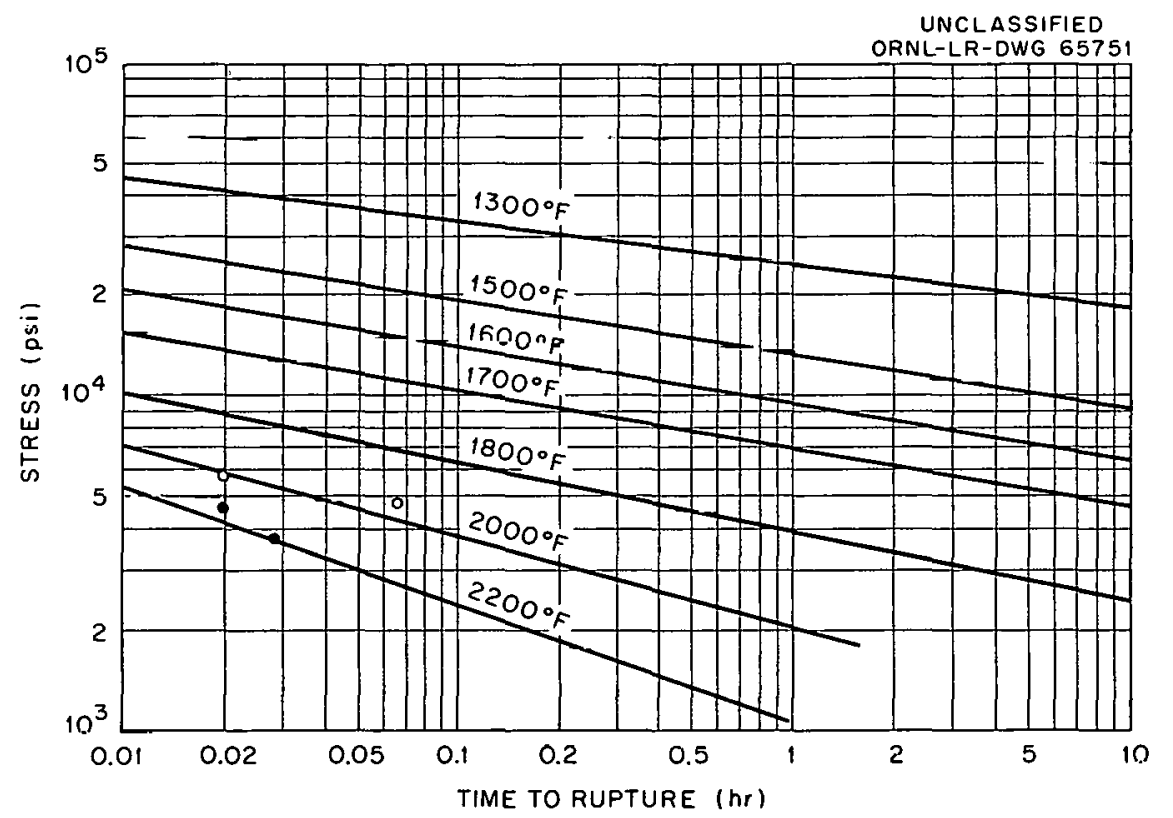
Tubing.

Fig. B.7. Stress Rupture Properties of Type 304 Stainless Steel 
Babcock \& Wilcox data presented in Fig. B.8, which shows the time required to attain $2550^{\circ} \mathrm{F}$ at increasing core radii.

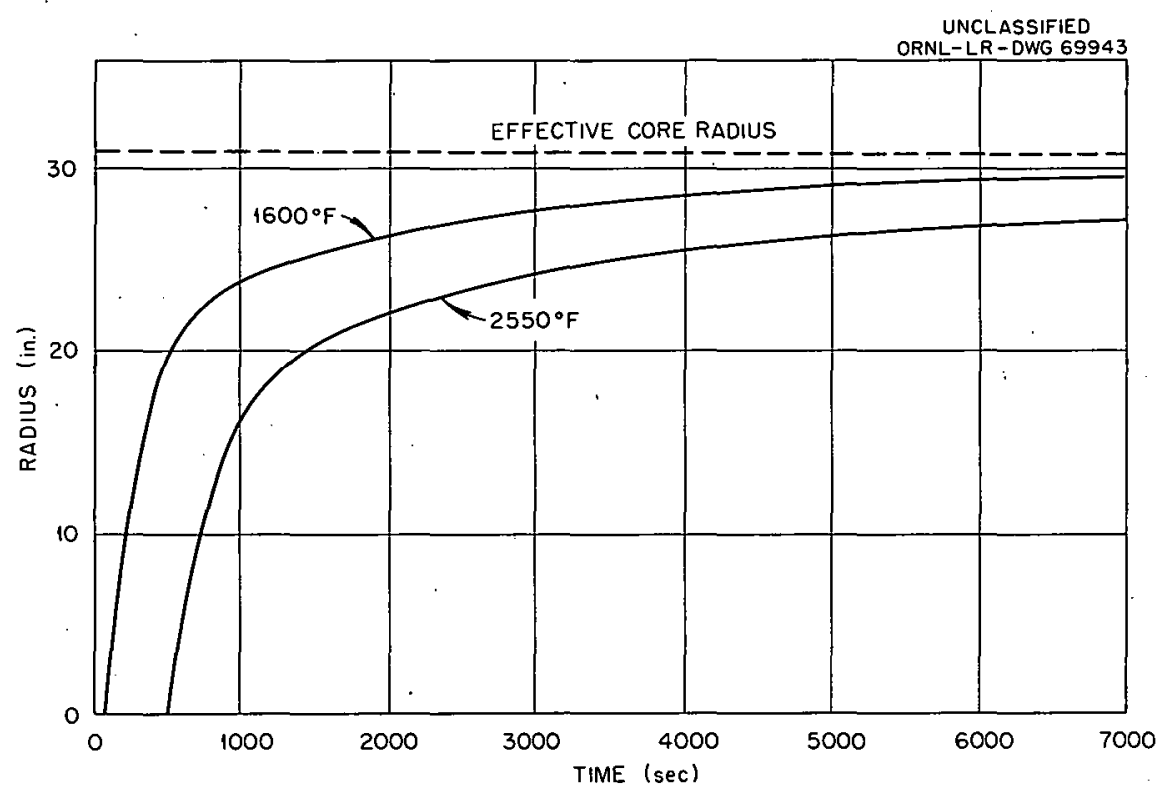

Fig. B.8. Time Variation of Radial Temperature Distribution in Reactor Following Loss-of-Coolant Accident. 


\section{Appendix C}

COMPARISON OF ACTUAL AND SYNTHESIZED DECAY CHAINS 43,45
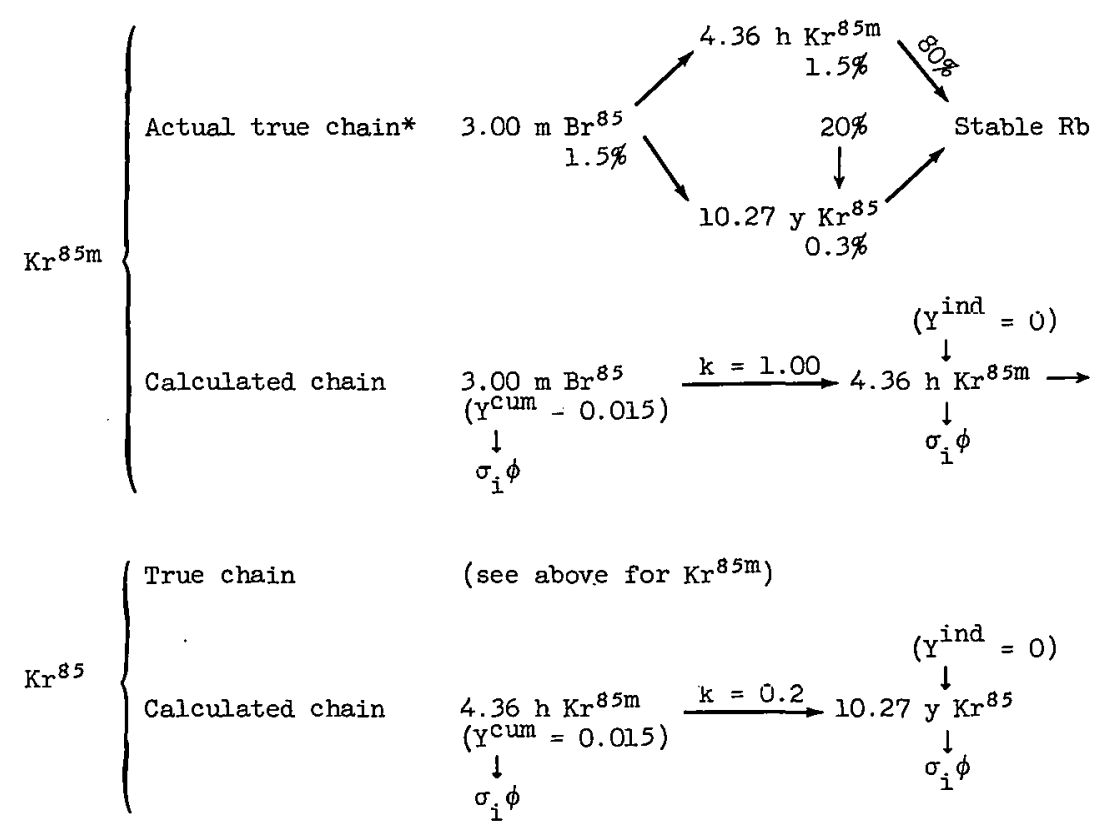

(see above for $\mathrm{Kr}^{85 \mathrm{~m}}$ )
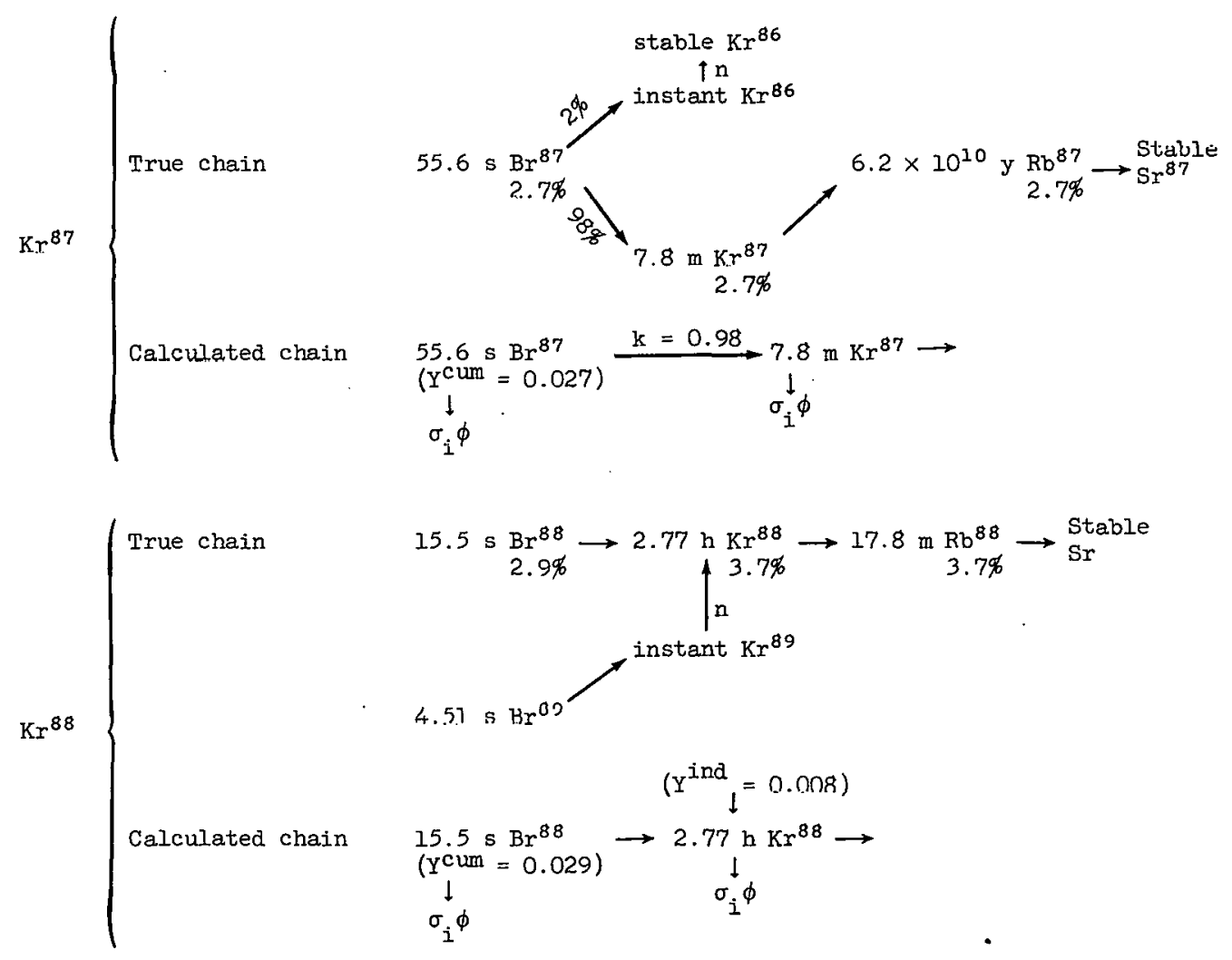

*Tho numbers unarer the nusilides refer to cumulative yield in per cent. 


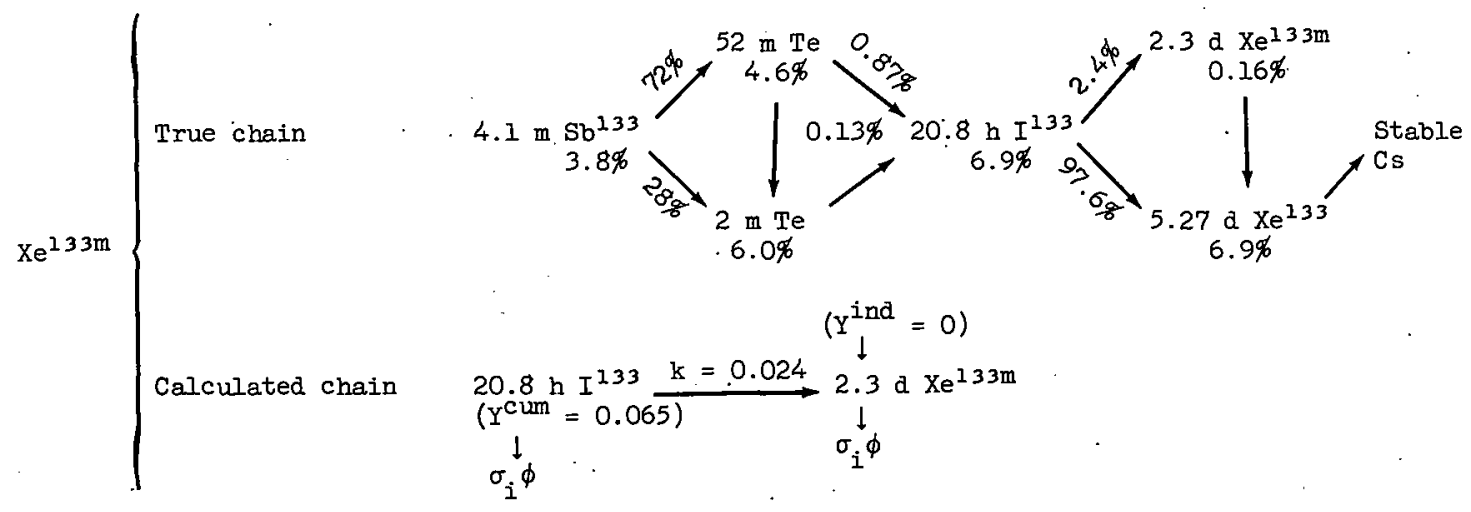

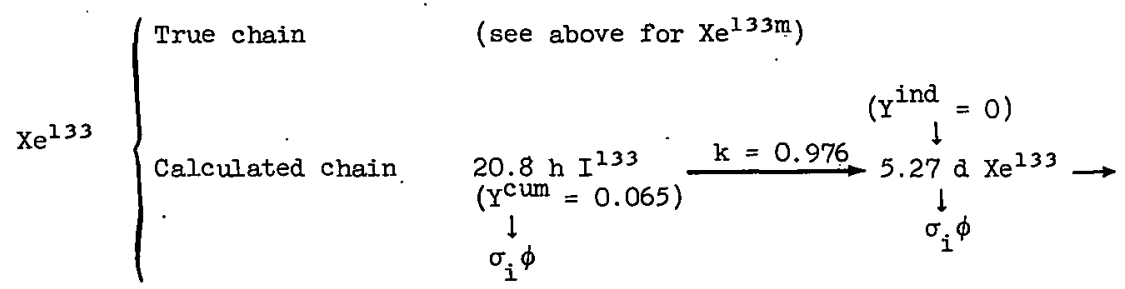

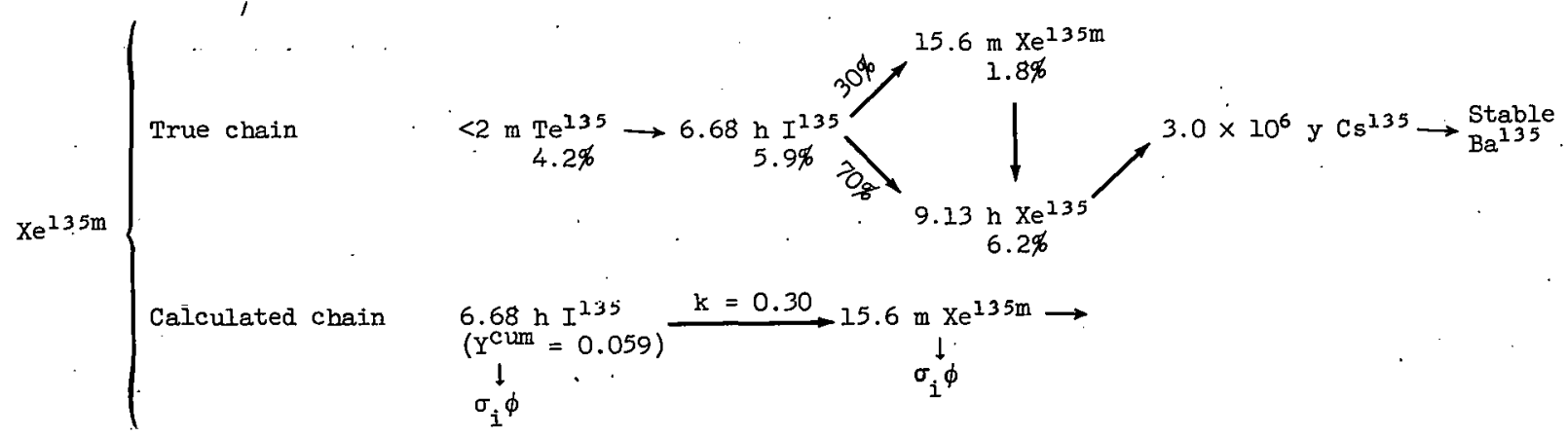

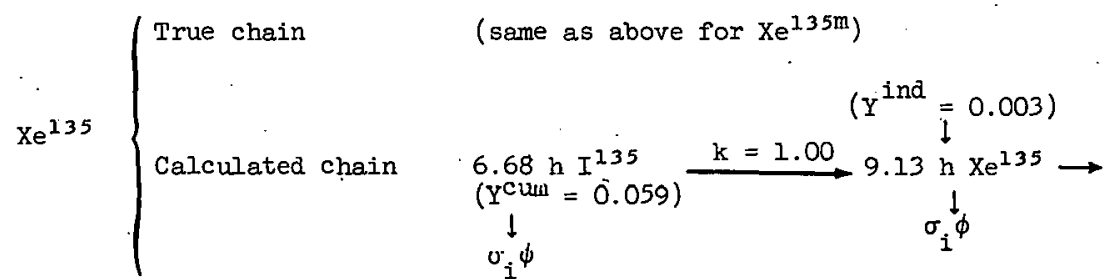

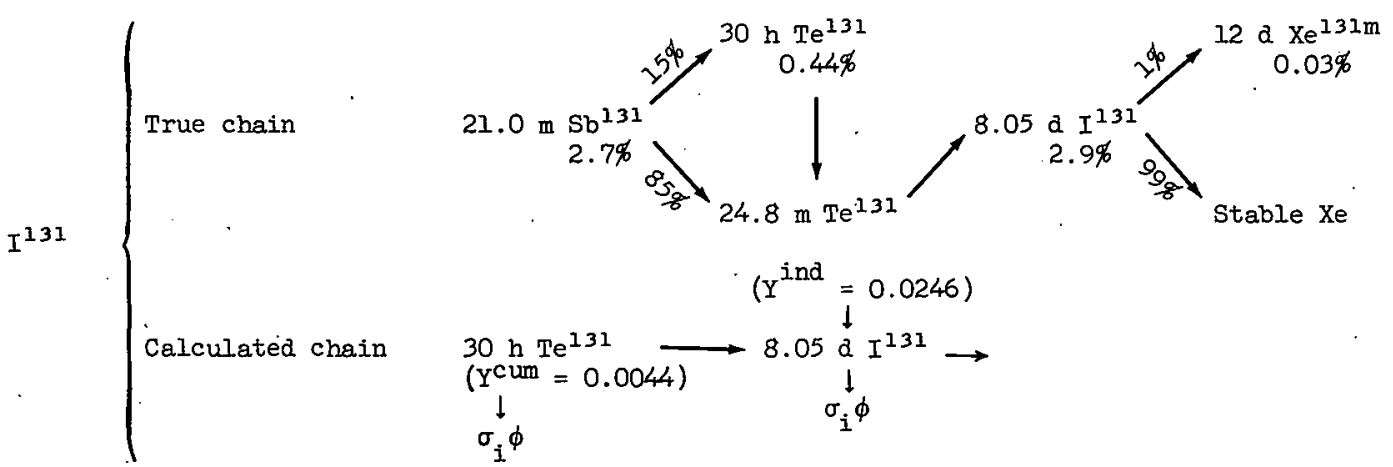




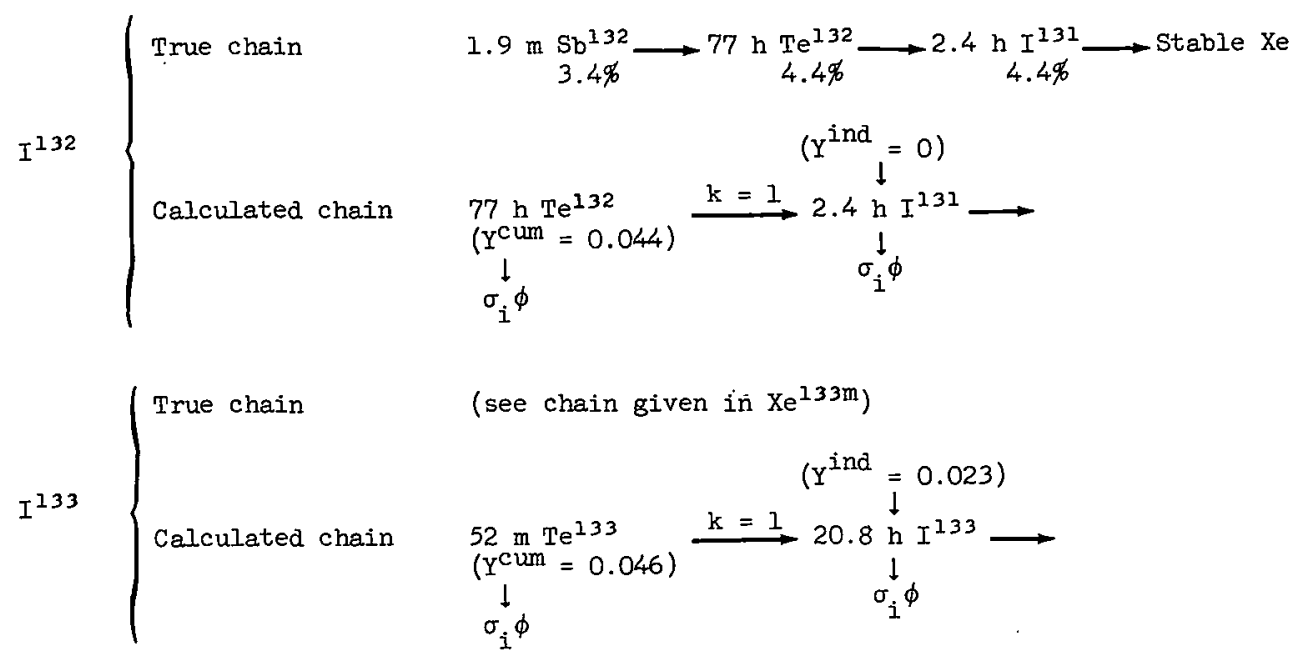

In the $\mathrm{Xe}^{135}$ case the delay of $15.6 \mathrm{~m} \mathrm{Xe}^{135 \mathrm{~m}}$ is negligible compared with $6.68 \mathrm{~h} \mathrm{I}^{135}$, and therefore the branching ratio from $\mathrm{I}^{135}$ to $\mathrm{Xe}^{135}$ was taken as one. Also, the simplification to the one precursor model for the $I^{131}$ concentration in the first hour or so after the beginning of the transient results in an overestimate of the $I^{131}$ concentration. Further, $\mathrm{Xe} \mathrm{e}^{133 \mathrm{~m}}$ and $\mathrm{Xe}^{133}$ are overestimated slightly in the first several hours after the accident because of the effects of the $52 \mathrm{~m} \mathrm{Te}$ calculating $\mathrm{I}^{133}$, it is assumed that the $52 \mathrm{~m} \mathrm{Te}^{133 \mathrm{~m}}$ is the parent, and the other effects are treated as direct fission yields. As may be seen, no great errors are introduced by these simplifications for time periods in excess of 1 or $2 \mathrm{hr}$, and errors in the affected nuclides in the shorter time periods are on the conservative (overestimated) side. 


\section{Appendix D}

BUILDUP OF ACTIVITY IN REACTOR COMPARTMENT

The concentration of activity (neglecting decay) in the reactor compartment approaches an equilibrium value in a manner uniquely determined by the compartment volume and, assuming uniform mixing, its ventilation. The time at which the compartment will be at any given fraction of the equilibrium concentration will be independent of the activity inleakage, although, of course, the absolute value will not. The differential equation for the concentration is

$$
\mathrm{W} d \mathrm{Q}=\mathrm{aR} d t-\mathrm{QV} d t,
$$

where

$$
\begin{aligned}
& \mathrm{W}=\text { compartment volume, } \mathrm{ft}^{3}, \\
& \mathrm{Q}=\text { activity concentration, } \mu \mathrm{c} / \mathrm{ft}^{3}, \\
& \mathrm{Q}=\text { activity in containment vessel, curies; } \\
& \mathrm{R}=\text { leakage rate, } \% / \mathrm{day}, \\
& \mathrm{V}=\text { ventilation rate, } \mathrm{ft}^{3} / \mathrm{min}, \\
& \mathrm{t}=\text { time, min. }
\end{aligned}
$$

This equation was differentiated and the results were expressed in terms of the percentage of the equilibrium concentration. The data thus obtained are plotted in Fig. D.I to show the effect of reactor compartment holdup. 
UNCLASSIFIED

ORNL-DWG 63-2355

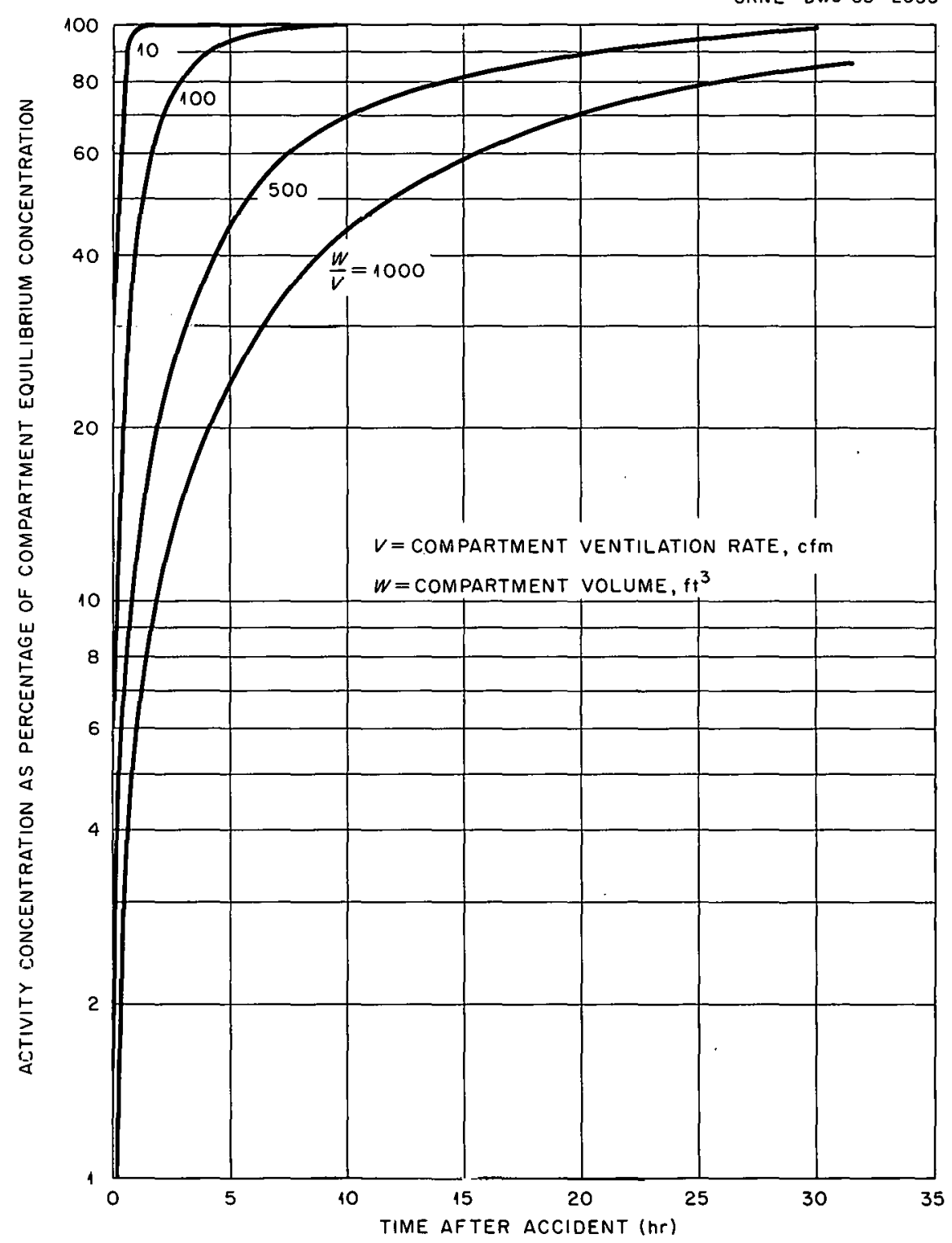

Fig. D.1. Reactor Compartment Holdup Effect as a Function of Compartment Volume and Ventilation Flow Rate. 


\section{Appendix E}

POPULATION EXPOSURE AROUND NEW YORK HARBOR

Population exposures resulting from atmospheric dispersion of radioactivity from ground-level release during inversion conditions following a maximum credible accident on the N.S. SAVANNAH were calculated for the harbor of New York City. The operating history prior to the accident was assumed to be that of case 2, that is, $100 \%$ power for infinite time followed by $50 \%$ power for $5 \mathrm{hr}$. A meltdown incident was evaluated under each of two conditions of ventilation of the reactor compartment, that is, normal and emergency. These and other controlling conditions during the accident are described below:

Iodine released - 25\%, with $50 \%$ of remainder held by fuel and $50 \%$ deposited in the containment vessel

Noble gases released - 100\%

Solids - Since the fuel was assumed to hold $99 \%$ of the solids and the effluent from the reactor compartment is filtered, the contribution of solid fission products was low enough to be neglected in calculations of submersion doses.

Primary container Leakage - $1.5 \%$ per day

Compartment ventilation system exhaust rates

Normal system - $4000 \mathrm{cfm}$

Emergency system - $2000 \mathrm{cfm}, 1800 \mathrm{cfm}$ of this dilution air

Ventilation filtration efficiencies for iodine

Normal system - 90\%

Emergency system - 99\%

Release - ground level and point source, as in Section 6

It was assumed that the N.S. SAVANNAH was berthed in New York Harbor at either pier 84 or pier 86 in the Hudson River. If the wind carried radioactivity in the most direct path to the public on Manhattan Island, the distance traveled to the nearest uncontrolled area would be about $650 \mathrm{ft}$. For the purposes of determining total population exposures, this was the distance used. Overall, the plume was assumed to travel in a north-easterly direction so that it would remain over densely populated areas. It would travel over Harlem, the Bronx, and along the Connecticut 
coast through Bridgeport. A total downwind distance of 60 miles was considered in estimating the population exposures.

Results of the incident evaluations are presented in Figs. E.I through E.3. The first figure gives total integrated submersion doses during the first day after the accident. The different modes of activity release are described below:

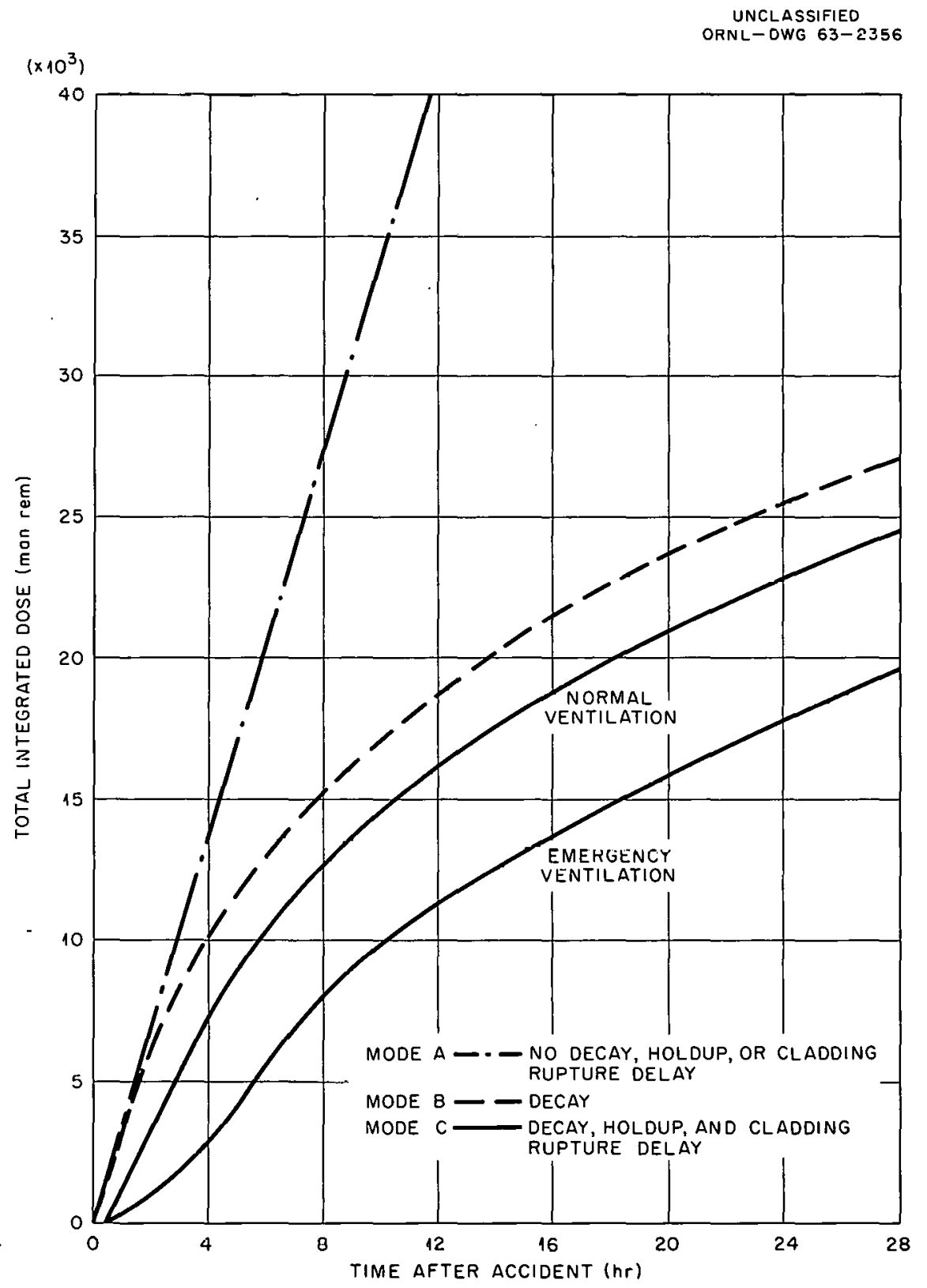

M1g. E.1. Trtal Tntegraten Submersion Dose for Case 2 at New York. 


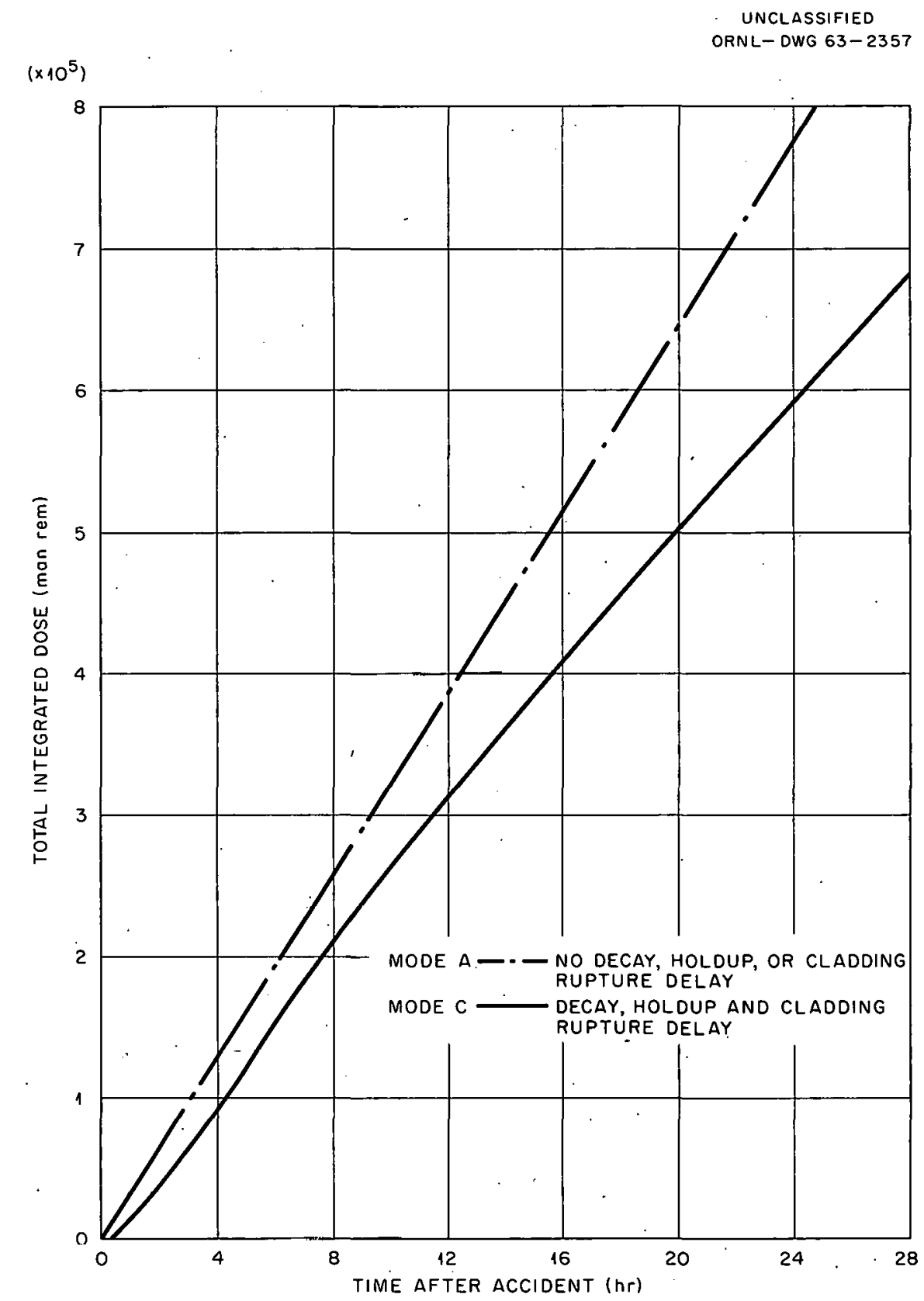

Fig. E.2. Total Integrated Thyroid Dose for Case 2 with Normal Ventilation at New York.

Mode A is based on continuous equilibrium activity release from the containment system commencing at the instant of the accident. Fission-product decay after the accident, the time required for the fuel elements to heat up and fail, and the holdup time provided by the reactor compartment were ignored. 


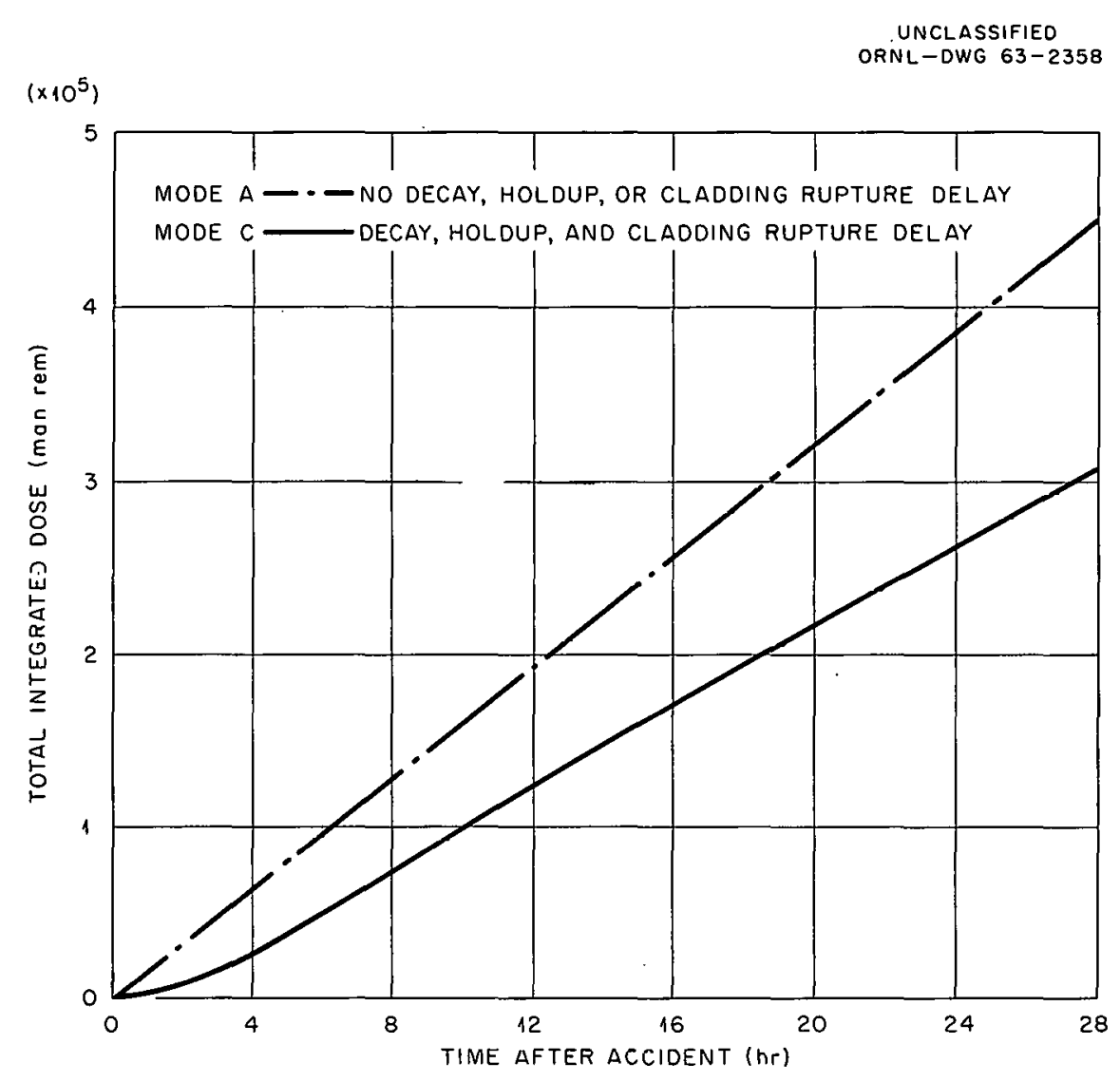

Fig. E.3. Total Integrated Thyroid Dose for Case 2 with Emergency Ventilation at New York.

Mode $B$ is identical to mode A except that the decay of fission pro. ducts between the instant of the accident and the time they were released from the compartment to enter the atmosphere was included. This assumption is suill somewhat concervative, since it, ignores the decay during the time required for the activity to travel from the ship to the exposed personnel.

Mode $C$ includes, in addition to fission-product decay as in mode $B$, the time required for the fuel elements to fail and the holdup of the ventilation system. Of the various modes considered, this one is thought to be closest to real accident conditions. Mode $\mathrm{C}$ calculations were made for both the normal ventilation system and for the emergency system. 
Exposure information available from the Figs. E.1, E.2, and E.3 are assembled in Table E.l for time intervals of 2, 4, 8, and $24 \mathrm{hr}$ after the accident.

Calculation Method

The atmospheric dispersion of radioactivity from ground-level release was calculated from Sutton's equation:

$$
\frac{X}{Q}=\frac{2}{\pi C_{y} C_{z} \bar{U} x^{2-n}} \exp \left(-\frac{y^{2}}{C_{y}^{2} x^{2-n}}\right)
$$

The meanings of the symbols are given in Table E.2. The release was assumed to take place during a nighttime inversion, the period of poorest atmospheric dilution. The corresponding atmospheric parameters are listed in Table E.3. Isopleths for these conditions are shown in Figs. E.4 and E.5. The fission-product inventory considered was that given in Table 1 of section 4.

\section{Submersion Exposures}

The individual total integrated submersion dose in rems was estimated. from the following expression, which was adapted from report ORNL-2867:4

$$
\operatorname{TID}=9.4 \times 10^{-4} \frac{X}{Q} \int_{0}^{t} E_{\gamma} Q d t
$$

For mode $A, E_{\gamma}$ is the effective gamma energy in Mev per disintegration, $Q$ is the source strength in microcuries, and t. is the exposure time in hours. The $\mathrm{E}_{\gamma}$ value was taken as $0.01 \mathrm{l} \mathrm{Mev,} \mathrm{since} \mathrm{the} \mathrm{noble} \mathrm{gas}$ activity predominates under the assumed release conditions. The integral $\int_{0}^{t} E_{\gamma} Q d t$ was assumed to equal $E_{\gamma} Q t$, since the source strength and effective gamma strength were assumed to be constant. The individual dose for any given geographical area was determined by taking the appropriate $X / Q$ factor from Figs. E. 4 and E. 5 and multiplying it by the amount of activity released in microcuries determined from the product of $9.4 \times 10^{-4} \mathrm{E}_{\gamma} \mathrm{Qt}$. The lowest individual exposure considered was 
Table E.1. Total Integrated Doses for Case 2 at NeW York

\begin{tabular}{|c|c|c|c|c|c|c|c|}
\hline \multirow{3}{*}{$\begin{array}{l}\text { Time } \\
\text { After } \\
\text { Accident } \\
\text { (hr) }\end{array}$} & \multicolumn{3}{|c|}{ Submersion Doses (man rem) } & \multicolumn{4}{|c|}{ Thyroid Doses (may rem) } \\
\hline & \multirow{2}{*}{$\begin{array}{l}\text { No Decay, } \\
\text { Holdup, or } \\
\text { Cladding } \\
\text { Rupture } \\
\text { Delay }\end{array}$} & \multicolumn{2}{|c|}{$\begin{array}{l}\text { Decay, Holdup, and Clad- } \\
\text { ding Rup-ure Considered }\end{array}$} & \multicolumn{2}{|c|}{ Normal Ventilation } & \multicolumn{2}{|c|}{ Emergency Ventilation } \\
\hline & & $\begin{array}{l}\text { Normal } \\
\text { Ventilation }\end{array}$ & $\begin{array}{l}\text { Emergency } \\
\text { Ventilation }\end{array}$ & $\begin{array}{l}\text { No Decay, } \\
\text { Holdup, or } \\
\text { Cladding } \\
\text { Rupture } \\
\text { Delay }\end{array}$ & $\begin{array}{c}\text { Decay, Holdup, } \\
\text { and Cladding } \\
\text { Rupture } \\
\text { Considered }\end{array}$ & $\begin{array}{l}\text { No Decay, } \\
\text { Holdup, or } \\
\text { Cladding } \\
\text { Rupture } \\
\text { Delay }\end{array}$ & $\begin{array}{l}\text { Decay, Holdup, } \\
\text { and Cladding } \\
\text { Rupture } \\
\text { Delay } \\
\text { Considered }\end{array}$ \\
\hline 2 & 6,800 & $3,2 \mathrm{CO}$ & 950 & 64,000 & 36,000 & 31,000 & 8,000 \\
\hline 4 & 13,700 & 7,200 & 2,900 & 128,000 & 90,000 & 64,000 & 27,000 \\
\hline 8 & 27,500 & 12,700 & 8,000 & 256,000 & 209,000 & 128,000 & 74,000 \\
\hline 24 & 82,500 & 22,800 & 17,800 & 768,000 & 580,000 & 385,000 & 262,000 \\
\hline
\end{tabular}


Table E.2. Nomenclature

\begin{tabular}{|c|c|c|}
\hline Symbol & Definition & Units \\
\hline $\mathrm{C}_{\mathrm{y}}, \mathrm{C}_{\mathrm{z}}$ & $\begin{array}{l}\text { Diffusion coefficients in the } \mathrm{y} \text { and } \\
\mathrm{z} \text { planes, respectively }\end{array}$ & $\mathrm{m}^{\mathrm{n} / 2}$ \\
\hline $\mathrm{n}$ & $\begin{array}{l}\text { Parameter associated with meteoro- } \\
\text { logical stability }\end{array}$ & Dimensionless \\
\hline \multirow[t]{2}{*}{ Q } & Source strength. as total or rate & \\
\hline & $\begin{array}{l}\text { 1. Instantaneous source } \\
\text { strength, total }\end{array}$ & curies \\
\hline 1 & $\begin{array}{l}\text { 2. Continuous point source } \\
\text { emission rate }\end{array}$ & curies/sec \\
\hline$t$ & Time & sec \\
\hline$\overline{\mathrm{U}}$ & Mean wind velocity & $\mathrm{m} / \mathrm{sec}$ \\
\hline $\mathrm{x}$ & $\begin{array}{l}\text { Distance directly downwind from } \\
\text { source }\end{array}$ & $\mathrm{m}$ \\
\hline $\mathrm{y}$ & $\begin{array}{l}\text { Distance horizontal distance nor- } \\
\text { mal to } \mathrm{x}\end{array}$ & $\mathrm{m}$ \\
\hline $\mathrm{z}$ & $\begin{array}{l}\text { Vertical distance from ground level } \\
\text { (as to center of radioactive } \\
\text { cloud or to source, etc.) }\end{array}$ & $\mathrm{m}$ \\
\hline$x$ & Concentration & $\begin{array}{l}\text { curies } / \mathrm{m}^{3} \text { or } \\
\text { curies } \cdot \mathrm{m}^{-3} \cdot \mathrm{sec}^{-1}\end{array}$ \\
\hline
\end{tabular}

Table E.3. Atmospheric Parameters for Nighttime Inversion

\begin{tabular}{ll}
\hline Site & New York City \\
Windspeed, $\overline{\mathrm{U}}(\mathrm{m} / \mathrm{sec})$ & 1.64 \\
Diffusion coefficient, $\mathrm{C}_{\mathrm{y}}$ & 0.19 \\
Diffusion coefficient, $\mathrm{C}_{\mathrm{z}} \cdot$ & 0.09 \\
Stability parameter, $\mathrm{n}$ & 0.5 \\
\hline
\end{tabular}




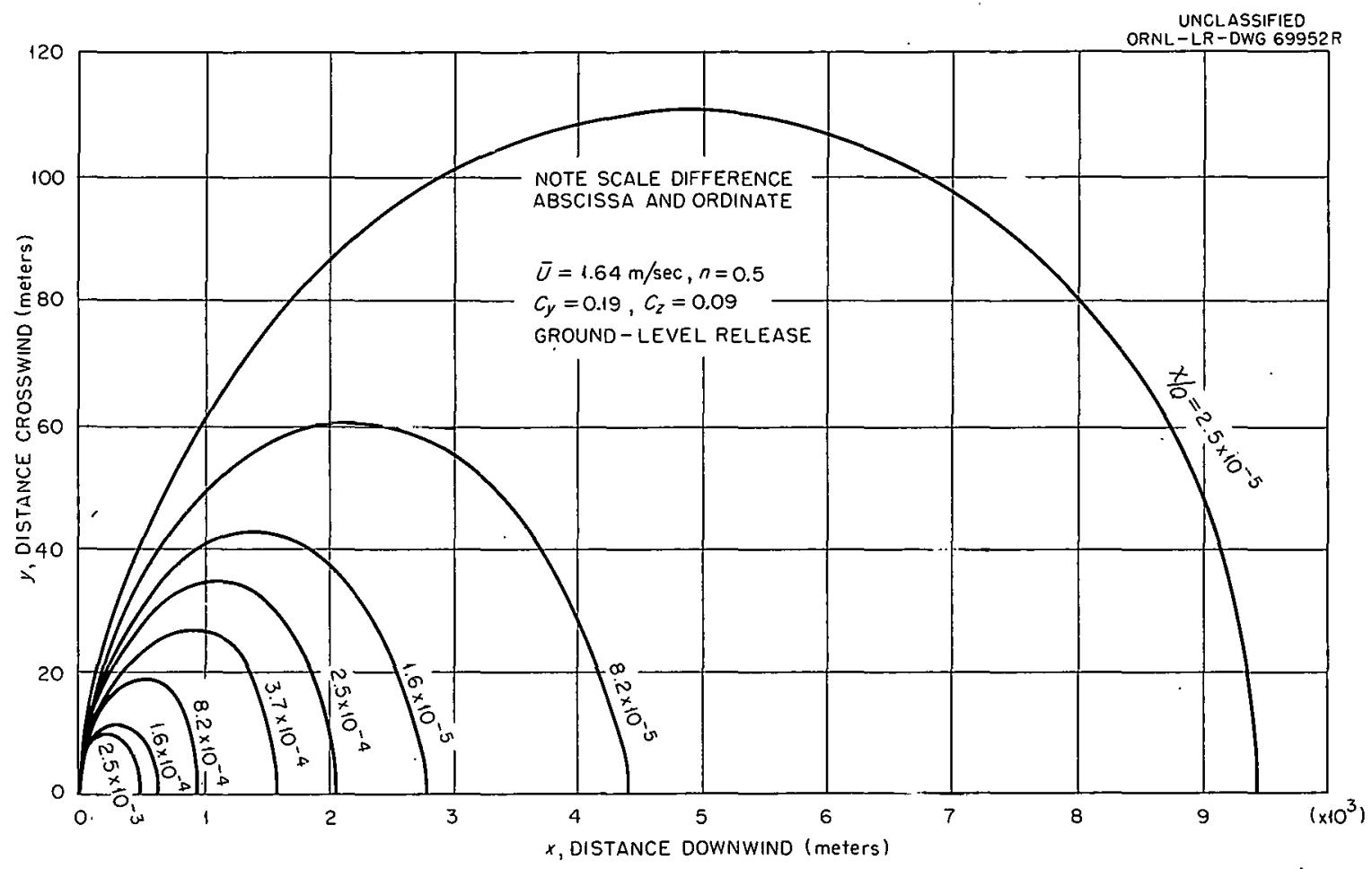

Fig. E.4. Isopleths for Typical Inversion Conditions at New York.

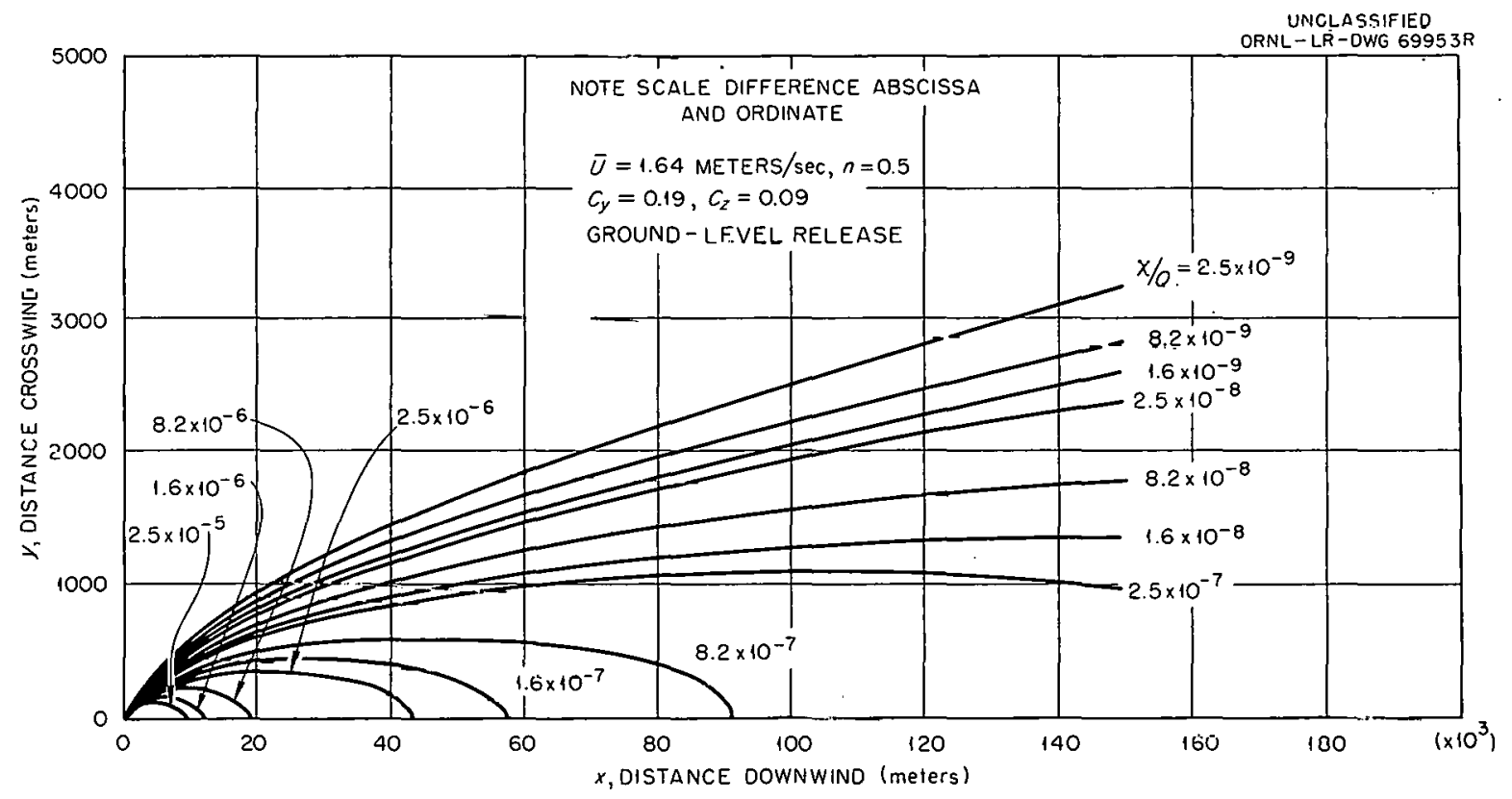

Fig. E.5. Isoplethe for Typical Inversion Conditions at New York. 
0.005 rem. Population submersion exposures were obtained by multiplying the individual exposure by the population density for each given geographical area.

For mode $B$,

$$
\mathrm{TID}_{\text {mode } \mathrm{B}}=\mathrm{TID} \text { mode } \mathrm{A} \frac{1}{\mathrm{t}} \int_{0}^{\mathrm{t}}\left(\begin{array}{r}
\text { fraction of reference } \\
\text { energy release rate }
\end{array}\right) d t \text {. }
$$

The fractions of reference energy release rate were obtained from Fig. 5, where the fraction of reference energy release rate is

$$
\frac{\left[\Sigma E_{\gamma} Q(t)\right]}{\left[\Sigma E_{\gamma} Q(0)\right]}
$$

Exposures during the first $24 \mathrm{hr}$ following the accident were computed.

For mode $\mathrm{C}$,

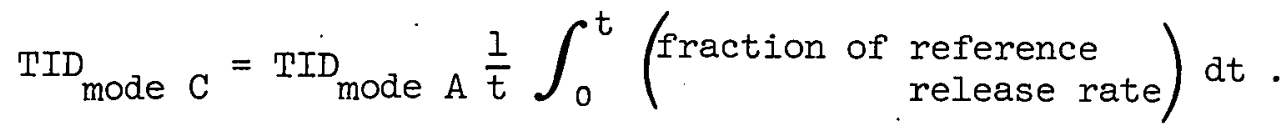

The fraction of the reference release rate was obtained from Figs. 14 and 15. Again, exposures during the first $2 / \mathrm{hr}$ filluwing the accident were computed.

\section{Thyroid Exposure}

The total integrated dose per person due to inhalation of any given isotope during a period $t$ is given by:

$$
\operatorname{TID}=\mathrm{DBR} \frac{\chi}{Q} \int_{0}^{t} Q d t
$$

as adapted from report ORNL-2867.4

For mode $A$, the continuous source strength, $Q$, released to the atmosphere in curies per second is constant, so $\int_{0}^{t} Q d t=Q t$. Values of $Q$ for iodine were taken from Table 1 and adjusted to account for filtering, containment leak rate, plateout, and retention in the fuel; $t$ is the exposure time in seconds; and $D$ is the exposure from the intake of 
I $\mu c$ of iodine. Values for D were taken from ref. 46 and revised according to the report of committee II on permissible dose for internal radiation. 47 Values of $D$ for the isotopes important to the thyroid are listed in Table E.4. The term BR is the breathing rate, which was taken as $500 \mathrm{~cm}^{3} / \mathrm{sec}$. Values of $X / Q$ were chosen, as before, for a particular geographical area. Population density information was then applied to yield total thyroid exposures to individuals.

For mode B, thyroid exposures were not calculated. The effect of fission-product decay is expected to be minor during the first few hours after the accident because of the relatively long half-lives of $I^{131}$ and $\mathrm{I}^{133}$, the main contributors.

Table E.4. Thyroid Exposure from Intake of $1 \mu \mathrm{c}$ of Isotope

\begin{tabular}{lc}
\hline Isotope & $D($ mrem $)$ \\
\hline$I^{131}$ & 1484 \\
$I^{132}$ & 53.5 \\
$I^{233}$ & 399 \\
$I^{135}$ & 124 \\
\hline
\end{tabular}

For mode $\mathrm{C}$, the thyroid exposures were

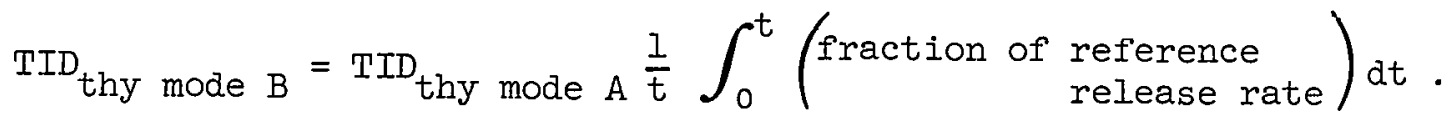
The integral was evaluated numerically from Figs. 16 through 23 for the four iodine isotopes of interest. 


\section{Appendix F \\ EFFECT OF CLOUD SIZE ON SUBMERSION EXPOSURE}

The adequacy of the site and the safety of a nuclear installation are determined by the exposures calculated to result as a consequence of various accidents. These exposure calculations involve three major components: direct, inhalation, and submersion. Inasmuch as the submersion exposure is usually at least an order of magnitude lower than the inhalation exposure, the submersion exposure is usually calculated on the presumption of an infinite or semi-infinite "cloud" of. uniform concentration. This conservative assumption is reasonable and convenient to make because the resulting exposures are not controlling and because the exact solution to the problem employing a finite cloud with a concentration gradient is difficult mathematically.

In the case of the N.S. SAVANNAH the filtration of the released gases from the outer container reduces the level of the inhalation exposure to the extent that the submersion exposure becomes controlling. In this situation it becomes important to make a more accurate estimate of the submersion exposures.

The determination of the submersion exposure from a finite cloud is discussed in Meteorology and Atomic Energy. ${ }^{10}$. Although the derivation is not given, the solution is presented in the form of two nomograms, one for a power excursion release and another for steady-state fission-product release. The ratio of the infinite submersion exposure to the finite submersion exposure as a function of distance from the source was determined from the latter nomogram for meteorological conditions which correspond to the N.S. SAVANNAH maximum credible accident. The relationship thus determined is plotted in Fig. F.I. The conditions that were assumed in determining this information from the nomograms in Meteorology and Atomic Energy were the following:

$\begin{array}{ll}\text { Wind speed } & 1 \mathrm{~m} / \mathrm{sec} \\ \mathrm{C}_{\mathrm{x}} & 0.07 \mathrm{~m}^{\mathrm{n} / 2} \\ \mathrm{C}_{\mathrm{y}} & 0.4 \mathrm{~m}^{\mathrm{n} / 2} \\ \mathrm{n} & 0.5 \mathrm{dimensionless}\end{array}$




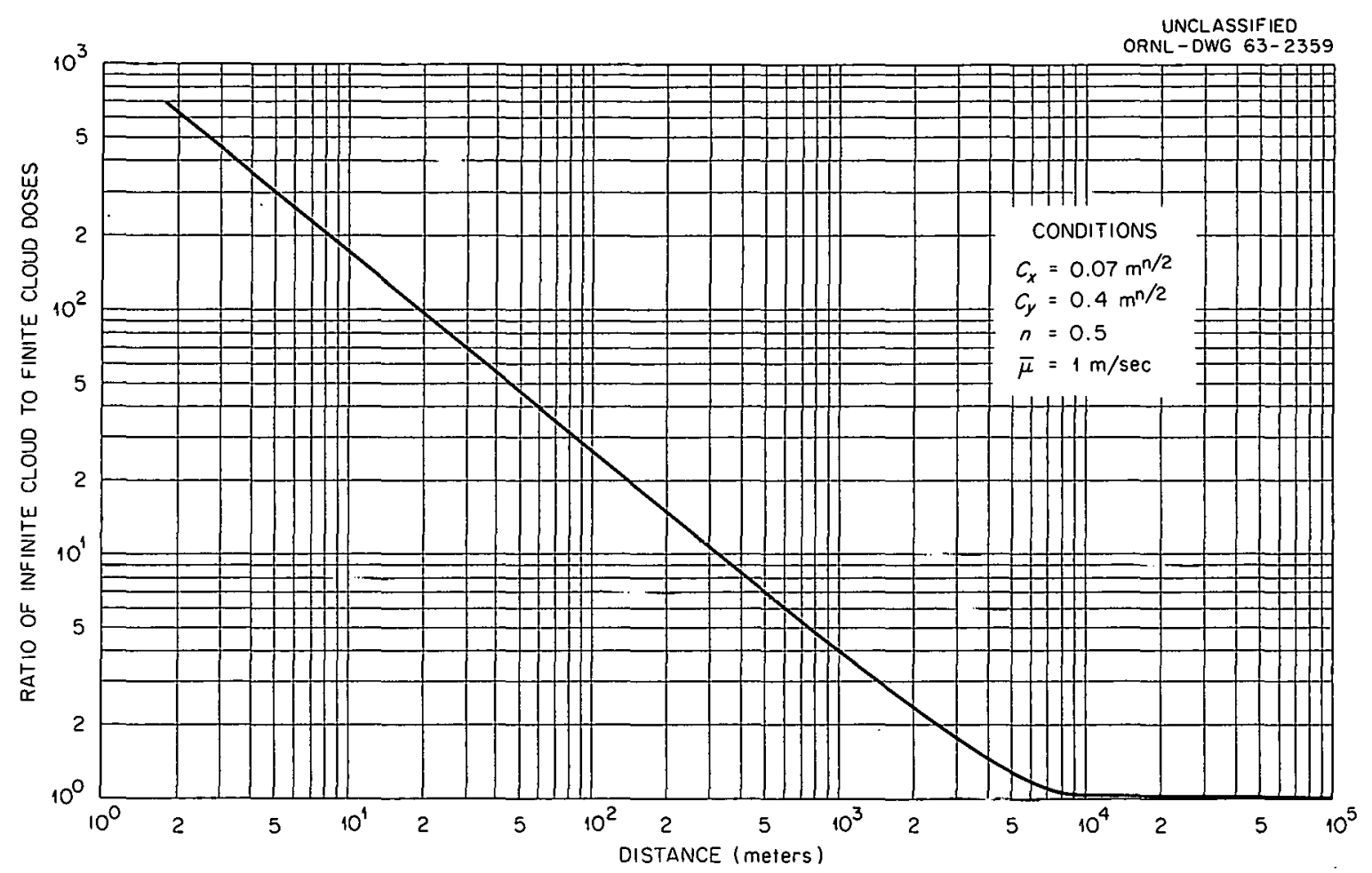

Fig. F.1. Ratio of Dose from Infinite Cloud to Dose from Finite. Cloud vs Distance from Source.

As may be seen from Fig. F.I, at distauces close to the source the use of the actual finite cloud results in calculated exposures much less than those calculated for the infinite cloud. Even as far from the source as $1000 \mathrm{ft}(315 \mathrm{~m})$ the finite cloud dose is lower by a factor of approximately 10 . 
REFERENCES

1. Code of Federal Regulations, Title 10, Part 100, Reactor Site Criteria, Federal Register, 27(71): 3509-3511 (April 12, 1962).

2. "Port Operation in the Matter of the N.S. SAVAINIAH," AEC-MARAD Joint Group, 970/5053, Revised, August 1, 1962.

3. Babcock \& Wilcox Company, "Muclear Merchant Ship Reactor Final Safeguards Report," Vol. 1, USAEC Report BAW-1164, 1961.

4. W. B. Cottrell, L. A. Mann, E. L. Parker, and G. D. Schmidt, "Environmental Analysis of the N.S. SAVANNIAH Operation at Camden," Rev. 1, USAEC Report ORNL-2867, Oak Ridge National Laboratory, January 24, 1961.

5. "Site Report: York River, Virginia," Maritime Administration and USAEC, May 1960.

6. R. O. Mekann, States Marine Line, Inc., personal communication to T. D. Anderson, Oak Ridge National Laboratory, May 29, 1962.

7. G. R. Thomas, "Nuclear Merchant Ship Reactor Final Safeguards Report Power Plant Accidents," USAEC Report BAW-1164, Vol. VII, Babcock \& Wilcox Company, March 1960.

8. T. D. Anderson, "Time-Dependent Release of Gaseous Material from a. Three-Barrier Containment System, " USAEC Report ORNL-TM-397, Oak Rige National Laboratory, November 19, 1962.

9. J. DiNunno et al., "Calculation of Distance Factors for Power Test Reactor Sites," USAEC Report TID-14844, March 23, 1962.

10. "Meteorology and Atomic Energy," US Department of Commerce and USAEC Report AECU-3066, July 1955.

11. "Meteorological Factors in the Appraisal and Control of Acute Exposures to Stack Effluents," Proceedings of the Second Urited Nations International Conference on the Peaceful Uses of Atomic Energy, Geneva, 1958, Vol. 18, United Nations, New York, 1958.

12. J. I. Owens, "Metal-Water Reactors: II, An Evaluation of Seven Nuclear Excursions in Light Water Reactors, " USAEC Report GEAP-3178, General Electric Company, June 15, 1959. 
13. A. H. Spano et al., "Self-Limiting Power Excursion Tests of a Water Moderated Low-Enrichment $\mathrm{UO}_{2}$ Core in SPERT I," USAEC Report IDO-166751, Phillips Petroleum Company, Feb. 28, 1962.

14. "Port Analysis Report, Savannah, Ga.," prepared by the AEC-Maritime Administration, Aug. 7, 1962, submitted for the Public Hearing on the interim sea and port operation of the N.S. SAVANNAH.

15. "Port Analys is Report, Norfolk, Va.," prepared by the AEC-Maritime Administration, Aug. 15, 1962, No. 970/4592, submitted for the Public Hearing on the interim sea and port operation of the N.S. SAVAINNAH.

16. "Port Analysis Report, Panama Canal," prepared by the AEC-Maritime Administration, Aug. 22, 1962, No. 970/4603, submitted for the Public Hearing on the interim sea and port operation of the N.S. SAVANNAH.

17. "Port Analysis Report, Seattle, Washington," prepared by the AECMaritime Administration, August 1962, No. 970/4715, submitted for the Public Hearing on the interim sea and port operation of the N.S. SAVANNAH.

18. "Port Analysis Report, San Francisco," prepared by the AEC-Maritime Administration, September 1962, submitted for the Public Hearing on the interim sea and port operation of the N.S. SAVANNAH.

19. W. B. Cottrell, L. A. Mann, F. L. Parker, and G. D. Schmidt, "Accidental Activity Release from Nuclear Ships," paper in Nuclear Ship Propulsion, International Atomic Energy Agency, 1961.

20. "Site Report: New York Harbur," Maritime Administration and USAEC, May 1962.

21. "Site Report: Savannah, Georgia," Maritime Administration and USAEC, May 1962.

22. "Site Report: Seattle, Washington," Maritime Administration and USAEC, May 1962.

23. "Site Report: Panama Canal," Maritime Administration and USAEC, May 1962.

24. "Site Report: Galveston, Texas," Maritime Administration and USAEC, April 1961. 
25. "Recommendations of the International Commission on Radiological Protection," adopted September 9, 1958, Pergamon Press, New York.

26. W. B. Cottrell, L. A. Mann, F. L. Parker, and G. D. Schmidt,

"Environmental Analysis of the N.S. SAVANNAH Operation at Camden," Rev. 1, USAEC Report ORNL-2867, Oak Ridge National Laboratory, January 24, 1961, Figs. 4.20-4.23.

27. "Muclear Merchant Ship Reactor Final Safeguards Report," Vol. VIII, USAEC Report BAW-1164, The Babcock \& Wilcox Company, 1961.

28. "Nuclear Merchant Ship Reactor Project, Preliminary Safeguards Report," Vol. I, USAEC Report BAW-1117, Revised, The Babcock \& Wilcox Company.

29. . W. B. Cottrell et al., "Fission Product Release from $\mathrm{UO}_{2}$, " USAEC Report ORNL-2935, Oak Ridge National Laboratory, Sept. 12, 1960.

30. A. H. Booth, "A Method for Calculating Fission Gas Diffusion from $\mathrm{UO}_{2}$ Fuel and Its Application to the X-2-f Loop Test," Canadian Report CRDC-721, Sept. 1957.

31. J. Belle (Ed.), Uranium Dioxide: Properties and Nuclear Application, Naval Reactors, Division of Reactor Development USAEC, available from Supt. of Dorıments, UsGro, 1961.

32. W. H. McAdams, Heat Transmission; 3rd ed., McGraw Hill, New'York, 1954.

33. Personal communication, T. D. Anderson, Oak Ridge National Laboratory, to M. H. Fontana, Oak Ridge National Laboratory, June 5, 1962.

34. W. D. Kingery et al., "Thermal Conductivity: X. Data for Several Pure Oxide Materials Corrected to Zero Porosity," J. Am. Ceram. Soc., 37: 107 (February 1954).

35. W. D. Kingery, "Thermal Conductivity: XIV. Conductivity of Multicomponent System," J. Am. Ceram. Soc., 42: 617 (December 1959).

36. J. C. Hedge and I. B. Fieldhouse, "Measurement of Thermal Conductivity of Uranium Oxide," AECU-3381 (September 20, 1956).

37. J. Crank, The Mathematics of Diffusion, Claredon Press, Oxford (1956). 
38. A. H. Booth and G. T. Rymer, "Determination of the Diffusion Constant of Fission Xenon in $\mathrm{UO}_{2}$ Crystals and Sintered Compacts," Canadian Report CRDC-720 (August 1958).

39. J. A. L. Robertson et al., "Irradiation Behavior of $\mathrm{UO}_{2}$ Fuel Elements," Nuclear Metallurgy, 6: 45-70 (1959).

40. Personal communication, L. D. Schaffer, Oak Ridge National Laboratory, to Preston P. Eddy, DRD, USAEC, June 23, 1960, Subject: $D^{\prime}$ Measurements in $\mathrm{UO}_{2}$.

41. D. L. Zimmerman, "Irradiation and Postirradiation Examination of N.S. SAVANNIAH Test Fuel Element Sl-a," GEAP-3342, General Electric Co., January 28, 1960.

42. W. B. Lewis, "Behavior of Fission-Gases in $\mathrm{UO}_{2}$ Fuel, " DL-45, Chalk River, Ontario, November 1961.

43. J. O. Blomeke and Mary F. Todd, "Uranium-235 Fission-Product Production as a Function of Thermal Neutron Flux, Irradiation Time and Decay Time. I. Atomic Concentrations and Gross Total," Part I, Vol. 1, USAEC Report ORNL-2127, Oak Ridge National Laboratory, December 1958.

44. J. R. Weir, Jr., Oak Ridge National Laboratory, as reported by T. H. Row, "EGCR Fuel Failures in Depressurization Accidents," unpublished report, April 16, 1962.

45. Seymour Katcoff, "Fission Product Yields from Neutron-Induced Fission," Nucleonics, pp. 201-208, November 1960.

46. T. S. Burnett, Nucl. Sci. Eng., Vol. 2, 1957.

47. Health Phys., 3(3), 3.960. 
THIS PAGE

\section{WAS INTENTIONALLY LEFT BLANK}




\author{
ORNL-3361 \\ UC-80 - Reactor Technology \\ TID-4500 (22nd ed.)
}

Internal Distribution

$\begin{array}{ll}\text { 1. } & \text { R. G. Affel } \\ \text { 2. } & \text { T. D. Anderson } \\ \text { 3. } & \text { C. A. Baumann } \\ \text { 4. } & \text { S. E. Beall } \\ \text { 5. } & \text { J. R. Buchanan } \\ \text { 6. } & \text { T. J. Burnett } \\ \text { 7. } & \text { C. D. Cagle } \\ \text { 8-12. } & \text { W. B. Cottrell } \\ \text { 13. } & \text { J. A. Cox } \\ \text { 14. } & \text { F. I. Culler } \\ \text { 15. } & \text { D. M. Davis } \\ \text { 16. } & \text { W. K. Ergen } \\ \text { 17. } & \text { B. R. Fish } \\ \text { 18. } & \text { M. H. Fontana } \\ \text { 19. } & \text { D. R. Gilfillan } \\ \text { 20. } & \text { A. A. Grau } \\ \text { 21. } & \text { C. E. Guthrie }\end{array}$

22. G. W. Keilholtz

23. O. H. Klepper

24. H. G. MacPhers on

25. H. C. McCurdy

26. J. R. McWherter

27. E. C. Miller

28. F. L. Parker

29. G. W. Parker

30. J. J. Pinajian

31. A. W. Savolainen

32. R. P. Shields

33. M. J. Skinner

34. G. M. Wats on

35-37. Central Research Library

38-40. Document Reference Library

41-62. Laboratory Records

63. Laboratory Records (RC)

\title{
External Distribution
}

64. Research and Development Division, ORO

65-66. Reactor Division, ORO

67-70. Division of Reactor Development (Mar1time Reactor's), AEC, Washington (Attention: J. E. Robb)

71. Division of Reactor Development (Nuclear Safety), AEC, Washington (Attention: Merson Bootli)

72. George G. Sharp, Inc., New York (Attention: D. L. Gorman)

73-74. States Marine Linas, Inc., Galveston, I'exas, c/o Todd Shipyard Corp. (Attention: R. O. Mehann)

75-76. Todd Shipyard Corp., Nuclear Division, (Attention: B. W. Winchell)

77-78. Babcock \& Wilcox Company, Atomic Energy Division, Lynchburg, Va. (Attention: W. F. Long)

79. Babcock \& Wilcox Company, Atomic Energy Division, Lynchburg, Va. (Attention: John H. MacMillan)

80-81. Division of Reactor Development (Army Reactors), AEC, Washington (Attention: Col. R. B. Burlin)

82-83. Nuclear Power Field Office, Ft. Belvoir, Virginia (Attention: L. J. Miseriheimer)

84-85. Martin-Marietta Company, Nuclear Division (Attention: J. F. O'Brien)

86. Commandant (MMT) U.S. Coast Guard, 1300 E. Street, N.W. , Washington, D.C.

87. Ebasco Services, Inc., New York ( $\Lambda$ ttention: W. C. Stamm) 
88. Zeluine Levine, The Martin-Marietta Co., Nuclear Division Baltimore, Ma.

89. R. E. Wascher, The Babcock \& Wilcox Company, Atomic Energy Division, Lynchburg, Va.

90-91. R. P. Denise, N. S. Savannah Technical Staff, Box 1750, Galveston, Texas

92-704. Given distribution as shown in TID-4500 (2lst ed.) under

Reactor Technology ( 75 copies - OTS) 